US Army Corps

of Engineers 。

Prepared for the U.S. Army Corps of Engineers, Portland District,

under an Interagency Agreement with the U.S. Department of Energy

Contract DE-AC05-76RL01830

\title{
Bonneville Powerhouse 2 Fish Guidance Efficiency Studies: CFD Model of the Forebay
}

\author{
CL Rakowski \\ MC Richmond \\ JA Serkowski
}

July 2012

\section{Pacific Northwest}

NATIONAL LABORATORY

Proudly Operated by Battelle Since 1965 


\title{
DISCLAIMER
}

This report was prepared as an account of work sponsored by an agency of the United States Government. Neither the United States Government nor any agency thereof, nor Battelle Memorial Institute, nor any of their employees, makes any warranty, express or implied, or assumes any legal liability or responsibility for the accuracy, completeness, or usefulness of any information, apparatus, product, or process disclosed, or represents that its use would not infringe privately owned rights. Reference herein to any specific commercial product, process, or service by trade name, trademark, manufacturer, or otherwise does not necessarily constitute or imply its endorsement, recommendation, or favoring by the United States Government or any agency thereof, or Battelle Memorial Institute. The views and opinions of authors expressed herein do not necessarily state or reflect those of the United States Government or any agency thereof.

\author{
PACIFIC NORTHWEST NATIONAL LABORATORY \\ operated by \\ BATTELLE \\ for the \\ UNITED STATES DEPARTMENT OF ENERGY \\ under Contract DE-AC05-76RL01830
}

Printed in the United States of America
Available to DOE and DOE contractors from the Office of Scientific and Technical Information,
P.O. Box 62, Oak Ridge, TN 37831-0062;
ph: (865) 576-8401
fax: (865) 576-5728
email: reports@adonis.osti.gov

Available to the public from the National Technical Information Service 5301 Shawnee Rd., Alexandria, VA 22312

ph: (800) 553-NTIS (6847)

email: orders@ntis.gov <http://www.ntis.gov/about/form.aspx>

Online ordering: http://www.ntis.gov 


\title{
Bonneville Powerhouse 2 Fish Guidance Efficiency Studies: CFD Model of the Forebay
}

\author{
CL Rakowski \\ MC Richmond \\ JA Serkowski
}

July 2012

Prepared for

the U.S. Army Corps of Engineers

Portland, OR

Pacific Northwest National Laboratory

Richland, Washington 99352 



\section{Summary}

In ongoing work, the U.S. Army Corps of Engineers, Portland District (CENWP) is seeking to better understand and improve the conditions within the Bonneville Powerhouse 2 (B2) turbine intakes to improve survival of downstream migrating salmonid smolt.

In this study, the existing B2 forebay computational fluid dynamics (CFD) model was modified to include a more detailed representation of all B2 turbine intakes. The modified model was validated to existing field-measured forebay acoustic Doppler current profiler velocities.

The validated CFD model was used to simulate the impact to water velocities of adding a forebay behavior guidance system (BGS), a B2 corner collector (B2CC), both the BGS and B2CC, and gatewell slot fillers within the turbine units. These operational scenarios with added structures had small impacts on forebay flows. Most notable was that the addition of the BGS and B2CC reduced the lateral extent of the recirculation areas on the Washington shore and Cascade Island and reduced the flow velocity parallel to B2 in front of B2 Units 11 and 12.

For these operational scenarios, at the turbine intakes across B2 there was very little difference in the flow volume into the gatewell for the forebay model with no BGS or B2CC flow, and the forebay model with the BGS in place and/or the B2CC operating. The largest differences were at Units 11 to 13.

The CFD model scenarios testing the impact of having gatewell slot fillers in place showed large differences in flow within the gatewells and through the VBS, but no impact on the forebay flows. The full forebay CFD model results showed very similar performance of the slot fillers to the CENWP single-unit model. With the slot fillers in place, the flow through the VBS increased at each turbine intake (average was 40, 35, and 29 cfs for Bays A, B, and C, respectively) and the gap flow decreased across the powerhouse for all scenarios. The increased flow up the gatewell was further enhanced when only half of the units were operating. The flow into the gatewell slot was increased about $35 \mathrm{cfs}$ for each bay of each intake across the powerhouse; this change was uniform across the powerhouse.

The flows in the gatewell of Unit 12, the most affected unit for the scenarios, were evaluated. In front of the VBS, the CFD model with slot fillers in place reduced the maximum velocities (in spite of the increased flow into the gatewell) and decreased the area of recirculation. The area near the VBS exceeding the normal velocity criterion of $1 \mathrm{ft} / \mathrm{s}$ was reduced and the flows were more balanced. 



\section{Abbreviations and Acronyms}

3D three dimensional

ADCP acoustic Doppler current profiler

ADV acoustic Doppler velocimeter

B2 Bonneville Powerhouse 2

B2CC Bonneville Powerhouse 2 corner collector

BGS behavior guidance system

$\mathrm{CC} \quad$ corner collector

CENWP U.S. Army Corps of Engineers, Portland District

cfs cubic feet per second

CFD computational fluid dynamics

DS downstream

FB forebay

FGE fish guidance efficiency

$\mathrm{ft} / \mathrm{s} \quad$ feet per second

GIS geographic information system

HNNN high flow scenario, no B2CC flow, no BGS

HNYN high flow scenario, no B2CC flow, with BGS in place

HYYN high flow scenario, B2CC flow, with BGS in place

HYNN high flow scenario, B2CC flow, no BGS

JBS juvenile bypass system

kcfs thousand cubic feet per second

ORN Oregon North State Plane feet

MARS monotone advection and reconstruction scheme

PNNL Pacific Northwest National Laboratory

RANS Reynolds-averaged Navier-Stokes

S second

STS submerged traveling screen

UD upwind differencing

US upstream

USACE U.S. Army Corps of Engineers

VBS vertical barrier screen

vmag velocity magnitude 



\section{Acknowledgments}

Financial support for this study was provided by the U.S. Army Corps of Engineers (USACE) under MIPR W66QK11794377. The authors would like to thank Liza Roy and Laurie Ebner (USACE, Portland District) for the discussions, support, and insight that improved this study, Pedro Romero-Gomez for his review and comments. 



\section{Contents}

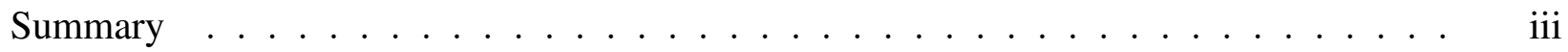

Abbreviations and Acronyms . . . . . . . . . . . . . . . . v v

Acknowledgments ..................................... vii

1.0 Introduction $\ldots \ldots \ldots \ldots \ldots \ldots \ldots \ldots$

2.0 Methods . . . . . . . . . . . . . . . . . . . . . . . . 2.1

2.1 Modeling Approach $\ldots \ldots \ldots \ldots \ldots \ldots$

2.2 Mesh Development . . . . . . . . . . . . . . . . . . 2.1

2.2 .1 Turbine Intake and Full Powerhouse . . . . . . . . . . . . . . . . . . 2.1

2.2.2 Forebay Mesh and Integration with the Powerhouse Mesh . . . . . . . . 2.2

2.3 Model Validation . . . . . . . . . . . . . . . . . . . . . . 2.2

2.3 .1 Field-Measured ADCP Velocities . . . . . . . . . . . . . . 2.2

2.3 .2 Gatewell Slot ADV Measurements . . . . . . . . . . . . . 2.2

2.4 Operational Scenarios $\ldots \ldots \ldots \ldots$

2.5 Slot Fillers $\ldots \ldots \ldots \ldots \ldots \ldots \ldots \ldots$

2.6 Analysis of Results $\ldots \ldots \ldots \ldots \ldots$

3.0 Results and Discussion . . . . . . . . . . . . . . . . . . . . . . . . . 3.1

3.1 Validation . . . . . . . . . . . . . . . . . . 3.1

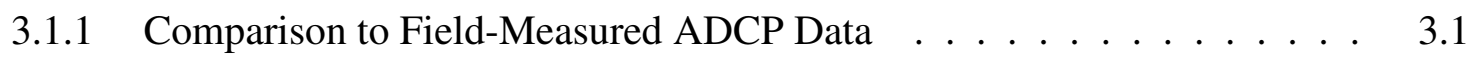

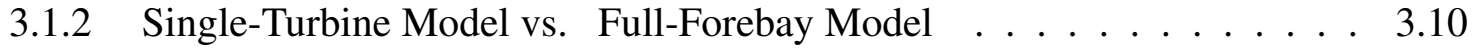

3.1 .3 Comparison with ADV Data $\ldots \ldots \ldots \ldots . \ldots . \ldots . \ldots . \ldots$

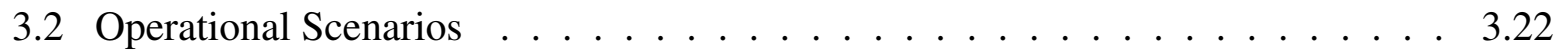

3.2.1 High Flow without B2CC Flow or BGS (HNNN) . . . . . . . . . . . . 3.22 
3.2 .2 High Flow with BGS (HNYN) $\ldots \ldots \ldots \ldots \ldots \ldots$

3.2 .3 High Flow with B2CC On (HYNN) $\ldots \ldots \ldots \ldots \ldots \ldots$

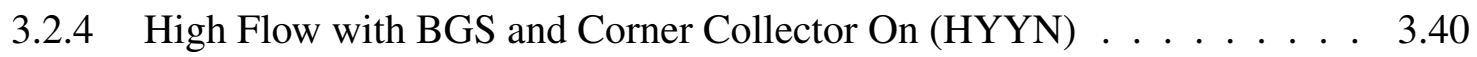

3.2.5 Comparison of Flows into the Gatewells for the Scenarios for Each Bay and Intake $\ldots \ldots \ldots \ldots \ldots \ldots \ldots \ldots$

3.3 Slot Fillers $\ldots \ldots \ldots \ldots \ldots$

$3.3 .1 \quad$ Comparison of Flows into the Gatewells with Slot Fillers $\ldots \ldots . .43 .48$

3.3 .2 HNNN with Slot Fillers $\ldots \ldots \ldots$. . . . . . . . . . . . 3.52

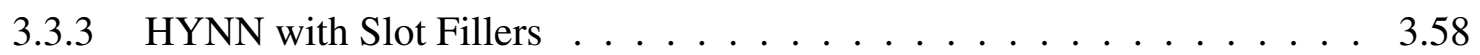

3.3.4 HNNN with Slot Fillers, but with Half of the Units Operating . . . . . . 3.64

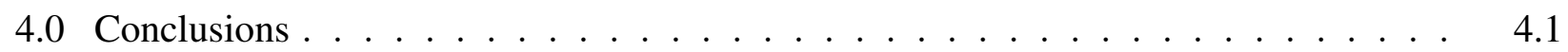

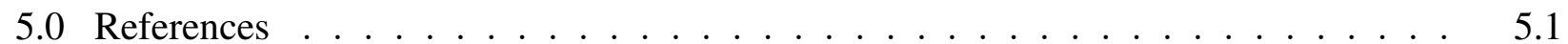




\section{Figures}

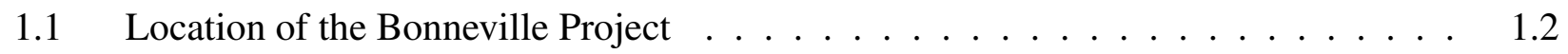

1.2 Detail of the Bonneville Project. $\ldots \ldots \ldots \ldots$. . . . . . . . . . . 1.3

$2.1 \quad$ Project operations during the ADV measurements for Unit 14 at $15.8 \mathrm{kcfs}$ with the

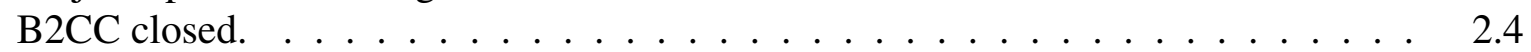

2.2 Project operations during the ADV measurements for Unit 14 at $12 \mathrm{kcfs}$ with the

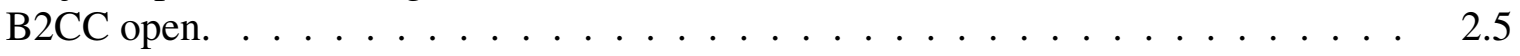

3.1 Velocity vectors for the CFD results and field-measured ADCP velocities at ele-

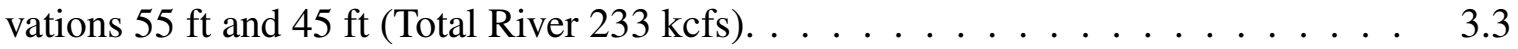

3.2 Velocity vectors for the CFD results and field-measured ADCP velocities at elevations $35 \mathrm{ft}$ and $25 \mathrm{ft}$ (Total River $233 \mathrm{kcfs}$ ). . . . . . . . . . . . . . . . . . 3.4

3.3 Velocity vectors for the CFD results and field-measured ADCP velocities at elevations $15 \mathrm{ft}$ and $5 \mathrm{ft}$ (Total River $233 \mathrm{kcfs}$ ). . . . . . . . . . . . . . . . . . 3.5

3.4 Velocity vectors for the CFD results and field-measured ADCP velocities at ele-

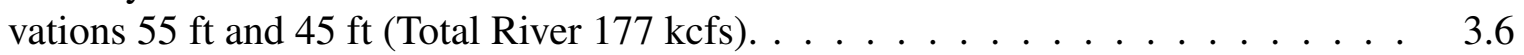

3.5 Velocity vectors for the CFD results and field-measured ADCP velocities at ele-

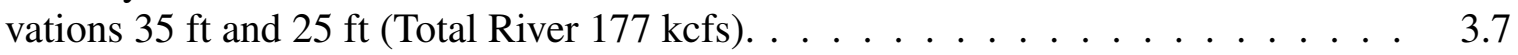

3.6 Velocity vectors for the CFD results and field-measured ADCP velocities at ele-

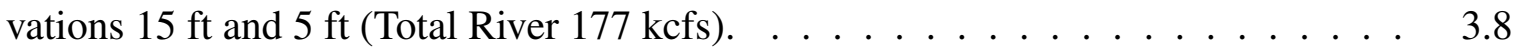

3.7 Comparison of measured and PNNL velocity magnitude upwind differencing (UD)

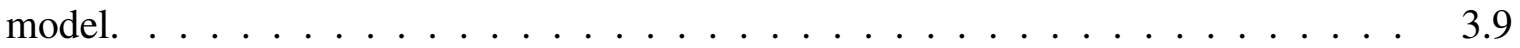

3.8 Velocity Magnitude at elevation $0 \mathrm{ft}$ for the single Unit 14 and Unit 14 in a fullforebay model for the ADCP February 4, 2000 scenario. . . . . . . . . . . . . . 3.11

$3.9 \quad$ Vertical slice in the center of Bay B for the ADCP February 4, 2000 scenario. . . . 3.12

3.10 Velocity magnitude of flow $0.48 \mathrm{ft}$ in front of the VBS. . . . . . . . . . . . 3.13

3.11 Velocity magnitude of flow $3.48 \mathrm{ft}$ in front of the VBS. . . . . . . . . . . . . . 3.14

3.12 Locations of ADV measurements. . . . . . . . . . . . . . . . . . . 3.15

\begin{tabular}{|ll}
\hline 3.13 & Normal and sweep velocities $0.65 \mathrm{ft}$ in front of the VBS for Unit 14 Bay A at 15.8 \\
\hline \hline kcfs with the B2CC off. $\ldots \ldots \ldots \ldots \ldots$
\end{tabular} 
3.14 Normal and sweep velocities $2.25 \mathrm{ft}$ in front of the VBS for Unit 14 Bay A at 15.8

kcfs with the B2CC off. . . . . . . . . . . . . . 3.17

3.15 Normal and sweep velocities $2.83 \mathrm{ft}$ in front of the VBS for Unit 14 Bay A at 15.8

kcfs with the B2CC off. $\ldots \ldots \ldots \ldots . \ldots \ldots$

3.16 Normal and sweep velocities $0.65 \mathrm{ft}$ in front of the VBS for Unit 14 Bay A at 12

kcfs with the B2CC on. . . . . . . . . . . . . . 3.19

3.17 Normal and sweep velocities $2.25 \mathrm{ft}$ in front of the VBS for Unit 14 Bay A at 12

kcfs with the B2CC on. . . . . . . . . . . . . . . 3.20

3.18 Normal and sweep velocities $2.83 \mathrm{ft}$ in front of the VBS for Unit 14 Bay A at 12

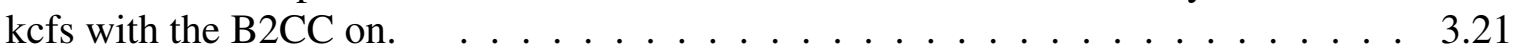

3.19 HNNN: Velocity magnitude and short streamlines at elevation $39 \mathrm{ft}$ and $64 \mathrm{ft}$. . . . 3.23

3.20 HNNN: Velocity magnitude and short streamlines at elevation $74 \mathrm{ft}$. . . . . . . . 3.24

3.21 HNNN: Streamlines seeded 300-ft upstream of the powerhouse and colored by velocity magnitude. . . . . . . . . . . . . . . . . 3.24

3.22 HNNN: Velocity magnitude and 10-s streamlines in the centerline Unit 12 (top) and Unit 15 (bottom). . . . . . . . . . . . . . . 3.25

3.23 HNNN: Sweep and normal velocities $0.65 \mathrm{ft}$ in front of the VBS . . . . . . . . . 3.26

3.24 HNNN: Sweep and normal velocities $2.25 \mathrm{ft}$ in front of the VBS. . . . . . . . . . 3.27

3.25 HNYN: Velocity magnitude and short streamlines at elevation $39 \mathrm{ft}$ and $64 \mathrm{ft}$. . . . 3.29

3.26 HNYN: Velocity magnitude and short streamlines for the HNYN simulation at elevation $74 \mathrm{ft} . \ldots \ldots \ldots \ldots \ldots \ldots \ldots$

3.27 HNYN: Streamlines seeded 300-ft upstream of the powerhouse and colored by velocity magnitude $\ldots \ldots \ldots \ldots \ldots \ldots \ldots \ldots \ldots$

3.28 HNYN: Velocity magnitude and 10-s streamlines in the centerline Unit 12 (top) and Unit 15 (bottom). . . . . . . . . . . . . . . . 3.31

3.29 HNYN: Sweep and normal velocities $0.65 \mathrm{ft}$ in front of the VBS . . . . . . . 3.32

$3.30 \quad$ HNYN: Sweep and normal velocities $2.25 \mathrm{ft}$ in front of the VBS. . . . . . . . . . . 3.33

3.31 HYNN: Velocity magnitude and short streamlines at elevation $39 \mathrm{ft}$ and $64 \mathrm{ft}$. . . . 3.35 
3.32 HYNN: Velocity magnitude and short streamlines at elevation $74 \mathrm{ft}$. . . . . . . 3.36

3.33 HYNN: Streamlines seeded 300-ft upstream of the powerhouse and colored by veloc-

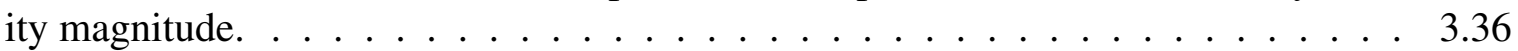

3.34 HYNN: Velocity magnitude and 10-s streamlines in the centerline Unit 12 (top) and Unit 15 (bottom). . . . . . . . . . . . . . . . . . 3.37

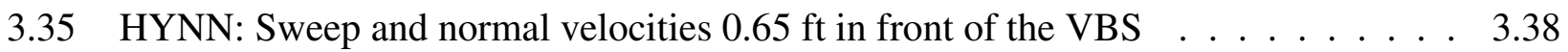

3.36 HYNN: Sweep and normal velocities $2.25 \mathrm{ft}$ in front of the VBS. . . . . . . . . . . 3.39

3.37 HYYN: Velocity magnitude and short streamlines at elevation $39 \mathrm{ft}$ and $64 \mathrm{ft}$. . . . 3.41

$3.38 \quad$ HYYN: Velocity magnitude and short streamlines at elevation $74 \mathrm{ft}$. . . . . . . . . 3.42

3.39 HYYN: Streamlines seeded 300-ft upstream of the powerhouse and colored by veloc-

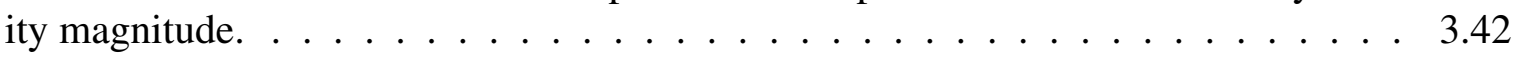

3.40 HYYN: Velocity magnitude and 10-s streamlines in the centerline Unit 12 (top) and Unit 15 (bottom). . . . . . . . . . . . . . . 3.43

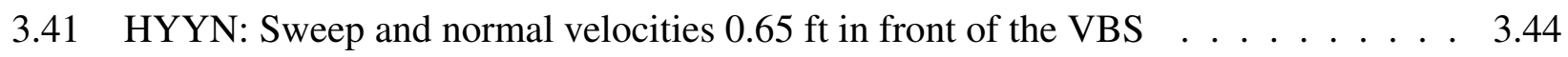

3.42 HYYN: Sweep and normal velocities $2.25 \mathrm{ft}$ in front of the VBS . . . . . . . . . 3.45

3.43 Locations of slices used for the flow calculations. . . . . . . . . . . . . . 3.46

3.44 Flow into the STS (top) and up the gatewell (bottom) for each bay and by unit for the B2 for the four scenarios. . . . . . . . . . . . . 3.47

3.45 Slot Fillers, HNNN: Flow into the STS (top) and up the gatewell (bottom) for each bay and by unit for B2 with slot fillers, without slot fillers, and with slot fillers and half of the turbines running. . . . . . . . . . . . . . . . . . 3.49

3.46 Slot Fillers, HYNN: Flow into the STS (top) and up the gatewell (bottom) for each bay and by unit for B2 without slot fillers (blue) and with slot fillers (cyan).. .3 .50$

3.47 Velocity magnitude and short streamlines for the HNNN with and without slot fillers simulation at elevation $64 \mathrm{ft} . \ldots \ldots \ldots \ldots . \ldots \ldots 33$

3.48 HNNN Unit 12 normal velocity with (top) and without (bottom) slot fillers 0.65

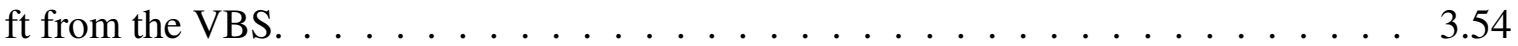

3.49 HNNN Unit 12 sweep velocity with (top) and without (bottom) slot fillers in place $0.65 \mathrm{ft}$ from the VBS. . . . . . . . . . . . . . . . . 3.55 
3.50 HNNN Unit 12 normal velocity with (top) and without (bottom) slot fillers in place $2.25 \mathrm{ft}$ from the VBS. . . . . . . . . . . . . . . . 3.56

3.51 HNNN Unit 12 sweep velocity with (top) and without (bottom) slot fillers in place $2.25 \mathrm{ft}$ from the VBS. . . . . . . . . . . . . . . . 3.57

3.52 Velocity magnitude and short streamlines for the HYNN with and without slot fillers simulation at elevation $64 \mathrm{ft} . \ldots \ldots \ldots \ldots . \ldots \ldots$

3.53 HYNN Unit 12 normal velocity with (top) and without (bottom) slot fillers 0.65 ft from the VBS. . . . . . . . . . . . . . . . . 3.60

3.54 HYNN Unit 12 sweep velocity with (top) and without (bottom) slot fillers in place $0.65 \mathrm{ft}$ from the VBS. . . . . . . . . . . . . . . . . . . . . . .

3.55 HYNN Unit 12 normal velocity with (top) and without (bottom) slot fillers in place $2.25 \mathrm{ft}$ from the VBS. . . . . . . . . . . . . . 3.62

3.56 HYNN Unit 12 sweep velocity with (top) and without (bottom) slot fillers in place $2.25 \mathrm{ft}$ from the VBS. . . . . . . . . . . . . . . . . . . . . .

3.57 Velocity magnitude and short streamlines for the HNNN half load with in-place slot fillers at elevation $64 \mathrm{ft} . \ldots \ldots \ldots \ldots . \ldots \ldots 4$

3.58 HNNN Unit 14 normal velocity with (top) and without (bottom) slot fillers 0.65 ft from the VBS. . . . . . . . . . . . . . . . . . . . . . . . . . . . .

3.59 HNNN Unit 14 sweep velocity with (top) and without (bottom) slot fillers in place $0.65 \mathrm{ft}$ from the VBS. . . . . . . . . . . . . . . . . . . . . . . . . .

3.60 HNNN Unit 14 normal velocity with (top) and without (bottom) slot fillers in place $2.25 \mathrm{ft}$ from the VBS. . . . . . . . . . . . . . . . 3.67

3.61 HNNN Unit 14 sweep velocity with (top) and without (bottom) slot fillers in place $2.25 \mathrm{ft}$ from the VBS. . . . . . . . . . . . . . . 3.68 


\section{Tables}

$2.1 \quad$ Specified operation for model validation. . . . . . . . . . . . . . . 2.2

$2.2 \quad$ Bonneville Powerhouse 2 flows for ADCP validation runs. . . . . . . . . . . . . . 2.3

$2.3 \quad$ Specified operation for comparison to field-measured VBS velocity data. . . . . . . 2.6

$2.4 \quad$ CFD model scenarios. . . . . . . . . . . . . . . . . . . . 2.6

3.1 Summary of average flow differences at each bay with, and without, slot fillers in

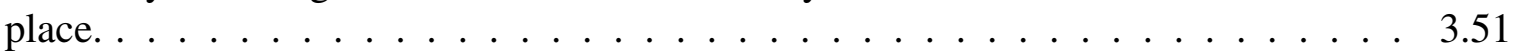





\subsection{Introduction}

In ongoing work, the U.S. Army Corps of Engineers, Portland District (CENWP) is seeking to better understand and improve the conditions within the Bonneville Powerhouse 2 turbine intakes to improve survival of downstream migrating salmonid smolts. Previously, researchers at Pacific Northwest National Laboratory (PNNL) developed a three-dimensional (3D) computational fluid dynamics (CFD) model of the Bonneville Project (Figures 1.1 and 1.2) forebay for CENWP (Rakowski et al.2010) to model the effects of project operations and the presence of a behavioral guidance system (BGS) on forebay hydraulics. The CFD model used for the BGS work was modified and used for this study.

The Bonneville Powerhouse 2 (B2) has several additions to the turbine intakes that were designed to improve the flow field, and modifications have been made within the gatewells to improve fish guidance efficiency. Near the face of the powerhouse, turbine intake extensions have been added on every other bay to decrease flow turbulence along the powerhouse face and in the entrance to the turbine intakes. Within the turbine intakes, large submerged traveling screens (STSs) designed to reduce the number of smolt that pass through the turbines have been added. These screens move the intercepted smolt up the gatewells and into the juvenile bypass system (JBS).

The CENWP Hydraulic Design Section created a detailed CFD model of a modified single turbine intake. This model included a turning vane, gap closure device, and vertical barrier screen (VBS). The VBS head-loss parameters were calibrated to provide the best match to velocities measured in a reduced-scale physical model of a single intake bay (CENWP 2011). This CFD model consisted of more than 2 million cells. In both the CENWP CFD model and the reduced-scale physical model, the effects of forebay flow conditions, including bathymetry, added structures, and project operations, were not included. There are indications that forebay conditions could influence the effectiveness and performance of the modified turbine intakes. In the work reported here, PNNL researchers incorporated the detailed turbine intake model created by CENWP into the existing PNNL B2 forebay model. The resulting CFD model has about 20 million cells.

The objectives of this study were as follows:

- Improve on the CFD model of Rakowski et al. (2010) by including the more detailed representation of the turbine intakes developed by CENWP.

- Validate the modified CFD model to field-measured acoustic Doppler current profiler (ADCP) data.

- Validate the CFD model flow in the gatewell slot to measured velocity data.

- Examine the impacts of powerhouse operations and the presence of the BGS and B2CC flows on flows approaching the turbine intakes and flows into the intake gatewells.

- Use the numerical model to understand the potential differences between a single-unit model, such as the CENWP CFD model, and a full-forebay CFD model. 
After the study was underway, CENWP proposed adding gatewell "slot fillers" (a) to the turbine intakes to improve flow conditions. Additional model runs were conducted to assess the impact of powerhouse operation and forebay configuration (B2CC/BGS) on the performance of the slot fillers in the gatewell and the consistency of any impacts across the whole powerhouse.

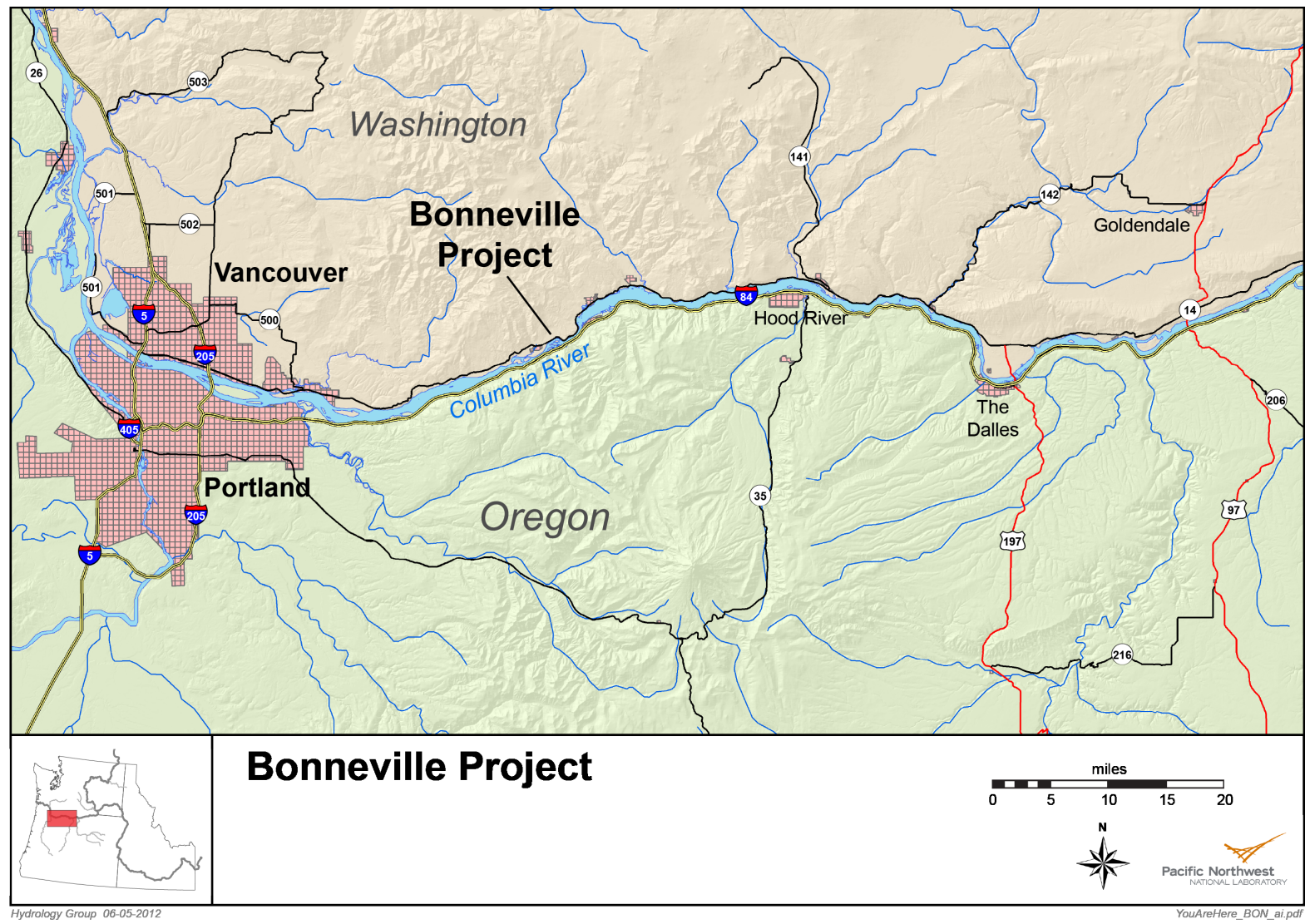

Figure 1.1. Location of the Bonneville Project

(a) Slot fillers block flow from the open slots used to guide turbine gates or, more often, the STS support rails into the turbine bay. 


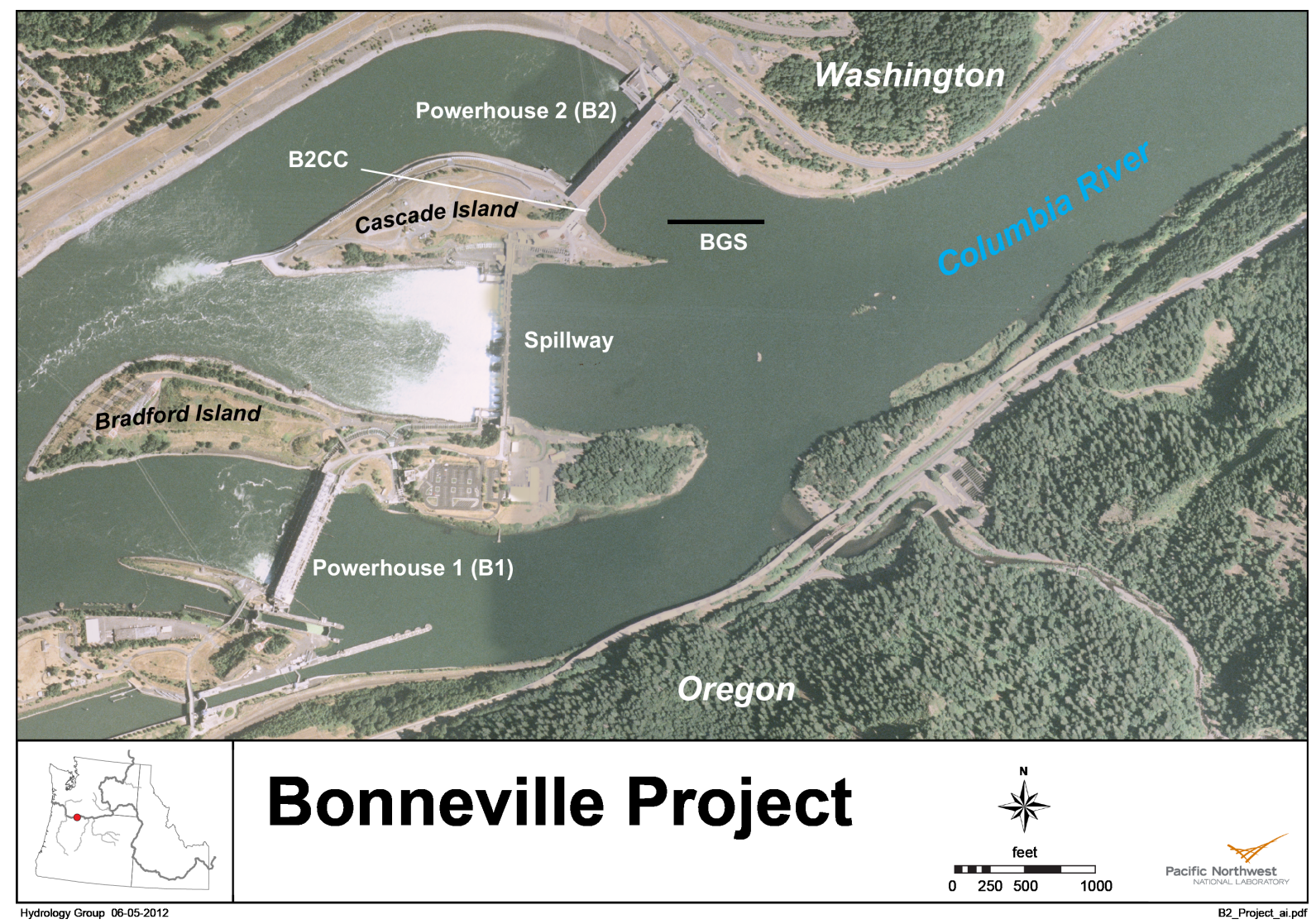

Figure 1.2. Detail of the Bonneville Project. 



\subsection{Methods}

The methods described below include the modeling approach, mesh development, model validation, operational scenarios, inclusion of slot fillers in the CFD model, and analysis of results.

\subsection{Modeling Approach}

This work used the approach described by Rakowski et al. (2010, 2005). A commercial CFD software, STAR-CD v4.10 (ADAPCO, Computational Dynamics Limited 2004), was used as the flow solver for this study. The code is a Reynolds-averaged Navier-Stokes (RANS) finite volume code. The simulations were performed using the following code options: steady state, RANS, and k- $\varepsilon$ high-Reynolds number turbulence closure with a standard wall function. The model was configured with a pressure boundary in the upstream, and the outflows specified for each bay of each turbine and the spillway. Bonneville Powerhouse 1 flows were specified as a single outflow just below the head of Bradford Island.

Velocities were calculated for each boundary based on flow discharge and boundary area. Local coordinate systems were used to specify vectors orthogonal to the boundary. Flow splits for the B2 turbine intakes were $37.8,34.2$, and $28 \%$ for Bays A, B, and C, respectively. These splits were based on field measurements and have been used in past CFD studies.

In running the model, the maximum global residual tolerance was reduced to $1 \mathrm{e}-4$ and the residual tolerances were $0.001,0.0005$, and 0.001 for momentum, pressure, and turbulence, respectively. These steady-state models were run with SIMPLE and algebraic multigrid. Both upwind differencing (UD, a first-order scheme) and monotone advection and reconstruction scheme (MARS, a second-order scheme) differencing were tested.

\subsection{Mesh Development}

This work combined an older Bonneville forebay mesh (Rakowski et al. 2010) with the much more well-resolved mesh of a B2 turbine intake unit created by CENWP (CENWP 2011).

\subsubsection{Turbine Intake and Full Powerhouse}

The single turbine intake CFD model created by CENWP is described in Appendix C of the Post-Construction Alternative Report (CENWP 2011). This CFD model included the STS, turning vane, VBS, and orifice flow. This model had the VBS separated into panels calibrated by CENWP against physical model data (CENWP 2011). The unit was scaled, rotated, and translated onto a B2 baseline coordinate system. The computational mesh for a single turbine unit was exported and used as the basis for building a complete powerhouse. A forebay model with high-resolution intake units in the powerhouse was created and integrated with the existing B2 forebay mesh.

In STAR-CD, a tool was created to read the unit mesh into the software, place it in the desired location, and integrate it with the adjacent cells in the computational mesh. The purpose of this tool was to allow CENWP to take the coarser version of the powerhouse and replace single units 
with a higher-resolution intake unit for future work. It was also used to facilitate the creation of the high-resolution powerhouse for B2.

\subsubsection{Forebay Mesh and Integration with the Powerhouse Mesh}

The forebay mesh, including the $\mathrm{B} 2 \mathrm{CC}$ and fish units from the model developed by Rakowski et al. (2010) was slightly modified and reused in this study.

The two computational meshes were assembled into a single model using coincident planes at the joined faces. The completed model was checked for discontinuities and gaps.

\subsection{Model Validation}

There were very few sources of validation data for these CFD models. This study used ADCP measurements from the forebay and acoustic Doppler velocimeter (ADV) measurements made in the gatewells at two of the turbine units.

\subsubsection{Field-Measured ADCP Velocities}

The best available field-measured velocity data for the B2 forebay were collected in February 2000 (ENSR 2000). On-station 10-minute-duration velocity measurements were made at many locations in the forebay. As is characteristic of these types of measurements, the long duration of the on-station measurements was required for the average velocity to stabilize. However, the standard deviation of the measurements was large. This data set has been used in previous Bonneville forebay CFD studies (e.g., Rakowski et al.2010, 2000). Boundary conditions are detailed in Tables 2.1 and 2.2.

In addition, the simulation results for Unit 14 were compared for the full forebay model and the single unit model. Unit flow was $17.5 \mathrm{kcfs}$ with the standard flow splits between bays.

Table 2.1. Specified operation for model validation. On February 4, 2000 the flow was distributed across the full powerhouse and the water-surface elevation was $74.5 \mathrm{ft}$.

\begin{tabular}{|c|c|c|c|c|}
\hline Date & B1 (kcfs) & $\begin{array}{c}\text { Spillway } \\
\text { (kcfs) }\end{array}$ & B2 (kcfs) & $\begin{array}{l}\text { Total } \\
\text { River }\end{array}$ \\
\hline Feb. 4, 2000 Sur & 85.3 & 2.6 & 145.0 & 233 \\
\hline Feb. 6, 2000 Survey & 102.7 & 2.6 & 71.7 & 177 \\
\hline
\end{tabular}

\subsubsection{Gatewell Slot ADV Measurements}

In 2010, velocity measurements were made in the gatewell slots of B2 Units 12 and 14 (Hughes et al. 2011), but these measurements were averaged over large time periods and, while unit flows were held constant, project operations were changing.

In consultation with CENWP, PNNL chose to model flow conditions for measurement sampling 
Table 2.2. Bonneville Powerhouse 2 flows for ADCP validation runs.

\begin{tabular}{|c|c|}
\hline Data Set & $\begin{array}{l}\text { Discharge for Units 11-18 } \\
\text { in kcfs }\end{array}$ \\
\hline Feb. $4,2000 \mathrm{St}$ & $17.6,17.7,17.7,17.5,17.6,17.4,17.4,16.7,1$ \\
\hline Feb. 6, 2000 Survey (ADCP $177 \mathrm{kcfs}$ ) & Units 11,12,17,18@16.3 \\
\hline
\end{tabular}

periods at Unit 14 with a flow of $15.8 \mathrm{kcfs}$ with the B2CC closed and Unit 14 at $12 \mathrm{kcfs}$ with the $\mathrm{B} 2 \mathrm{CC}$ open. These chosen sampling periods represented 1) times with the most stable operations during the sampling period (Figures 2.1 and 2.2), 2) were for a higher and a low flow, and 3) were sampling periods for which there were no notes in the report indicating data issues. Model boundary conditions are detailed in Table 2.3. 


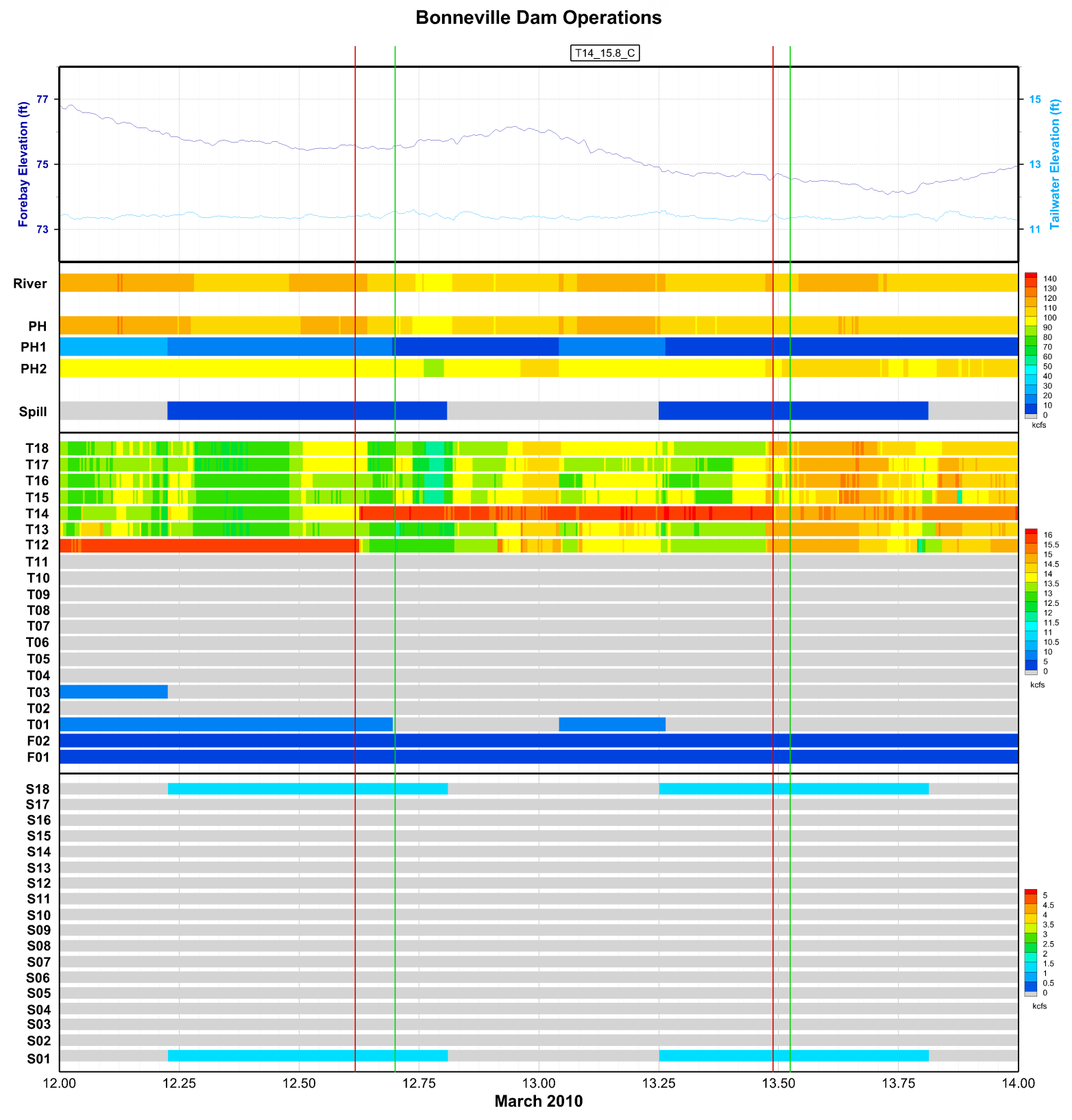

Figure 2.1. Project operations during the ADV measurements for Unit 14 at $15.8 \mathrm{kcfs}$ with the $\mathrm{B} 2 \mathrm{CC}$ closed. The vertical green line on left and red line on right bound the sampling period. 


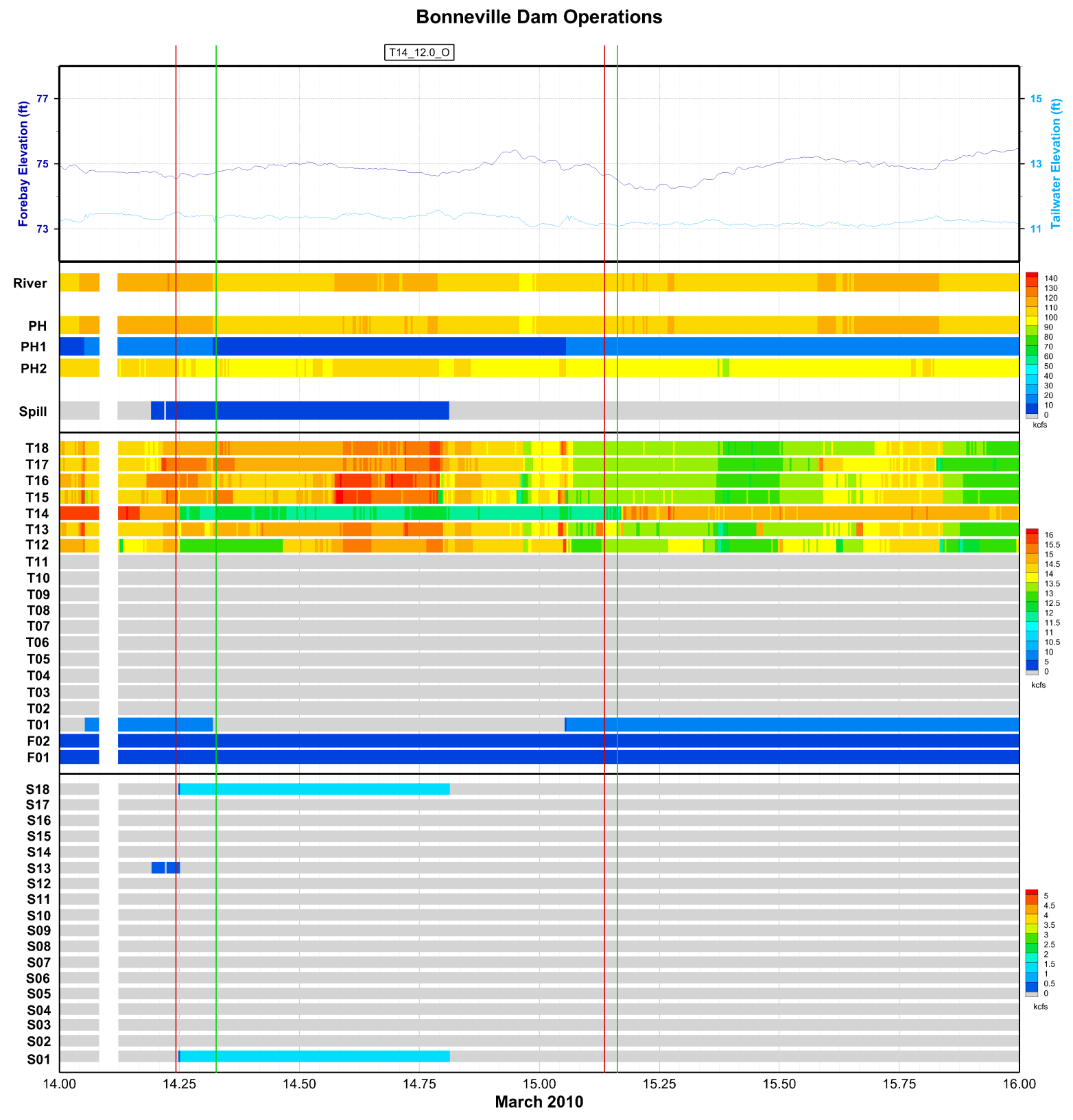

Figure 2.2. Project operations during the ADV measurements for Unit 14 at $12 \mathrm{kcfs}$ with the B2CC open. The vertical green line on left and red line on right bound the sampling period. 
Table 2.3. Specified operation for comparison to field-measured VBS velocity data.

\begin{tabular}{lcc}
\hline ADV Scenario & Unit 14@ 15.8 kcfs & Unit 14@ 12.0 kcfs \\
\hline Powerhouse 2 & & \\
Corner Collector & Closed & Open \\
\hline Unit & Flow (kcfs) & Flow (kcfs) \\
\hline 11 & 0 & 0 \\
12 & 13.57 & 14.16 \\
13 & 13.48 & 14.59 \\
14 & 15.78 & 11.99 \\
15 & 13.48 & 14.50 \\
16 & 13.40 & 14.61 \\
17 & 13.38 & 14.59 \\
18 & 13.48 & 14.61 \\
F1 & 2.8 & 2.8 \\
F2 & 2.6 & 2.7 \\
Powerhouse 1 & 85.3 & 6.4 \\
Spill & & \\
Spillbay 1 & 1.3 & 1.2 \\
Spillbay 18 & 1.3 & 1.2 \\
\hline Total & 189.87 & 113.35 \\
\hline
\end{tabular}

\subsection{Operational Scenarios}

CENWP specified four scenarios detailed in Table 2.4. The scenario abbreviations in the table are consistent with other CENWP work at B2. The first letter is the flow condition ( $\mathrm{H}=$ high), the following 3 letters ( $\mathrm{Y}$ or $\mathrm{N}$ ) are for the presence of B2CC flow, the BGS, and turbine intake extensions (TIEs), respectively. All scenarios had the same powerhouse and spillway flow conditions and the impacts on the flow field from the inclusion of the BGS and/or the operation of the B2CC were modeled (Table 2.4). Each B2 turbine had a flow of $17.6 \mathrm{kcfs}$, the fish units were at 2.6 and $2.8 \mathrm{kcfs}$, and the spillway was run in the Fish Passage Plan (http://www.nwdwc.usace.army.mil/tmt/documents/fpp/2012/) pattern for $100.9 \mathrm{kcfs}$.

Table 2.4. CFD model scenarios. Water-surface elevation was $74.5 \mathrm{ft}$ for all runs. B2 Units had $17.6 \mathrm{kcfs}$ each.

\begin{tabular}{lrcrccccc}
\hline Case & B1 (kcfs) & $\begin{array}{c}\text { Spillway } \\
(\mathrm{kcfs})\end{array}$ & B2 $(\mathrm{kcfs})$ & $\begin{array}{c}\text { Total } \\
\text { River }\end{array}$ & B2CC & $\begin{array}{c}\text { B2CC } \\
(\mathrm{kcfs})\end{array}$ & BGS & TIEs \\
\hline HNNN & 0 & 100.9 & 146.2 & 247.1 & No & 0 & No & No \\
HNYN & 0 & 100.9 & 146.2 & 247.1 & No & 0 & Yes & No \\
HYNN & 0 & 100.9 & 146.2 & 247.1 & Yes & 5 & No & No \\
HYYN & 0 & 100.9 & 146.2 & 247.1 & Yes & 5 & Yes & No \\
\hline
\end{tabular}




\subsection{Slot Fillers}

As the work progressed, one of the CENWP proposed alternatives (CENWP 2011) was to use slot fillers in the gatewell slots above the STS to reduce the flow expansion in the gatewell. The 1:12 reduced-scale physical model of a single bay did not have the gatewell slots included nor did it exhibit the same degree of recirculating flow in front of the VBS as was measured in the prototype or simulated in the CENWP CFD model that included the gatewell slots (CENWP 2011).

The HNNN and HYNN operational scenarios (see Table 2.4) were run with the gatewell slots filled. This was accomplished by turning the gatewell slot fluid cells in the CFD model into solid cells. In addition, another HNNN scenario (i.e., a forebay with no B2CC flow or BGS in place) was run with only Units $11,14,15$, and 18 operating at $17.6 \mathrm{kcfs}$.

\subsection{Analysis of Results}

Comparison graphics and metrics were produced using Tecplot $360^{T M}$ (Tecplot, Inc.) and Microsoft Excel (Microsoft Corporation). Simulation results were exported from STAR-CD to Tecplot binary format. Tecplot is a general-purpose scientific plotting application that includes specialized CFD processing capabilities. Specifically, Tecplot can create contour maps and vector-field plots, interpolate variables at arbitrary locations in the model domain, generate streamtraces through a velocity field, and perform integrations to calculate fluid fluxes. To be efficient and ensure consistency, most analysis processes used in this study were performed using the Tecplot scripting language.

Certain plots, most notably the discharge bar charts, were created in Microsoft Excel. A spreadsheet application was used to import processed model data from Tecplot, compare model results, and generate graphics. Processing was automated using custom Visual Basic for Applications modules. 



\subsection{Results and Discussion}

The CFD results were to be used to

- Assess the differences in forebay flow pattern.

- Understand the differences between the single-unit models (section numerical or reducedscale physical models) and the prototype.

- Assess the impact of lateral flows from the forebay within the intake on the STS and gatewell slot flow patterns.

- Understand how flow within the intakes and near the VBS might vary across the whole powerhouse.

The second item listed above was to improve the understanding of the differences that might be found in a sectional model with no lateral flow compared to the prototype and the impact of the $\mathrm{BGS}$ and $\mathrm{B} 2 \mathrm{CC}$ on within-turbine flows. The third item was to advance the understanding of whether the same changes to all turbine units might have the same impacts across the powerhouse.

\subsection{Validation}

Two very different types of prototype validation data were available: field-measured ADCP forebay velocities and within-gatewell ADV measurements. The comparison of the CFD model results and the field-measured data is discussed below.

\subsubsection{Comparison to Field-Measured ADCP Data}

The CFD model was validated as has been done in past studies with vector-on-vector plots and 1:1 plots of ADCP and modeled velocity magnitudes. In this study, the results were comparable to the previous CFD studies. The goodness of match was location dependent. The most upstream data points were very near the inlet boundary and did not match as well as was typical at downstream locations. The deepest sampled locations were very near the powerhouse; they had higher velocities and very large standard deviations.

As part of the validation process, the models were run with both upwind differencing (UD, a first-order scheme) and MARS (a second-order scheme); the most difference between the two schemes tended to be in areas of low velocity or recirculation zones. First-order convective differencing schemes are more dissipative, however they may more accurately represent prototype conditions if the turbulence model does under represent the amount of mixing that is actually present. Model results for the ADCP-measured points were very similar for both schemes, however, the extent of the areas of B2 forebay lateral recirculation was larger in the simulation that used MARS. The extent of the lateral recirculation, especially near the Cascade Island shoreline, was larger than expected based on field observations by CENWP personnel. In addition, all CENWP calibration of the screen head-loss coefficients for the VBS and STS were completed for 
models using UD. In consultation with CENWP, it was determined that all model runs should use UD rather than MARS for the differencing scheme.

Figures 3.1 through 3.3 show the velocity vectors from the numerical model and field measurements for the 233-kcfs day; Figures 3.4 through 3.6 show the velocity vectors from the numerical model and field measurements for the 177-kcfs day. Overall, the numerical model comparison to the ADCP measurements was very similar to past studies. It should be noted that the project operations and river flow conditions were changing somewhat during the period when velocities were measured and that the CFD models were run using steady-state boundary conditions.

The 1:1 plots of velocity magnitude (Figure 3.7) showed strong groupings by line location. The reason for this is twofold. First, each measured "line" has similar depths and velocities and second, each line was measured at about the same time of day, and hence under the same operational conditions. The lines nearest the powerhouse have the largest standard deviation-it being often larger than the average measurement. The area in front of the powerhouse was very deep and turbulent, and the lateral area over which the velocity bin was sampled is much larger than for shallower areas. These factors contribute to the measurements having a large standard deviation and less good agreement with the numerical model data. These results are very similar to those derived from past work. 


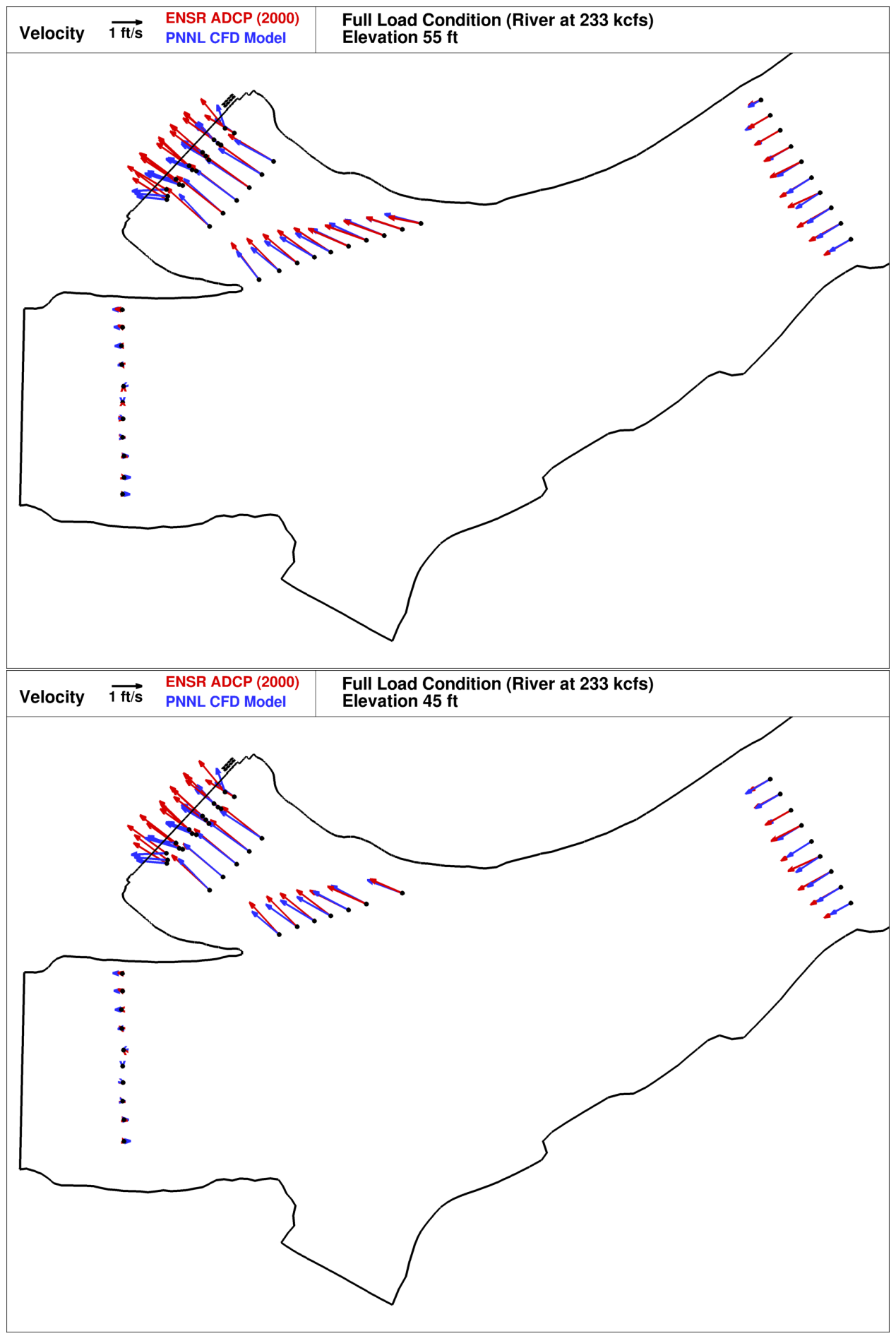

Figure 3.1. Velocity vectors for the CFD results and field-measured ADCP velocities at elevations $55 \mathrm{ft}$ and $45 \mathrm{ft}$ (Total River $233 \mathrm{kcfs}$ ). 


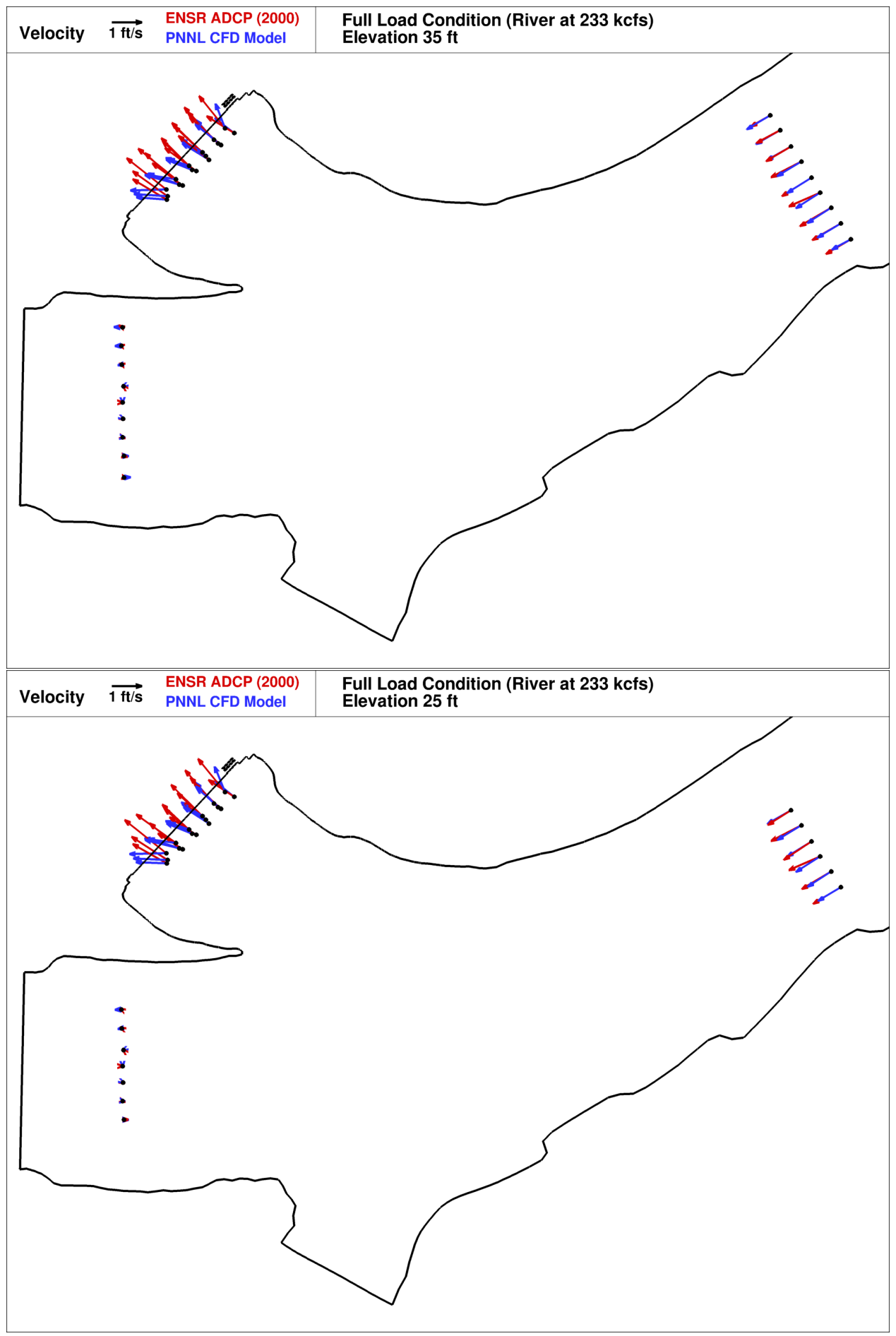

Figure 3.2. Velocity vectors for the CFD results and field-measured ADCP velocities at elevations $35 \mathrm{ft}$ and $25 \mathrm{ft}$ (Total River $233 \mathrm{kcfs}$ ). 


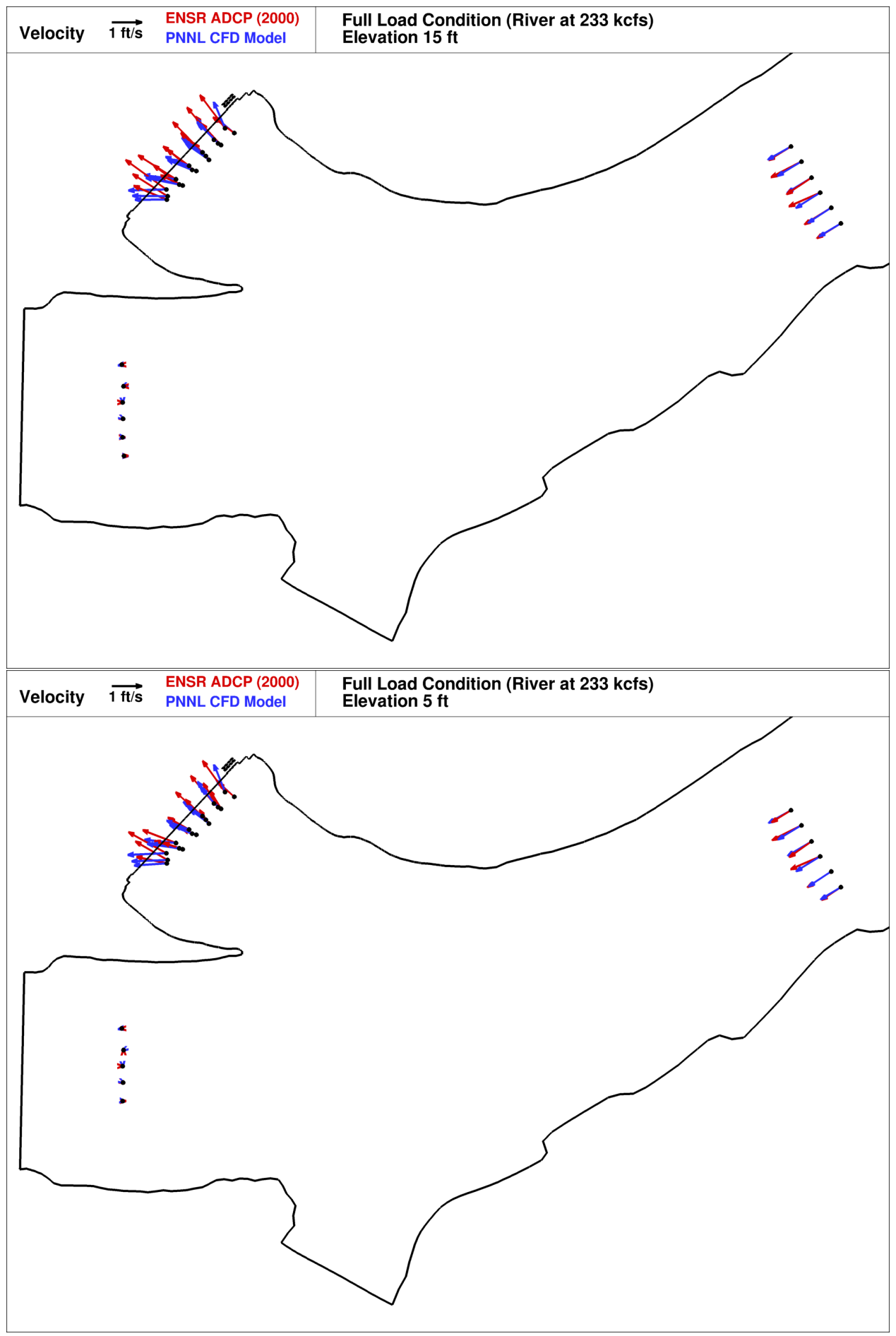

Figure 3.3. Velocity vectors for the CFD results and field-measured ADCP velocities at elevations $15 \mathrm{ft}$ and $5 \mathrm{ft}$ (Total River $233 \mathrm{kcfs}$ ). 


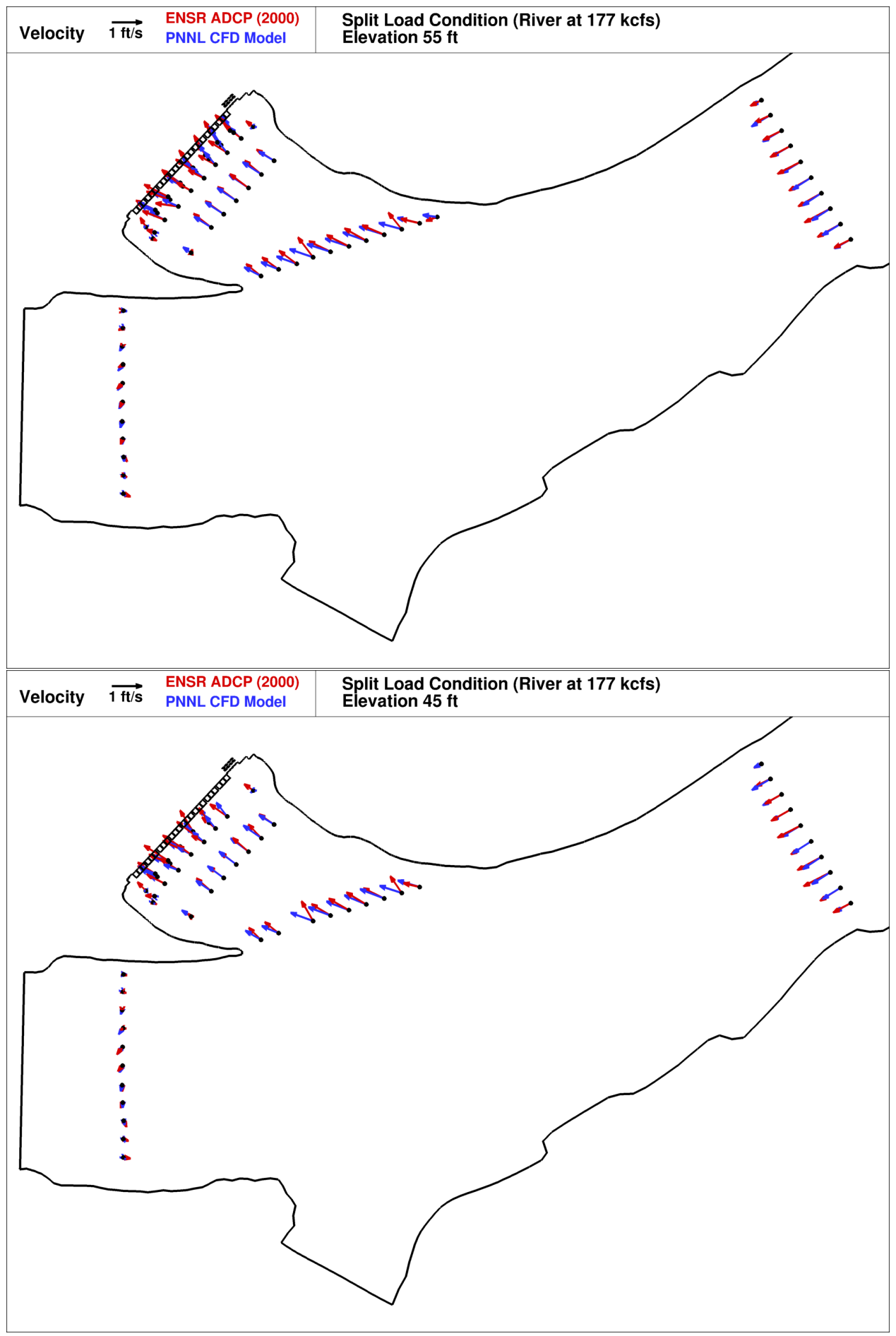

Figure 3.4. Velocity vectors for the CFD results and field-measured ADCP velocities at elevations $55 \mathrm{ft}$ and $45 \mathrm{ft}$ (Total River $177 \mathrm{kcfs}$ ). 


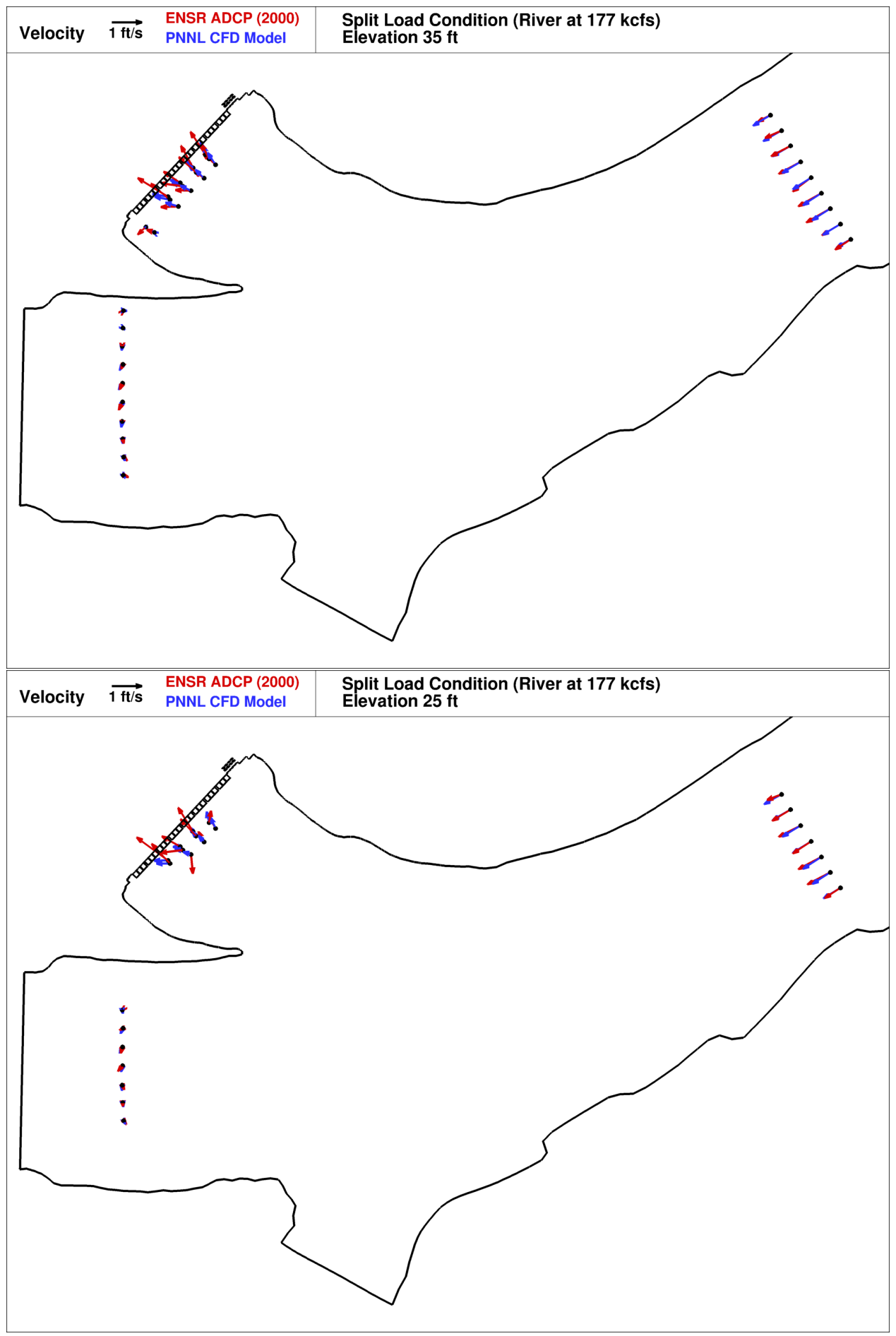

Figure 3.5. Velocity vectors for the CFD results and field-measured ADCP velocities at elevations $35 \mathrm{ft}$ and $25 \mathrm{ft}$ (Total River $177 \mathrm{kcfs}$ ). 


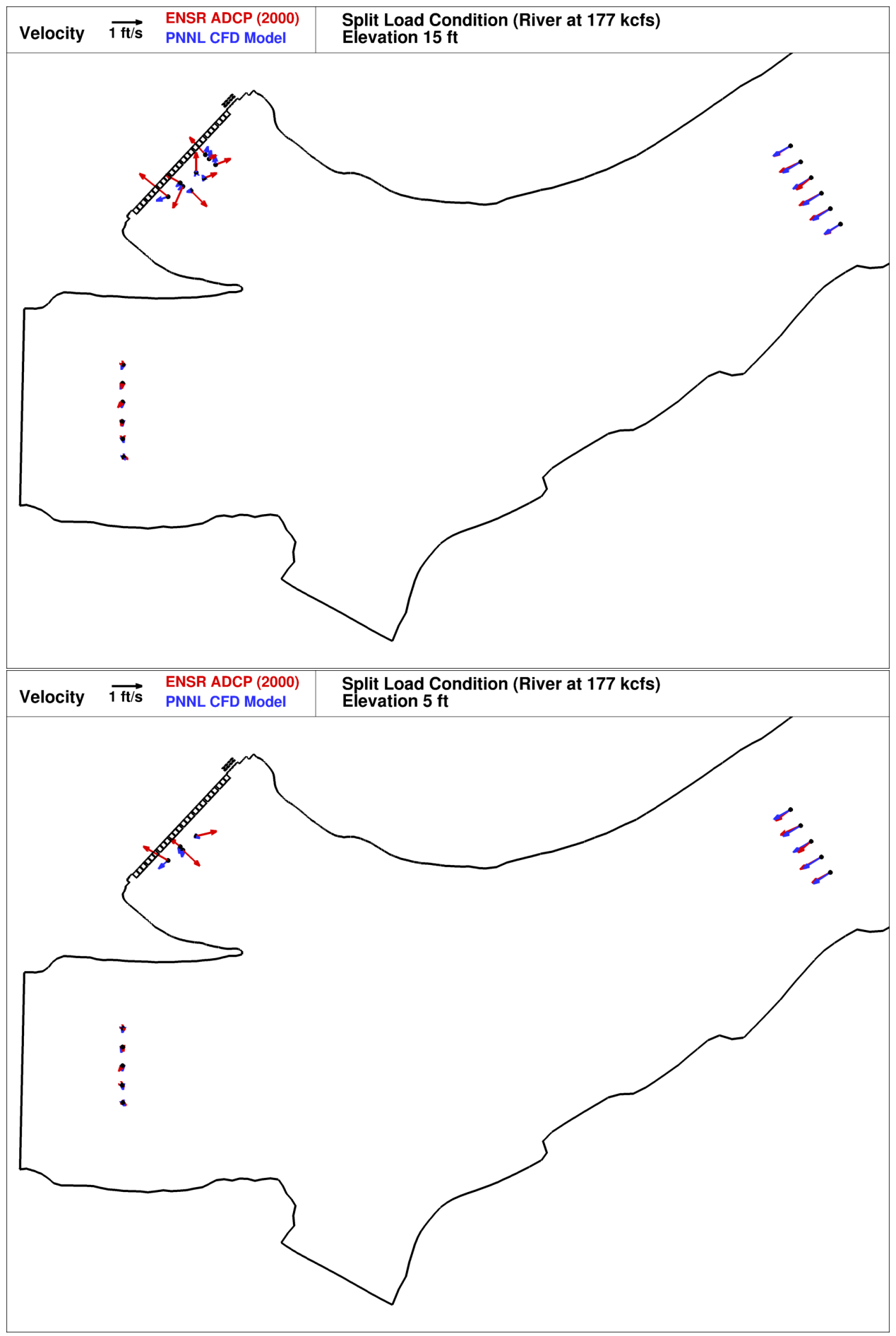

Figure 3.6. Velocity vectors for the CFD results and field-measured ADCP velocities at elevations $15 \mathrm{ft}$ and $5 \mathrm{ft}$ (Total River $177 \mathrm{kcfs}$ ). 

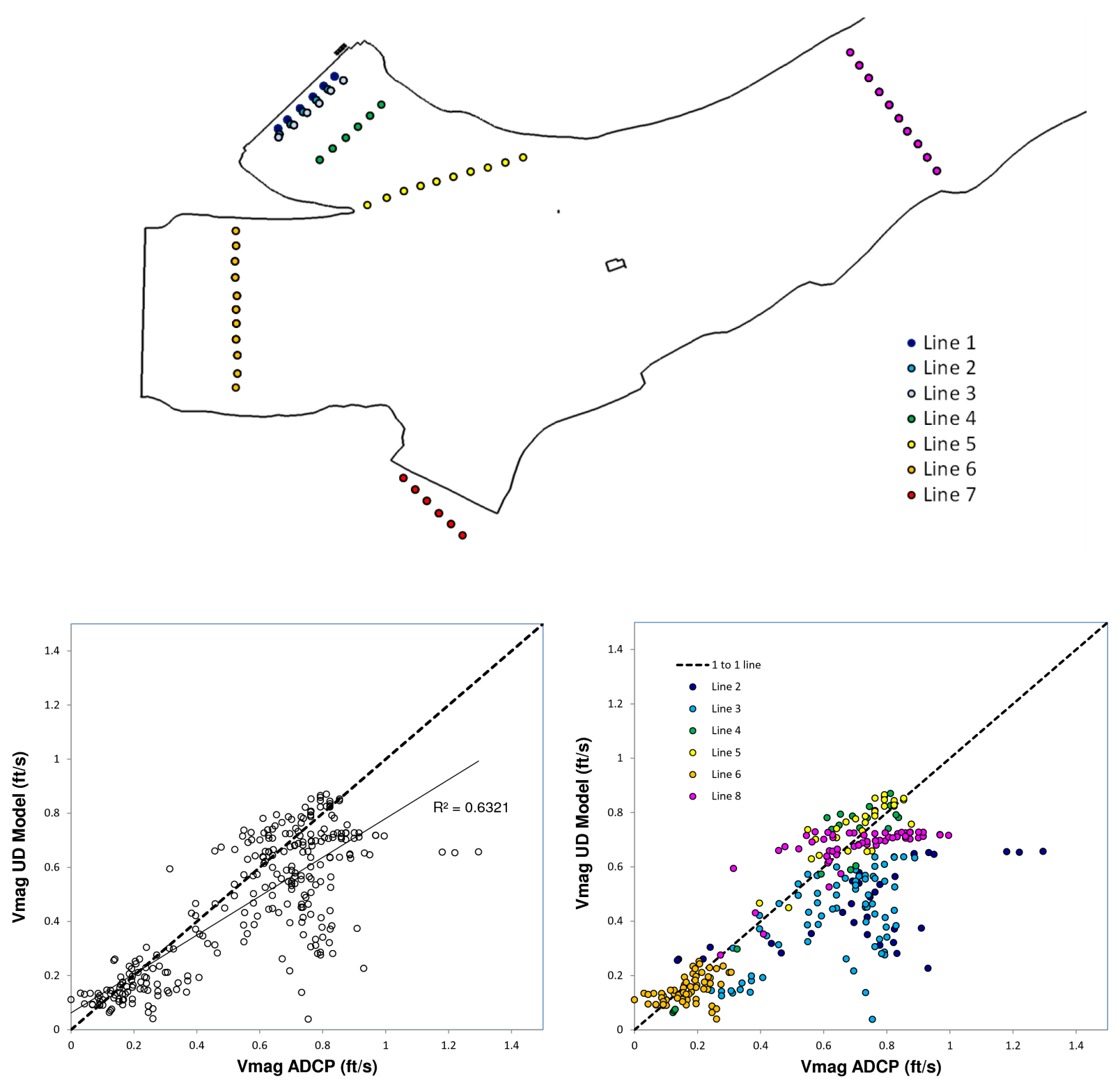

Figure 3.7. Comparison of measured and PNNL velocity magnitude upwind differencing (UD) model. Total River $233 \mathrm{kcfs}$. 


\subsubsection{Single-Turbine Model vs. Full-Forebay Model}

One objective of the study was to use the numerical model to understand the potential differences between a single-unit model, such as the CENWP CFD model, and a full-forebay model. The latter allows for lateral flow in front of the turbine units. Modeled Unit 14 flow patterns were compared for the flow conditions during the February 4, 2000 sampling period (see Tables 2.1 and 2.2) for the full-forebay CFD model and the single-turbine unit CFD model. This use of model results is not part of the model validation, per se, but it used the validation run results.

Figures 3.8 and 3.9 show the velocity magnitude at $0 \mathrm{ft}$ elevation and in the center of Unit 14 Bay $\mathrm{B}$ for the single unit and full-forebay models. The overall velocity magnitude was higher in the full-forebay model because of the lateral flow in front of Unit 14. This lateral flow exited the model through Units 11, 12, and 13 because a recirculation zone upstream of Units 11 and 12 modified flow direction into those units. There was also some change in the velocity distribution within the intake (Figure 3.9) and the gatewell slot (Figures 3.10 and 3.11). For both the singleturbine model and full-forebay model, there were areas of recirculation within the gatewell and in front of the VBS. The flow pattern was a bit different, but the range of velocities and the gradients were very similar. 


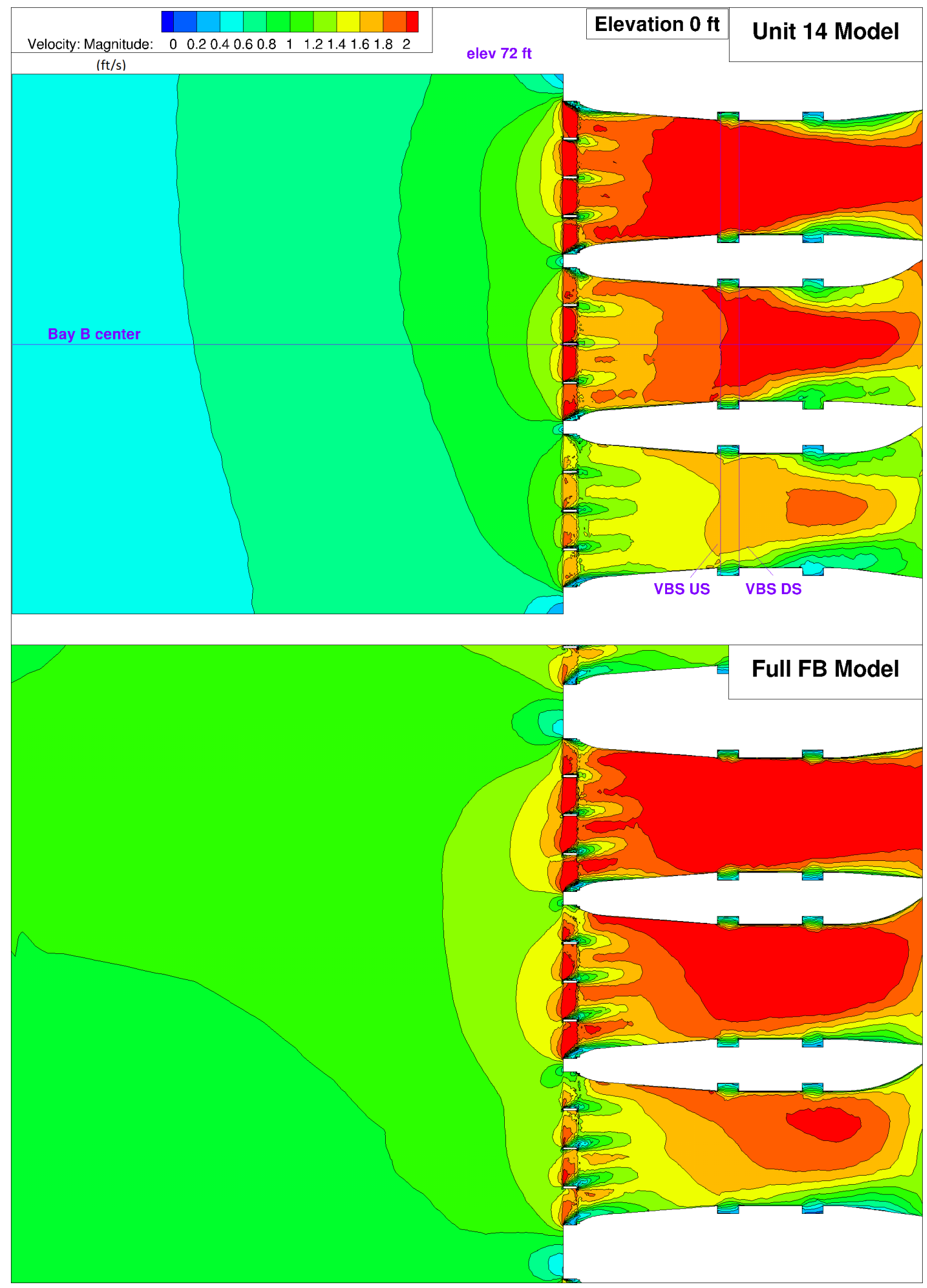

Figure 3.8. Velocity magnitude at elevation $0 \mathrm{ft}$ for the single Unit 14 (upper) and Unit 14 in a full-forebay model (lower) for the ADCP February 4, 2000 scenario. 


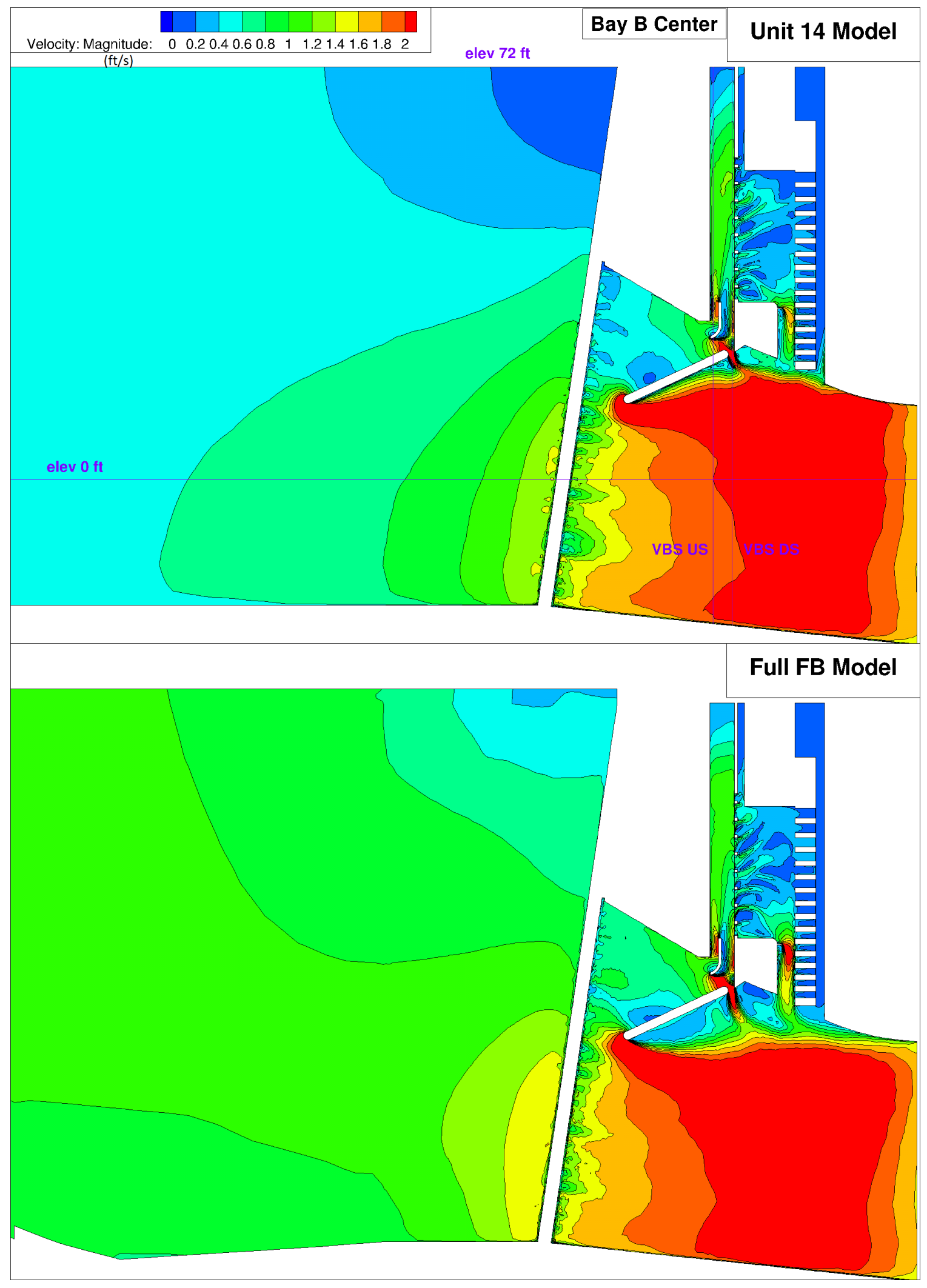

Figure 3.9. Vertical slice in the center of Bay B for the ADCP February 4, 2000 scenario. 


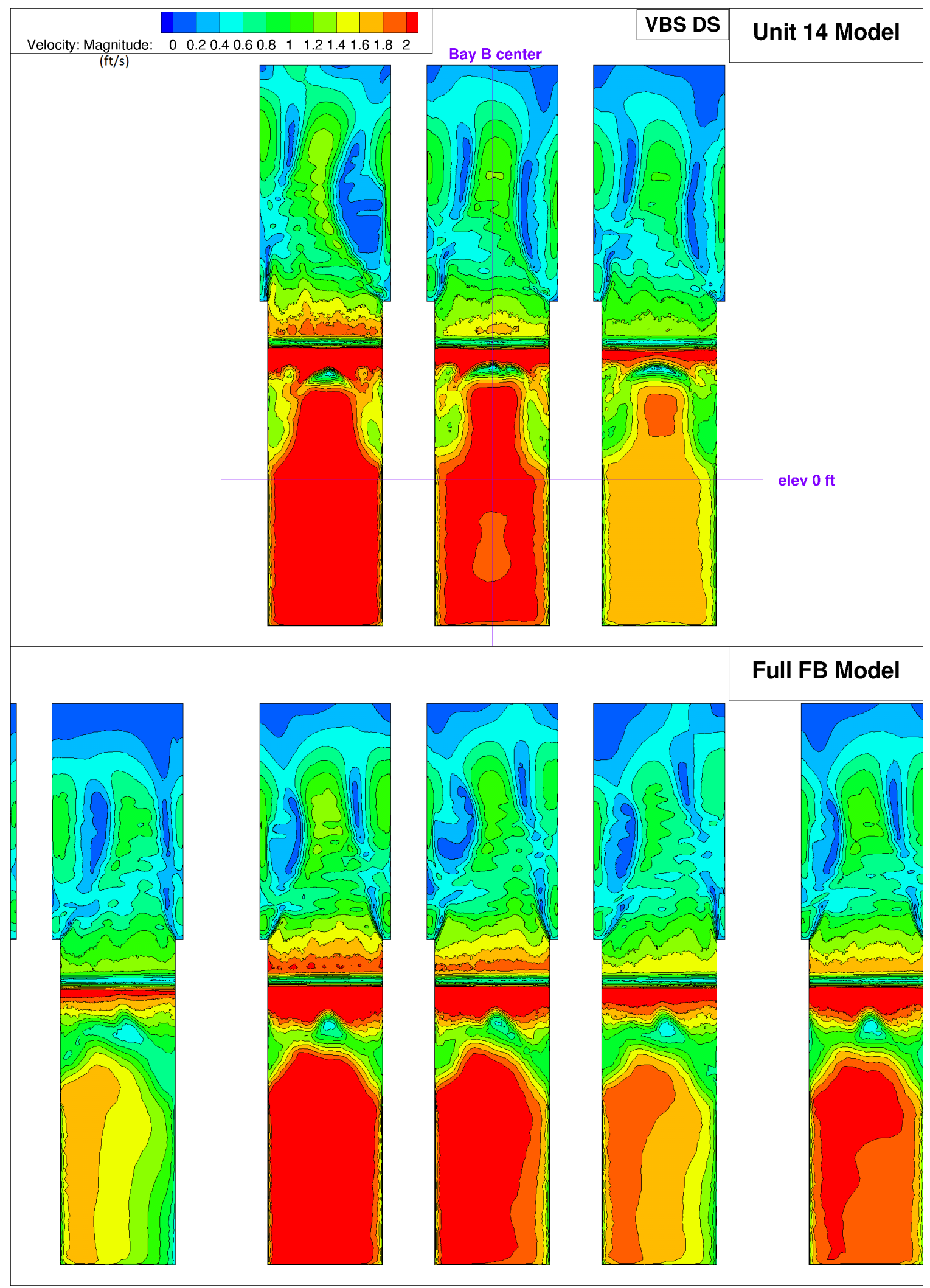

Figure 3.10. Velocity magnitude of flow $0.48 \mathrm{ft}$ in front of the VBS. View is looking downstream. 


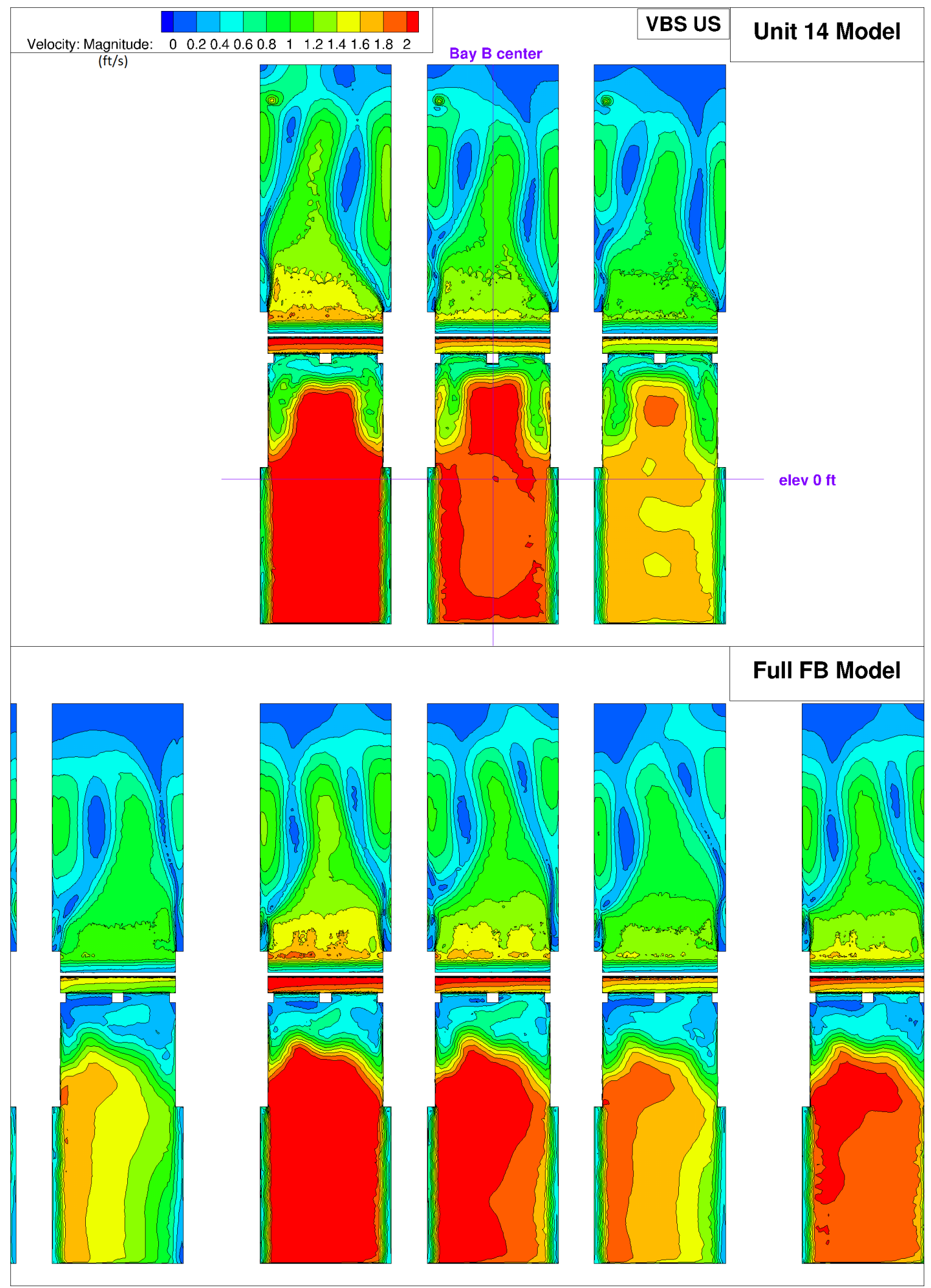

Figure 3.11. Velocity magnitude of flow $3.48 \mathrm{ft}$ in front of the VBS. View is looking downstream. 


\subsubsection{Comparison with ADV Data}

ADV data were collected in the gatewell of Unit 14, Bay A (Figure 3.12, Hughes et al. (2011)). The field data were collected over several hours and averaged. The comparison should be considered qualitatively for general flow patterns and the maximum and minimum velocities. The results are shown in Figures 3.13 through 3.18, there were general similarities in flow patterns and the velocity magnitudes for the normal and sweep velocities.

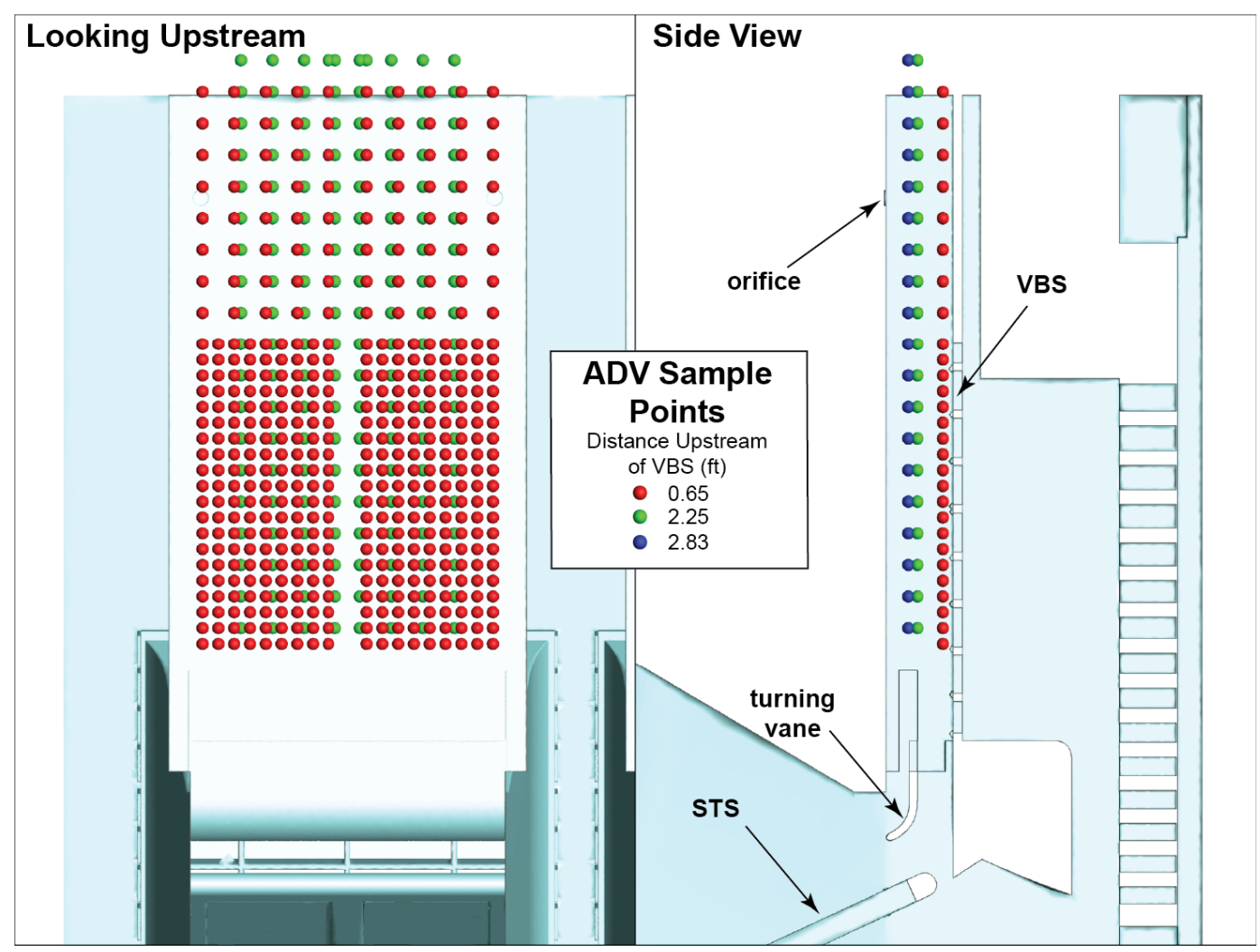

Figure 3.12. Locations of ADV measurements. 


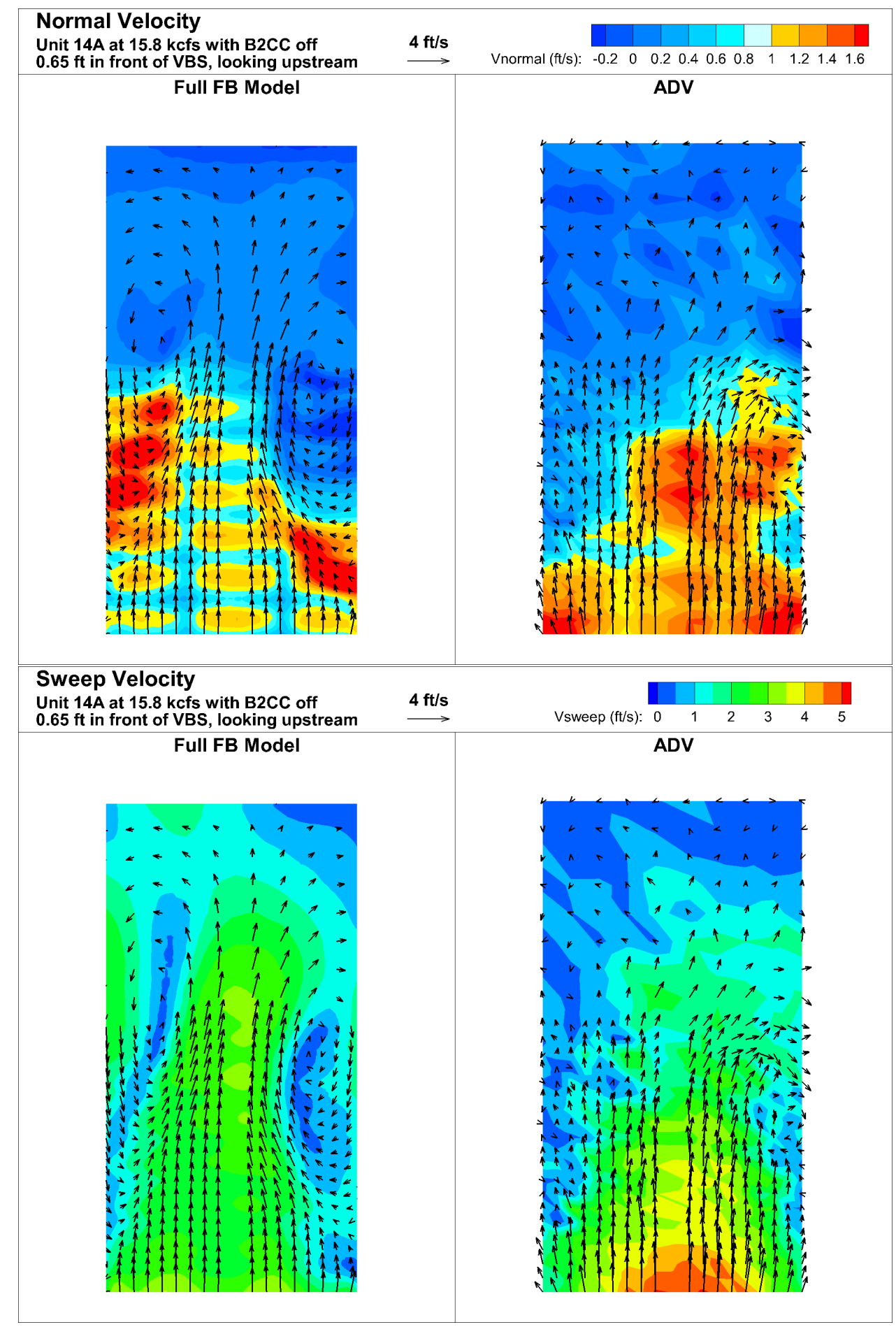

Figure 3.13. Normal and sweep velocities $0.65 \mathrm{ft}$ in front of the VBS for Unit 14 Bay A at 15.8 kcfs with the B2CC off. 


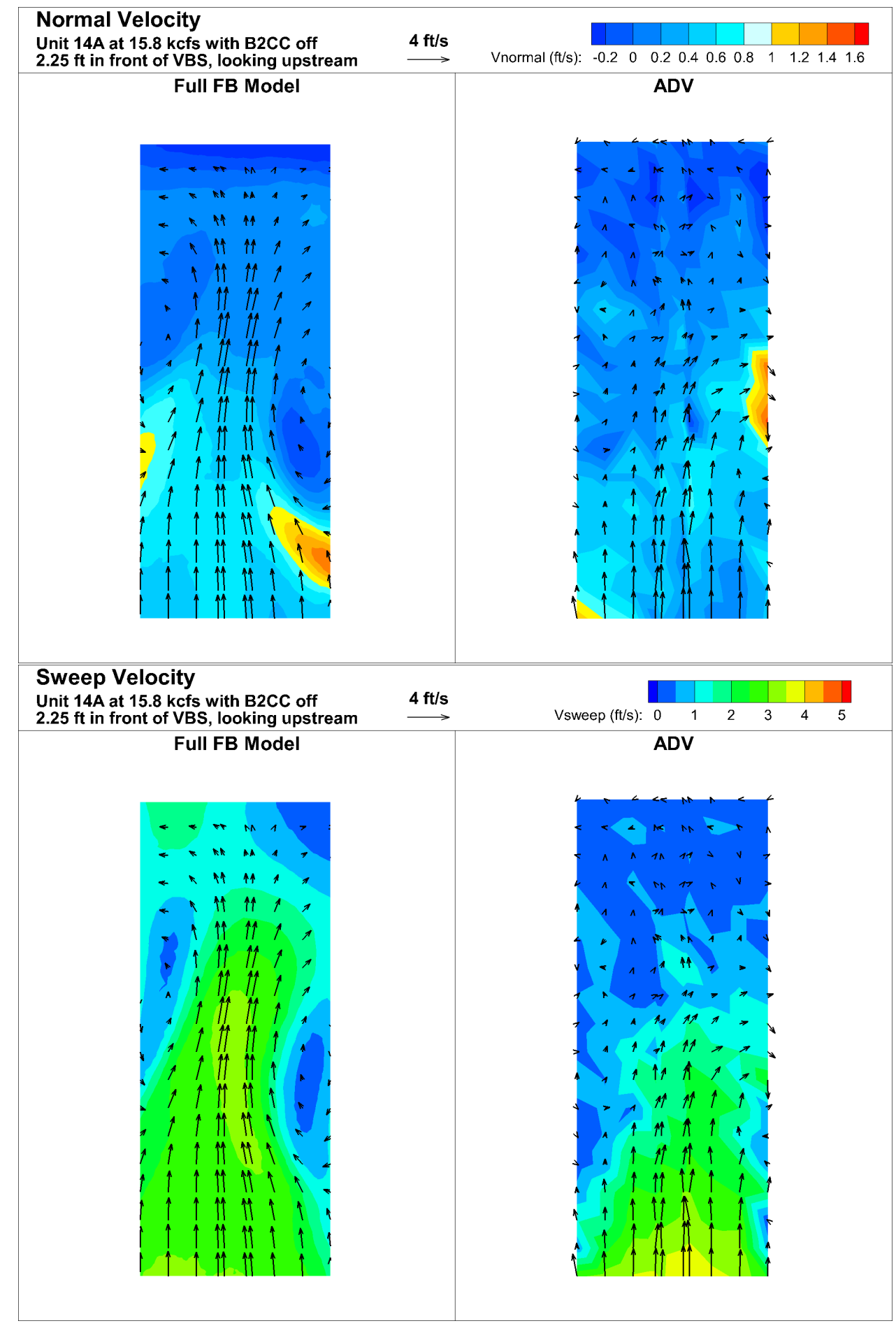

Figure 3.14. Normal and sweep velocities $2.25 \mathrm{ft}$ in front of the VBS for Unit 14 Bay A at 15.8 kcfs with the B2CC off. 


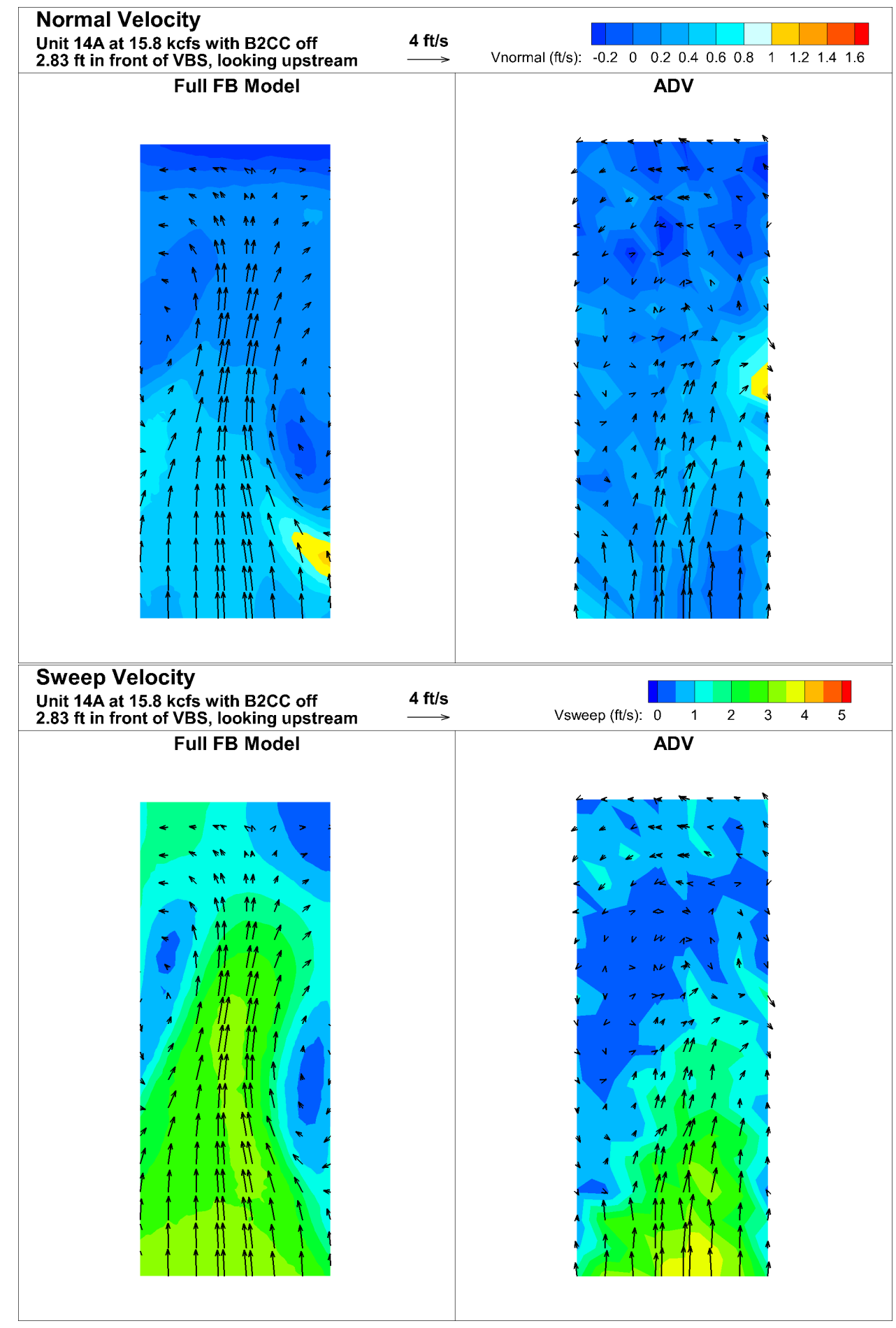

Figure 3.15. Normal and sweep velocities $2.83 \mathrm{ft}$ in front of the VBS for Unit 14 Bay A at 15.8 kcfs with the B2CC off. 


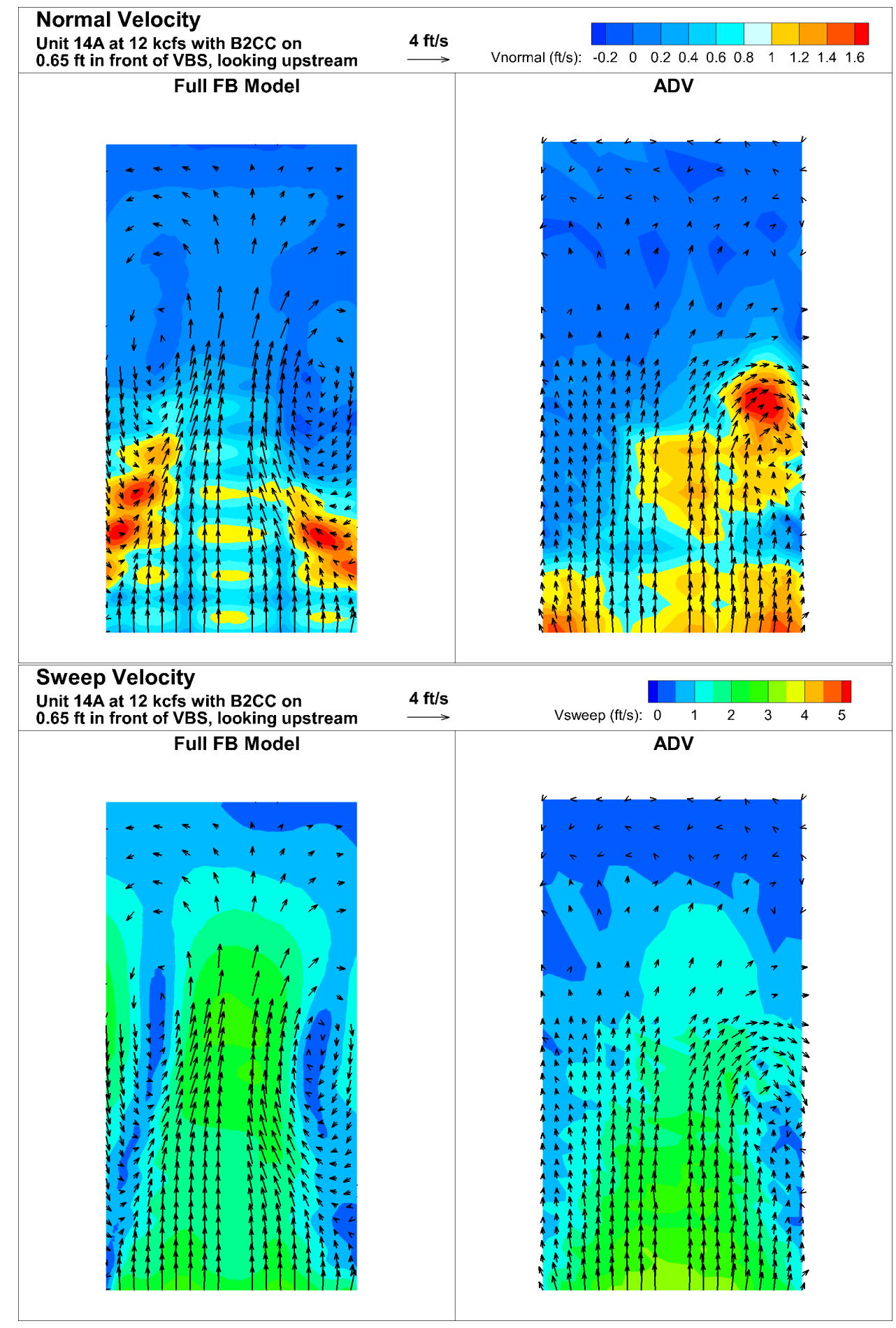

Figure 3.16. Normal and sweep velocities $0.65 \mathrm{ft}$ in front of the VBS for Unit 14 Bay A at 12 kcfs with the B2CC on. 


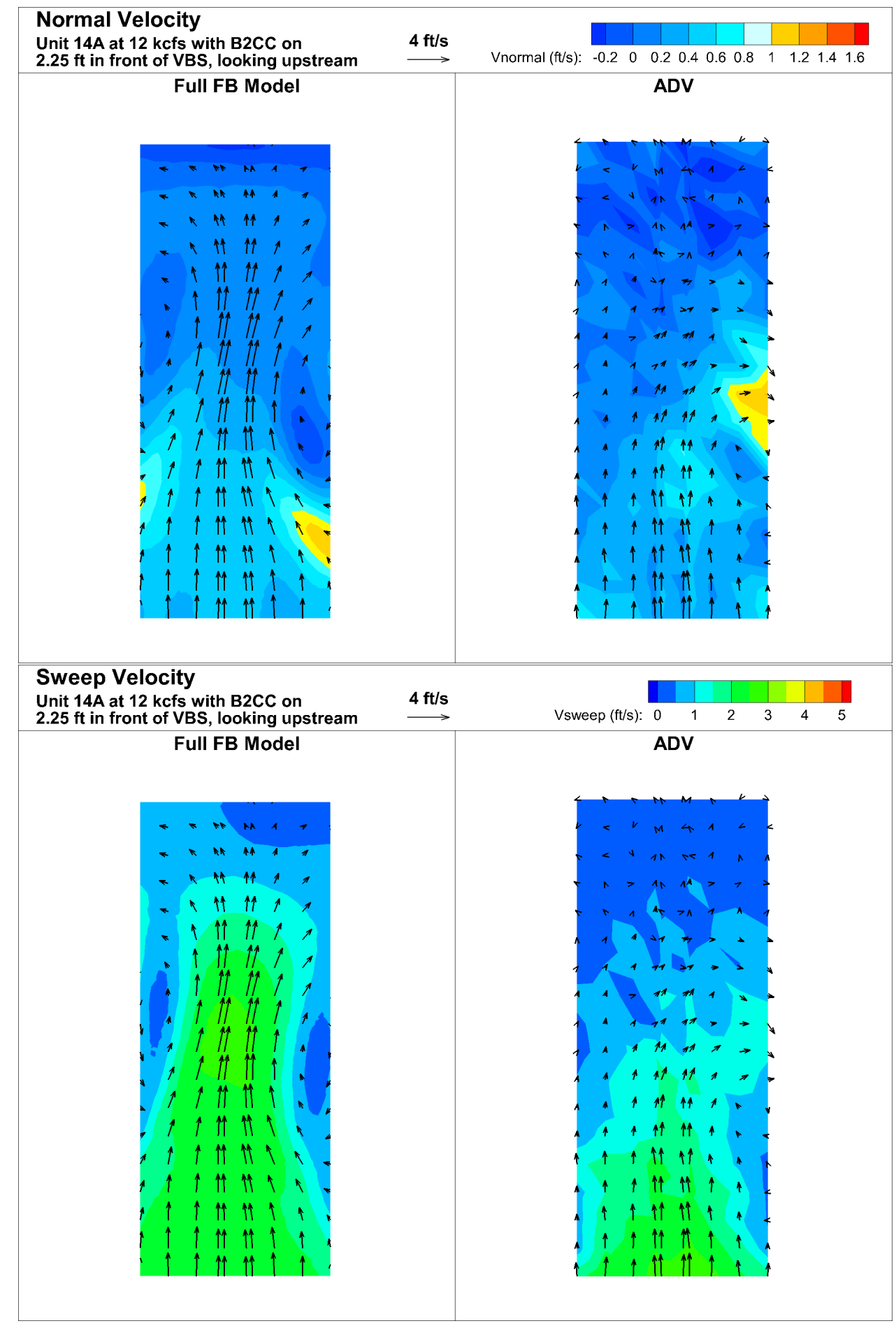

Figure 3.17. Normal and sweep velocities $2.25 \mathrm{ft}$ in front of the VBS for Unit 14 Bay A at 12 kcfs with the B2CC on. 


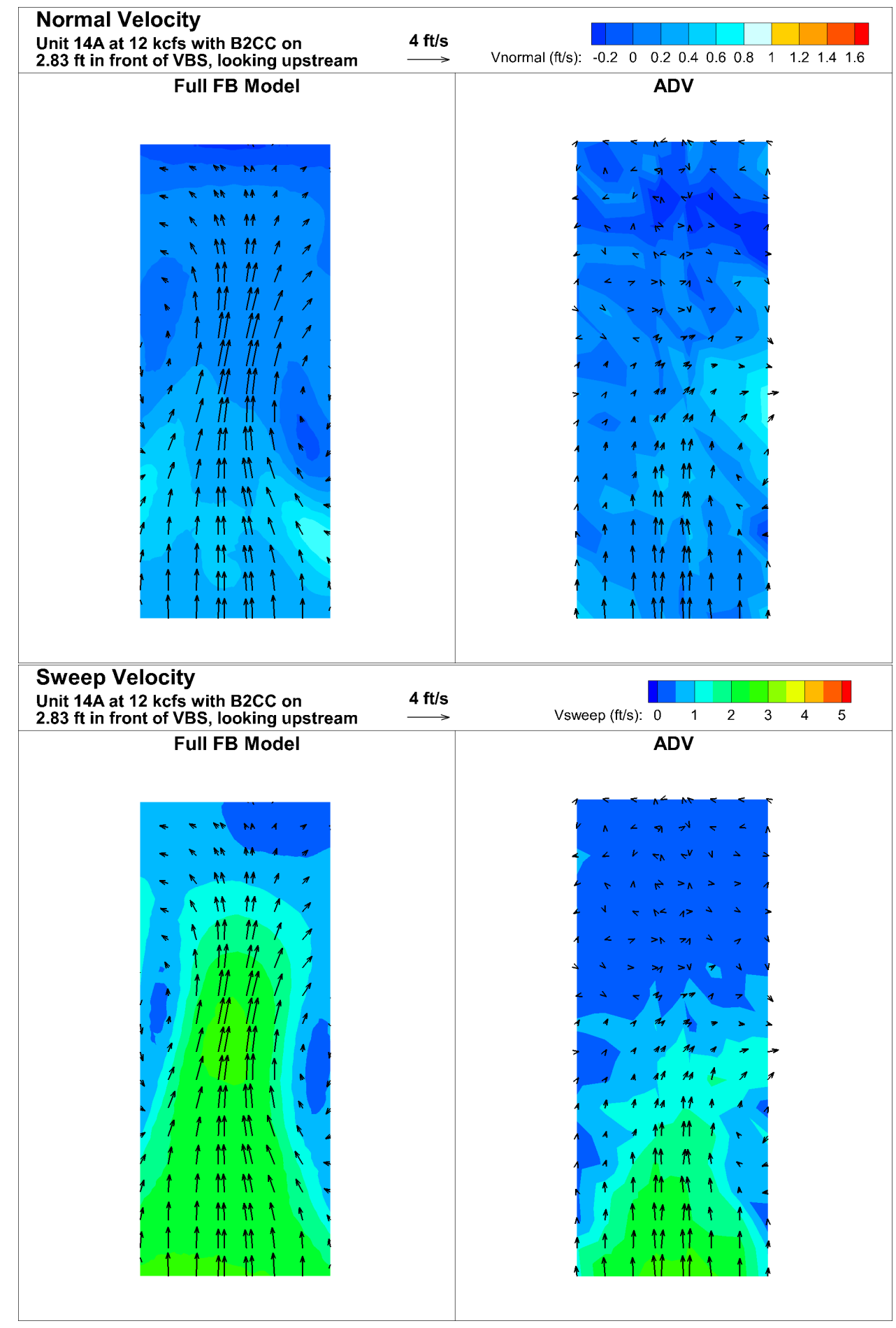

Figure 3.18. Normal and sweep velocities $2.83 \mathrm{ft}$ in front of the VBS for Unit 14 Bay A at 12 kcfs with the B2CC on. 


\subsection{Operational Scenarios}

Four forebay operational scenarios (Table 2.4) were simulated and the results were analyzed.

The overall forebay flow patterns were compared using streamlines and graphics of velocity at multiple elevations. The graphics of flow patterns are arranged by scenario (Sections 3.2.1 through 3.2.4); the intake flows across the whole powerhouse and between scenarios are compared in Section 3.2.5. For each scenario, the first set of graphics shows the velocity magnitude at three elevations: 39,64 , and $74 \mathrm{ft}$. For each elevation, an array of points near the powerhouse has a 30-s streamline; these streamlines show the overall flow pattern. The next set of graphics has an oblique view looking into the B2 turbine intakes with a vertical array of streamline release points $300 \mathrm{ft}$ in front of $\mathrm{B} 2$. The next graphic shows a vertical slice of velocity magnitude through the center bay of Unit 12 and Unit 15. This graphic has an array of release points for 10-s streamlines in front of the units. The last graphic in the series shows velocity magnitude and flow direction in the gatewell of Unit 12 in two locations- $0.65 \mathrm{ft}$ and $2.25 \mathrm{ft}$ from the VBS.

\subsubsection{High Flow without B2CC Flow or BGS (HNNN)}

This is the baseline scenario without a BGS or an operating B2CC. The numerical model results show areas of higher velocity that are parallel to the powerhouse and through the depth of flow in front of Unit 18 and Units 11 and 12 (Figures 3.19 and 3.20). Eddies set up on both sides of the channel, with the larger eddy occurring in front of Units 11 and 12, and lateral flow in front of the powerhouse occurs at all elevations (Figure 3.21). The velocity magnitude is higher throughout the water column in front of Unit 12 than it is in front of Unit 15 (Figure 3.22).

Within the gatewell in front of the VBS, the flow recirculated laterally with the gatewell slots as a flow expansion. Velocities decreased near the top of the gatewell; a higher velocity zone occurred in the center of the gatewell (Figures 3.23 and 3.24). 


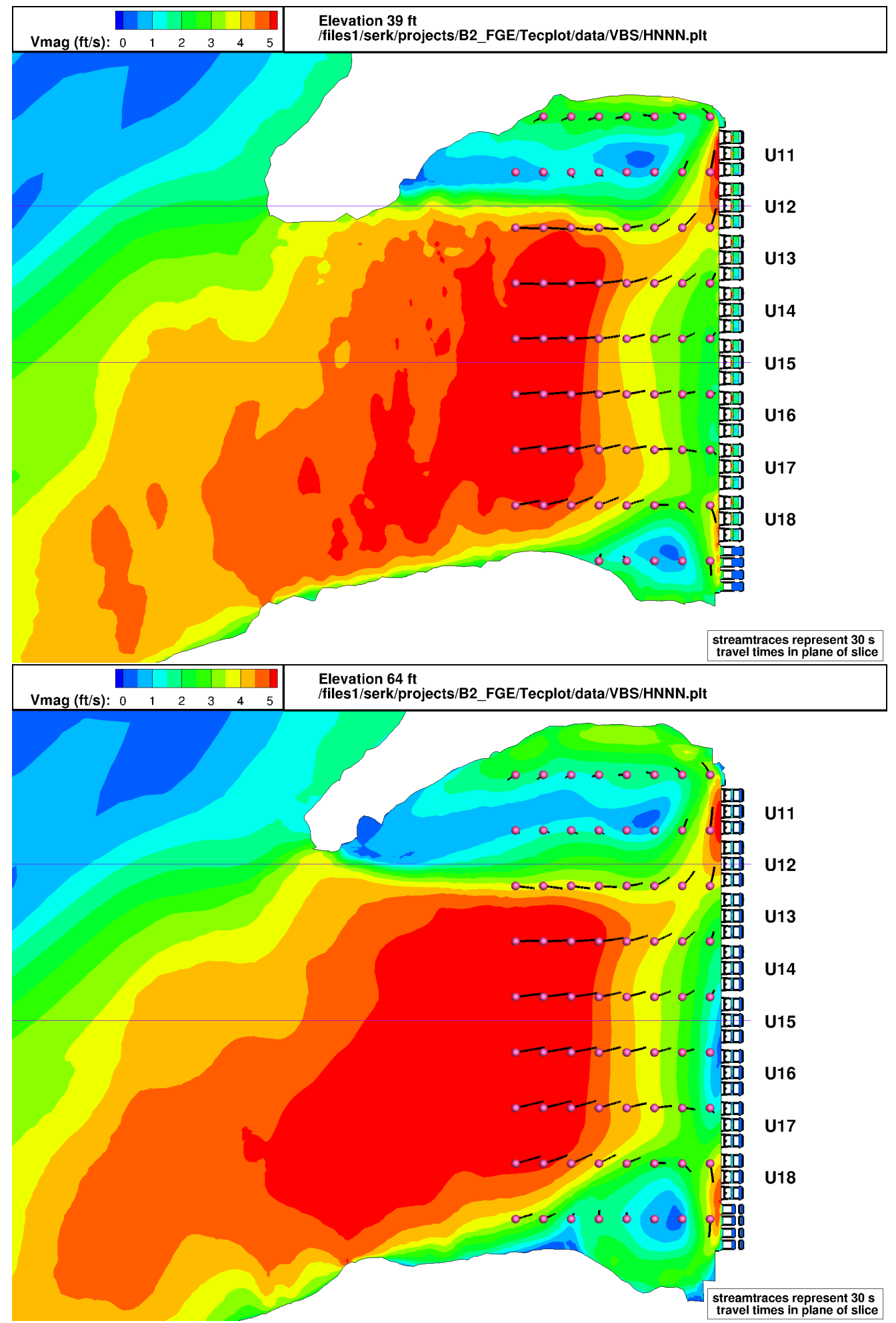

Figure 3.19. HNNN: Velocity magnitude and short streamlines at elevation $39 \mathrm{ft}$ (top) and $64 \mathrm{ft}$ (bottom). Flow is from left to right. 


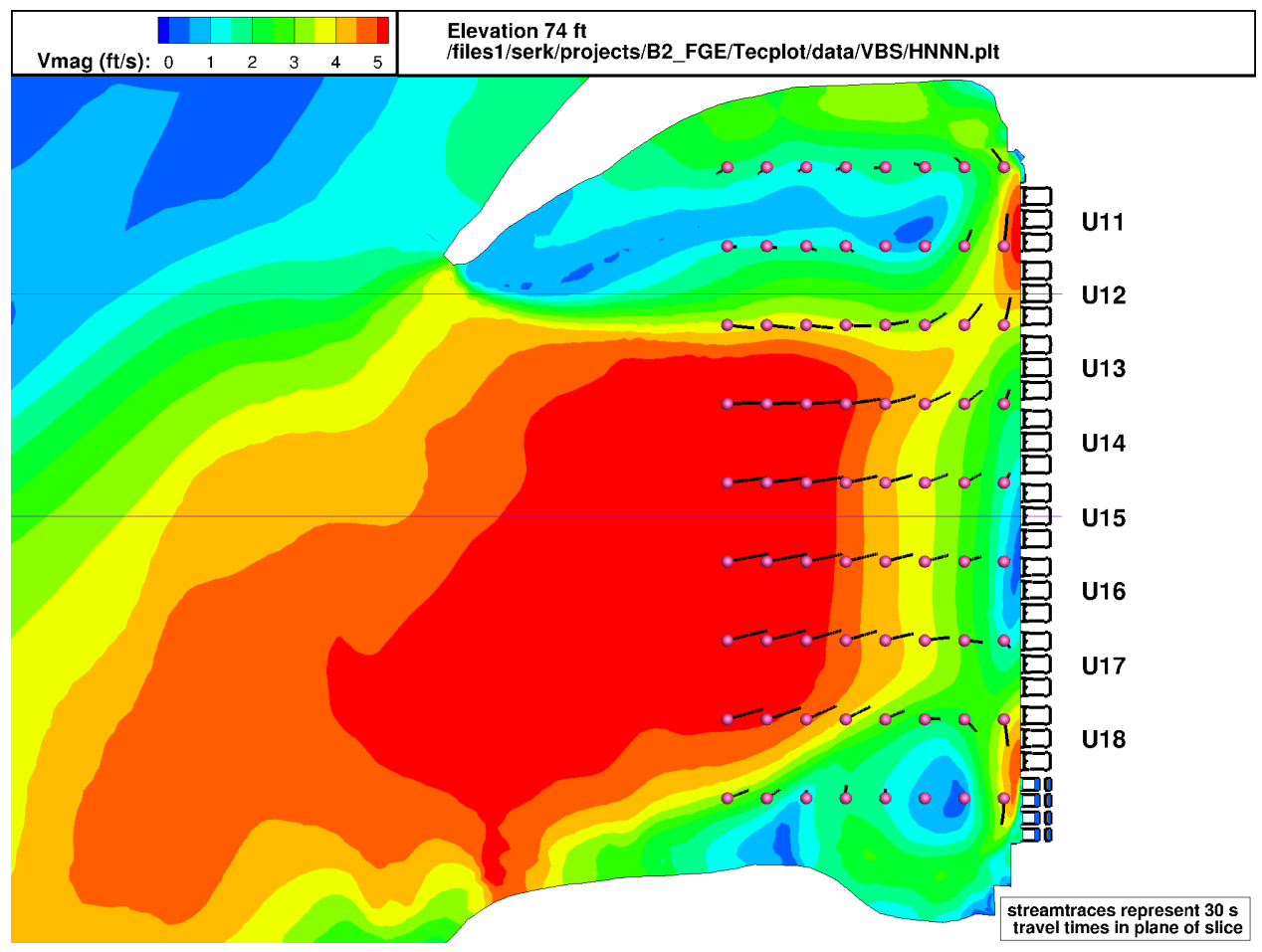

Figure 3.20. HNNN: Velocity magnitude and short streamlines at elevation $74 \mathrm{ft}$. Flow is from left to right.

\begin{tabular}{|l|llllll|l|l|l|}
\hline & & & & & & & $\begin{array}{l}\text { Streamtraces Starting 300 ft in Front of Dam at Elevation 74, 54, and } \mathbf{3 4} \mathrm{ft} \\
\text { /files1/serk/projects/B2_FGE/Tecplot/data/VBS/HNNN.plt }\end{array}$ \\
\hline
\end{tabular}

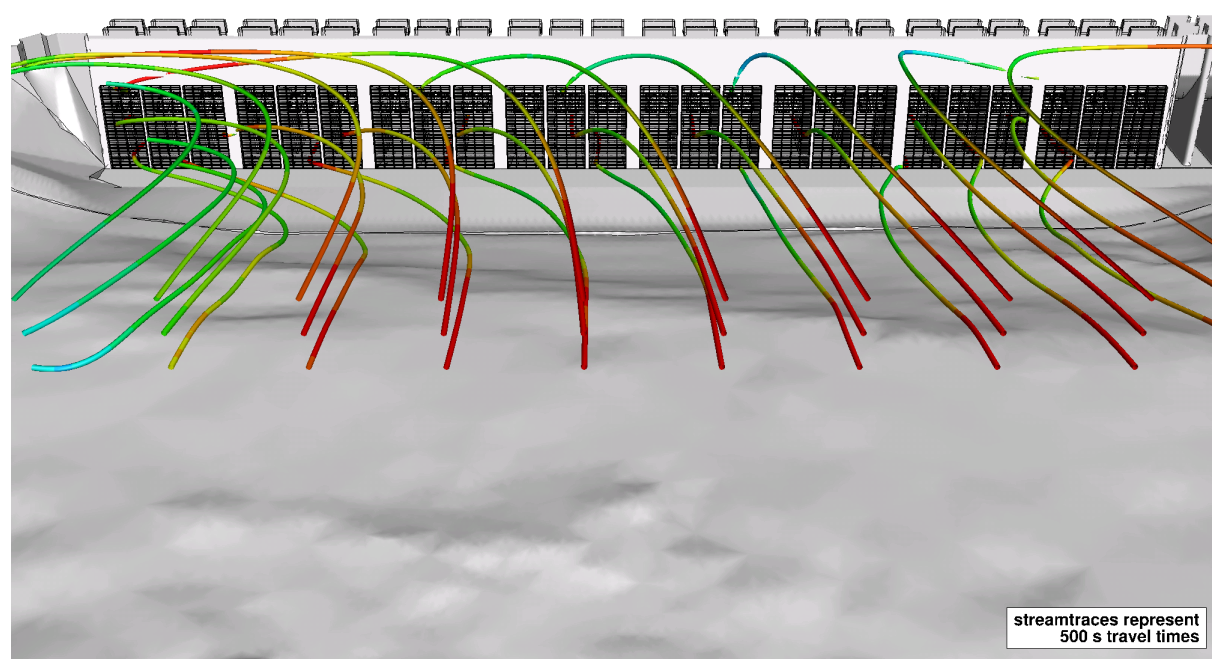

Figure 3.21. HNNN: Streamlines seeded 300-ft upstream of the powerhouse and colored by velocity magnitude. View is downstream looking into the turbine intakes. 


\begin{tabular}{|lllllll|l|l|}
\hline Vmag (ft/s): & 0 & 1 & 2 & 3 & 4 & 5 & $\begin{array}{l}\text { Middle Unit 12 } \\
\text { /files1/serk/projects/B2_FGE/Tecplot/data/VBS/HNNN.plt }\end{array}$ \\
\hline
\end{tabular}
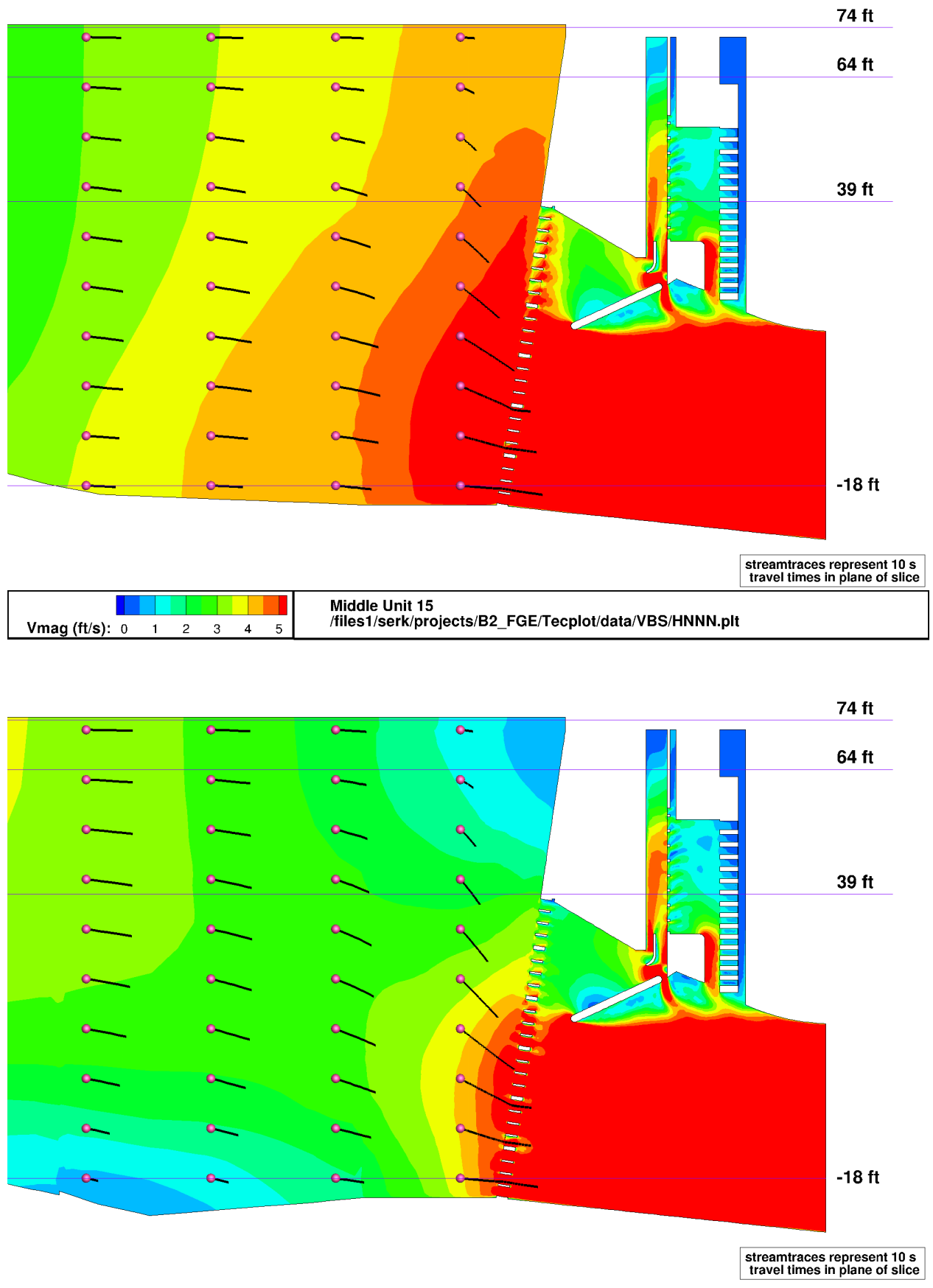

Figure 3.22. HNNN: Velocity magnitude and 10-s streamlines in the centerline Unit 12 (top) and Unit 15 (bottom). 


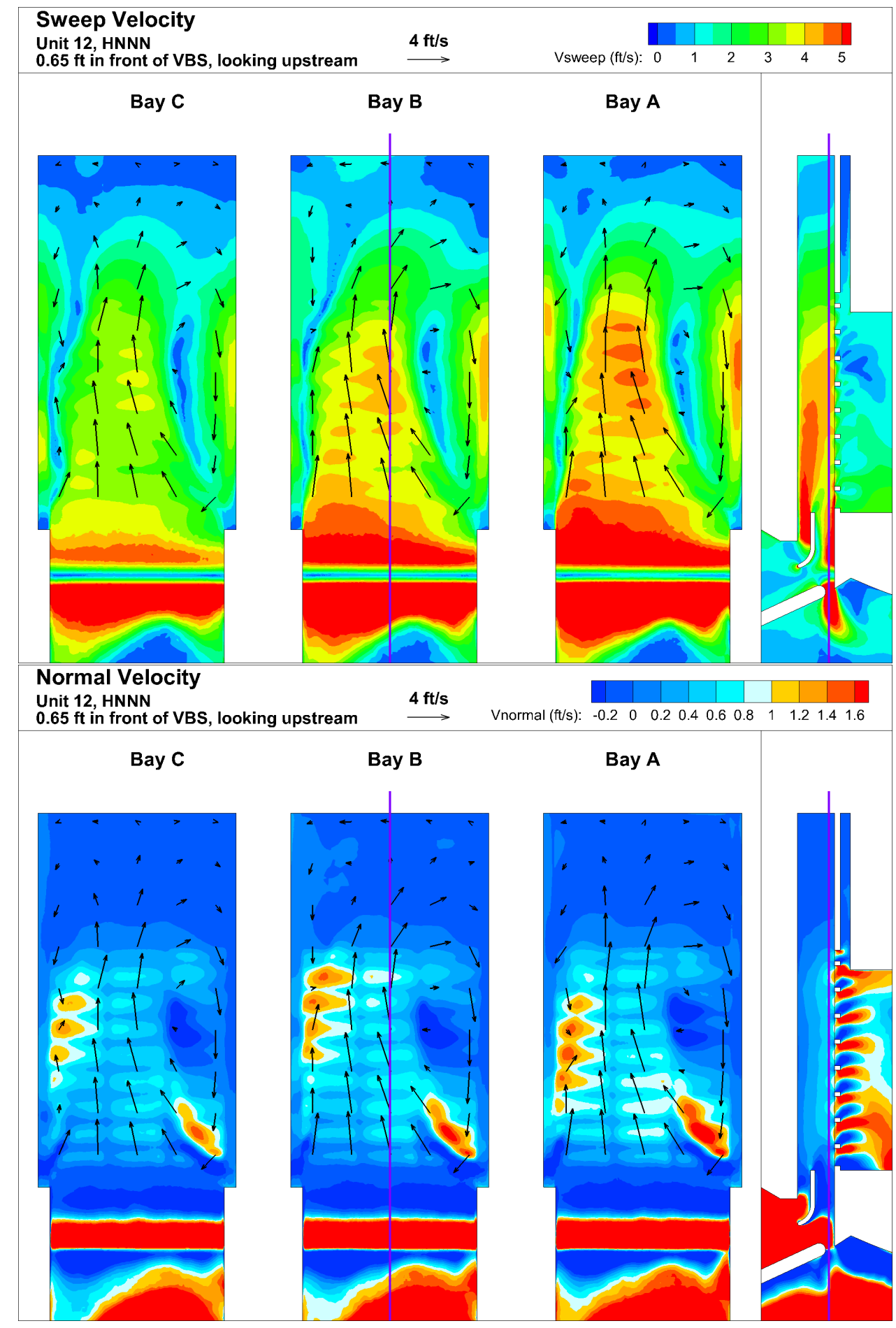

Figure 3.23. HNNN: Sweep (top) and normal (bottom) velocities $0.65 \mathrm{ft}$ in front of the VBS. 


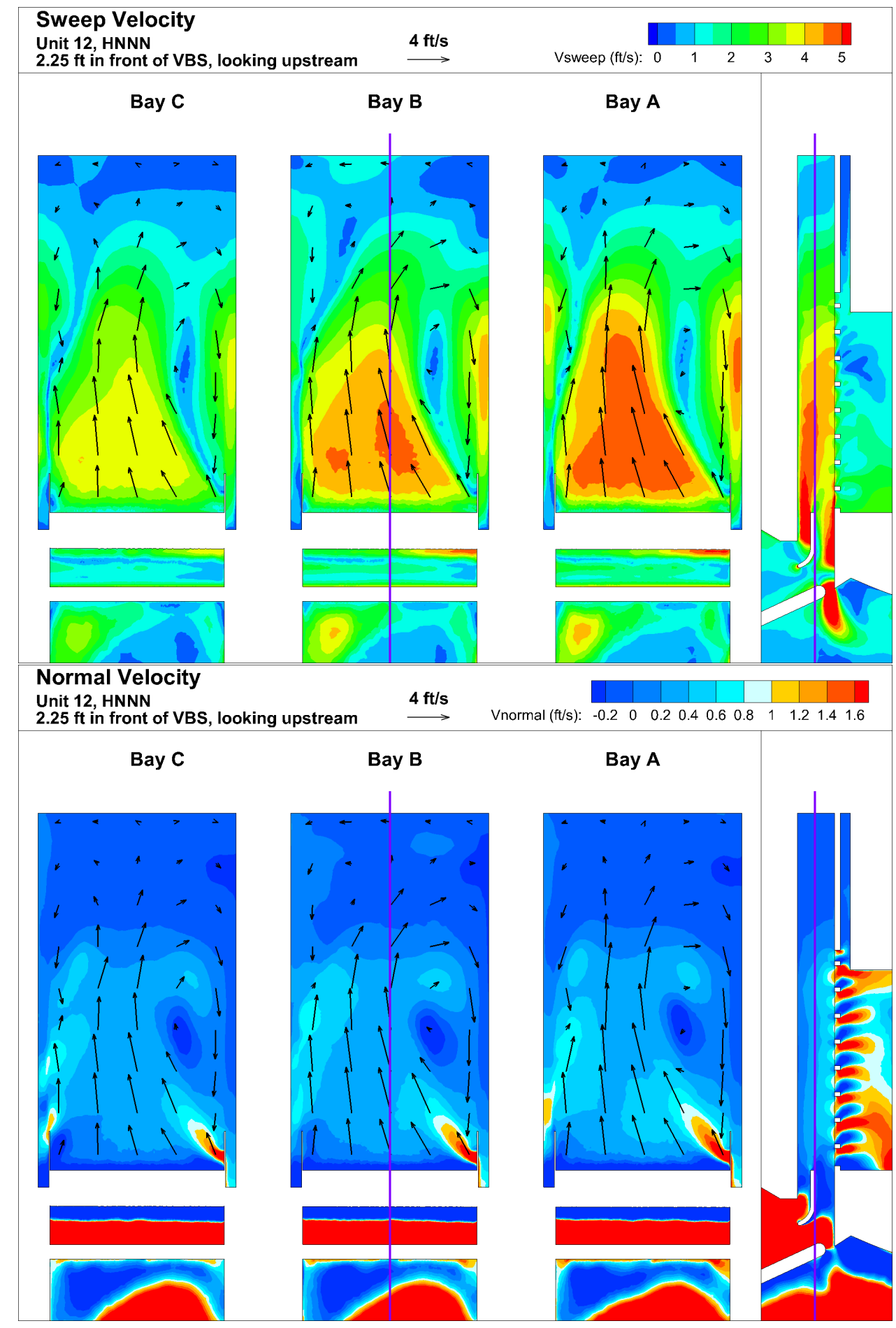

Figure 3.24. HNNN: Sweep (top) and normal (bottom) velocities $2.25 \mathrm{ft}$ in front of the VBS. 


\subsubsection{High Flow with BGS (HNYN)}

This scenario had the same turbine operations as the HNNN scenario but with a BGS added to the forebay. The numerical model results show that the BGS modifies the forebay velocities. The area near the powerhouse with higher-velocity lateral flow had reduced maximum velocities in front of Unit 18 and Units 11 and 12 (Figures 3.25 and 3.26). Eddies occurred on both sides of the channel, but the lateral extent of the larger eddy in front of Units 11 and 12 was some-

what reduced. Figure 3.27 shows the forebay streamlines. Figure 3.28 shows that the velocity magnitude was reduced in front of Unit 12 relative to the HNNN scenario.

The flows within the Unit 12 gatewell were virtually the same as those in the HNNN scenario (Figures 3.29 and 3.30, as expected. 


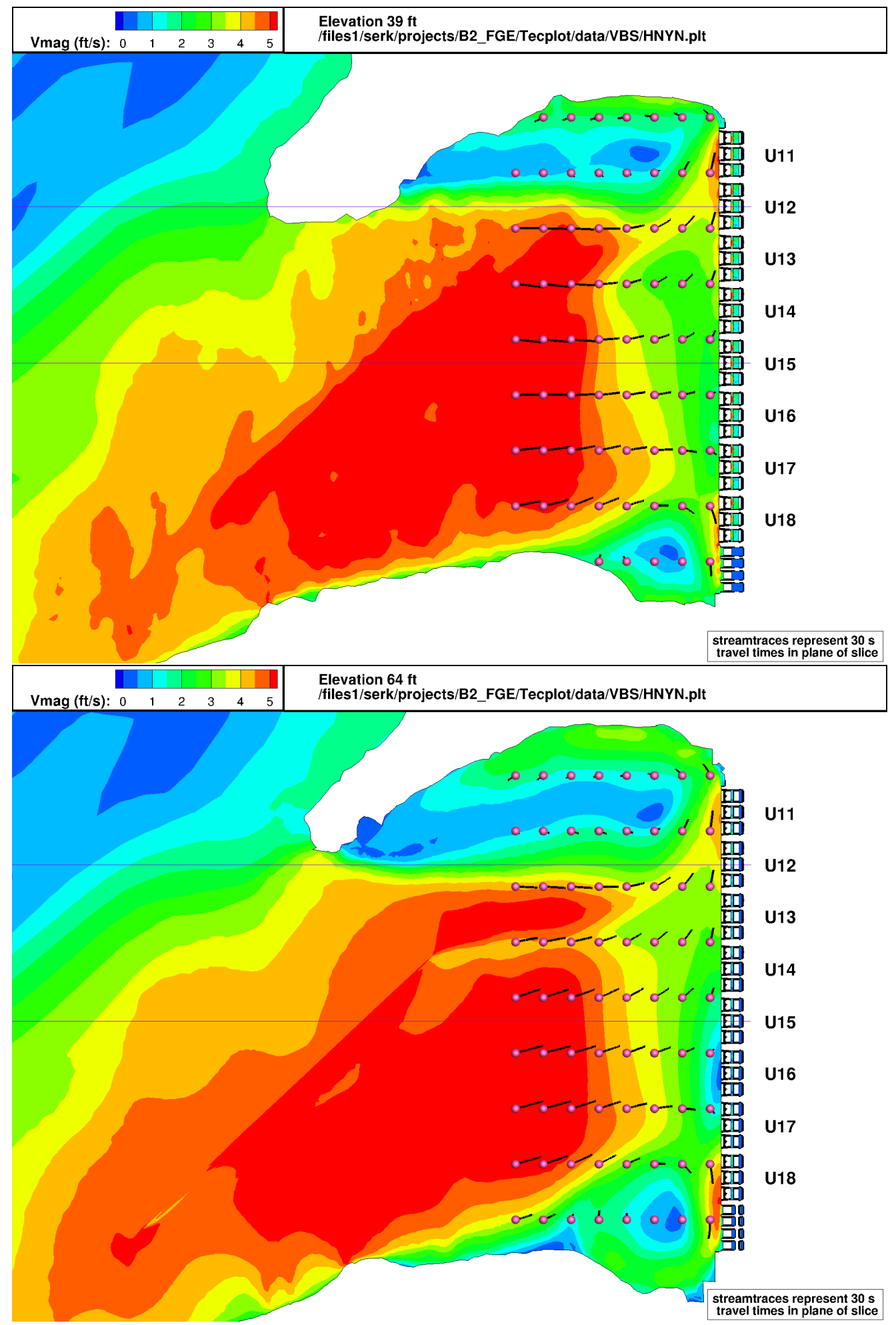

Figure 3.25. HNYN: Velocity magnitude and short streamlines at elevation $39 \mathrm{ft}$ (top) and $64 \mathrm{ft}$ (bottom). Flow is from left to right. 


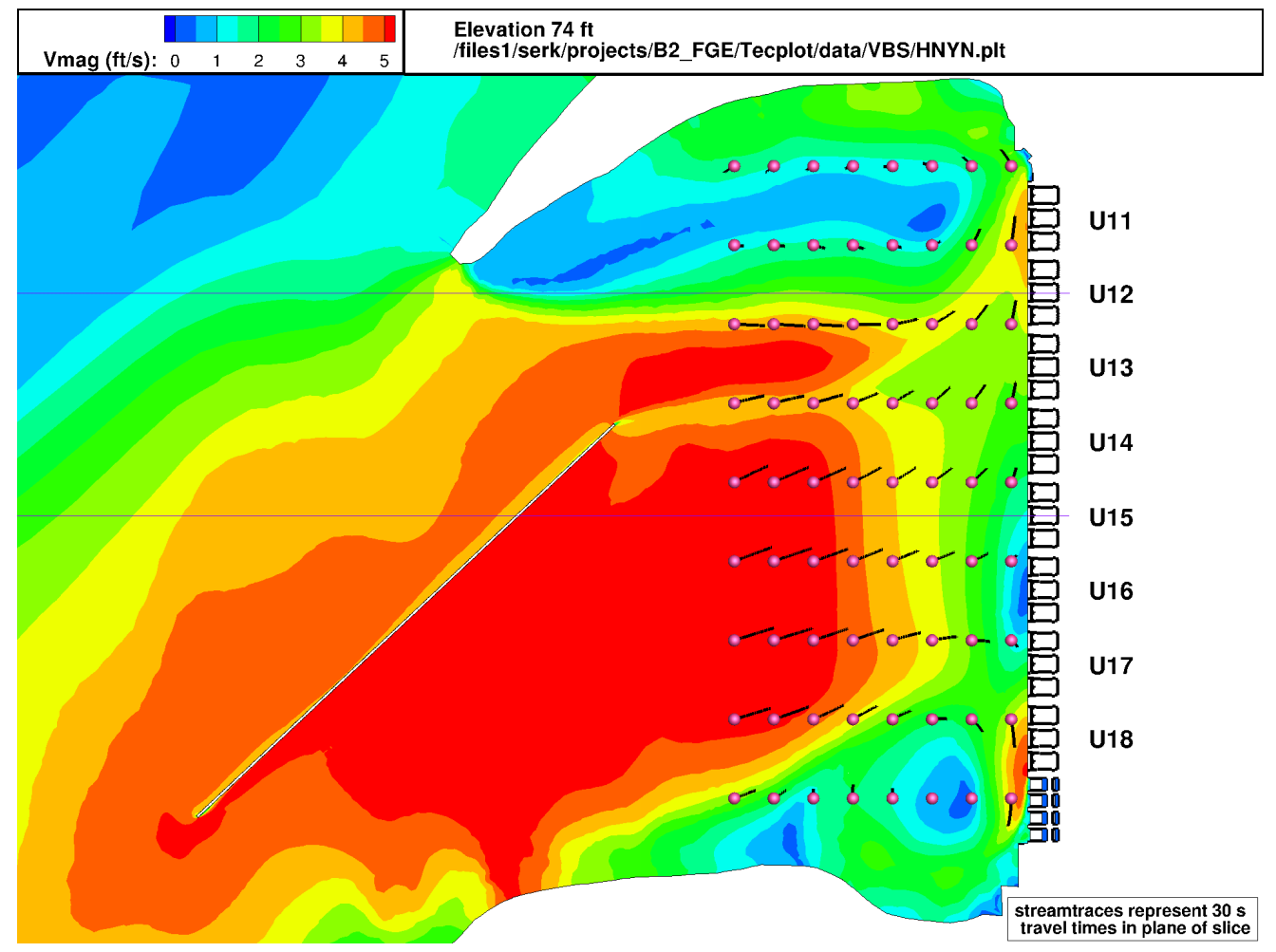

Figure 3.26. HNYN: Velocity magnitude and short streamlines at elevation $74 \mathrm{ft}$. Flow is from left to right.

\begin{tabular}{|lllllll|l|l|}
\hline & & & & & & & & $\begin{array}{l}\text { Streamtraces Starting } 300 \mathrm{ft} \text { in Front of Dam at Elevation 74, 54, and } 34 \mathrm{ft} \\
\text { /files1/serk/projects/B2_FGE/Tecplot/data/VBS/HNYN.plt }\end{array}$ \\
\hline
\end{tabular}

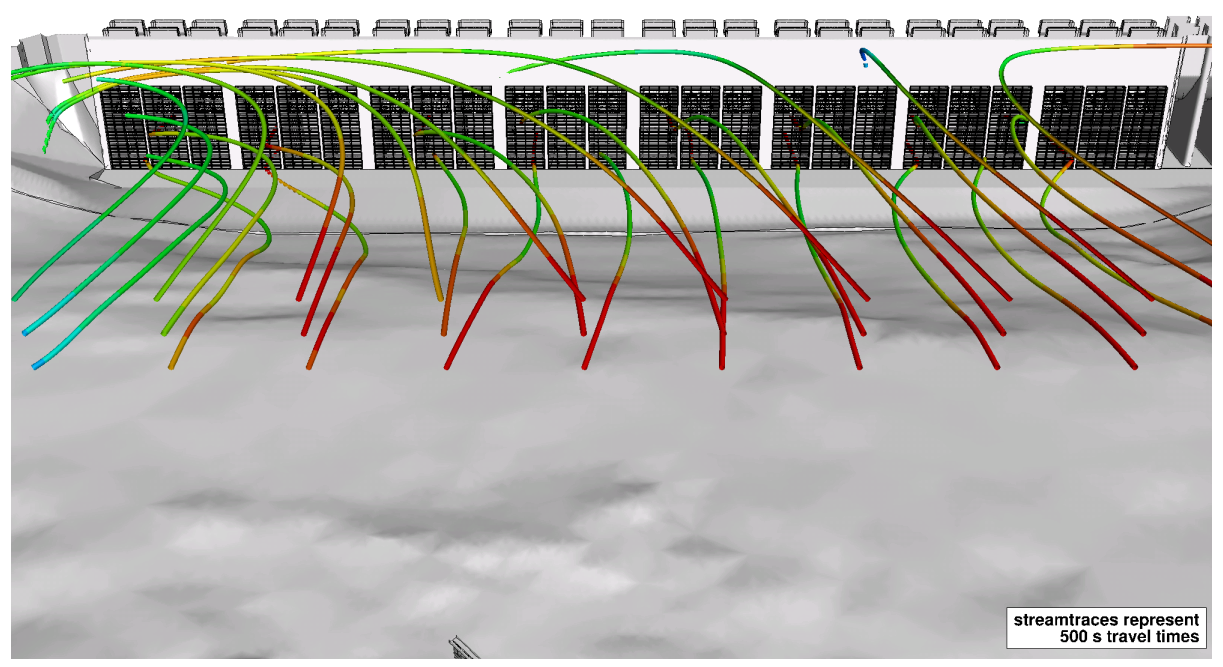

Figure 3.27. HNYN: Streamlines seeded 300-ft upstream of the powerhouse and colored by velocity magnitude. View is downstream looking into the turbine intakes. 


\begin{tabular}{|lllllll|l|l|}
\hline & & & & & & & Middle Unit 12 \\
Vmag (ft/s): & 0 & 1 & 2 & 3 & 4 & 5 & /files1/serk/projects/B2_FGE/Tecplot/data/VBS/HNYN.plt \\
\hline
\end{tabular}
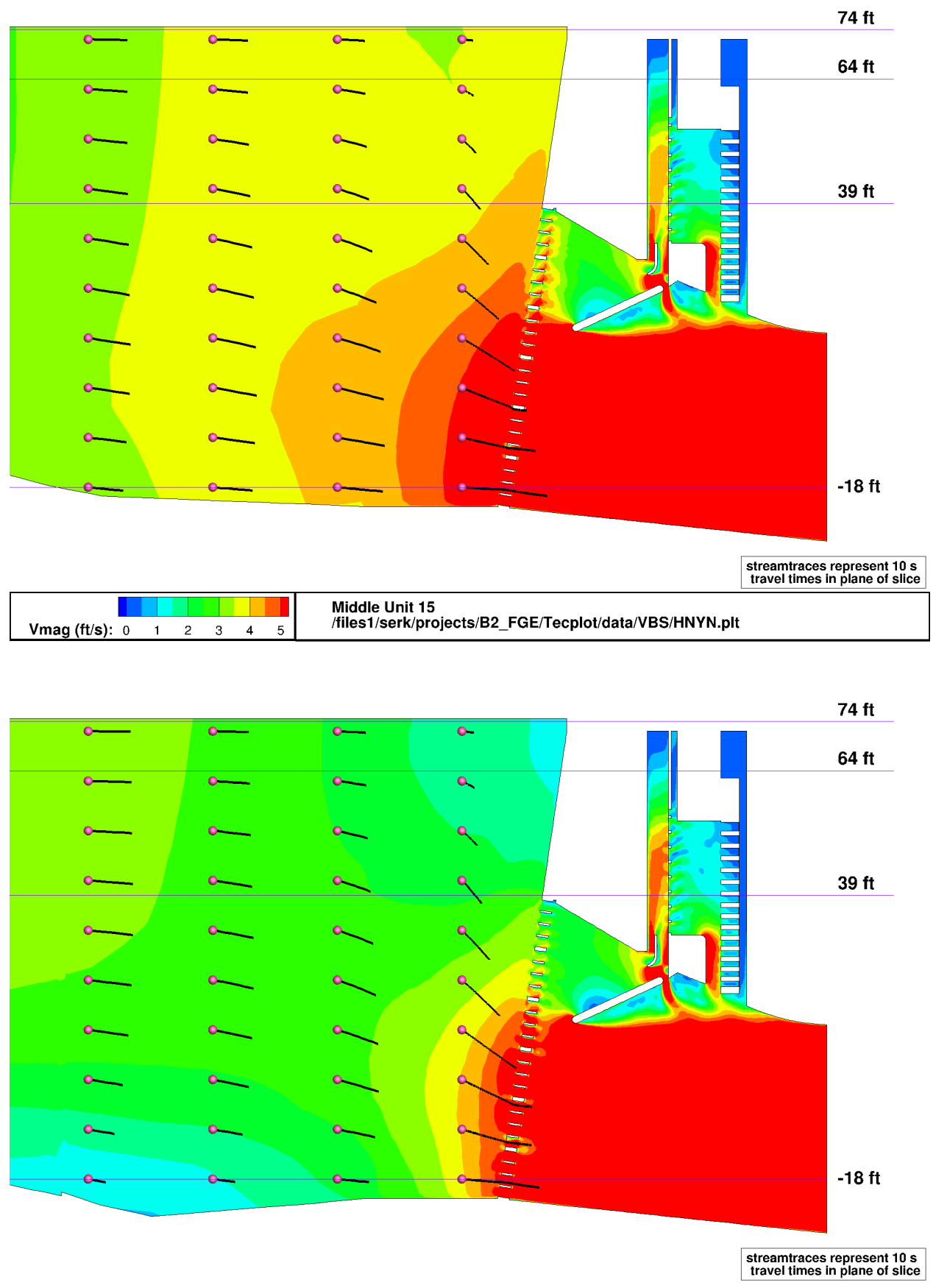

Figure 3.28. HNYN: Velocity magnitude and 10-s streamlines in the centerline Unit 12 (top) and Unit 15 (bottom). 


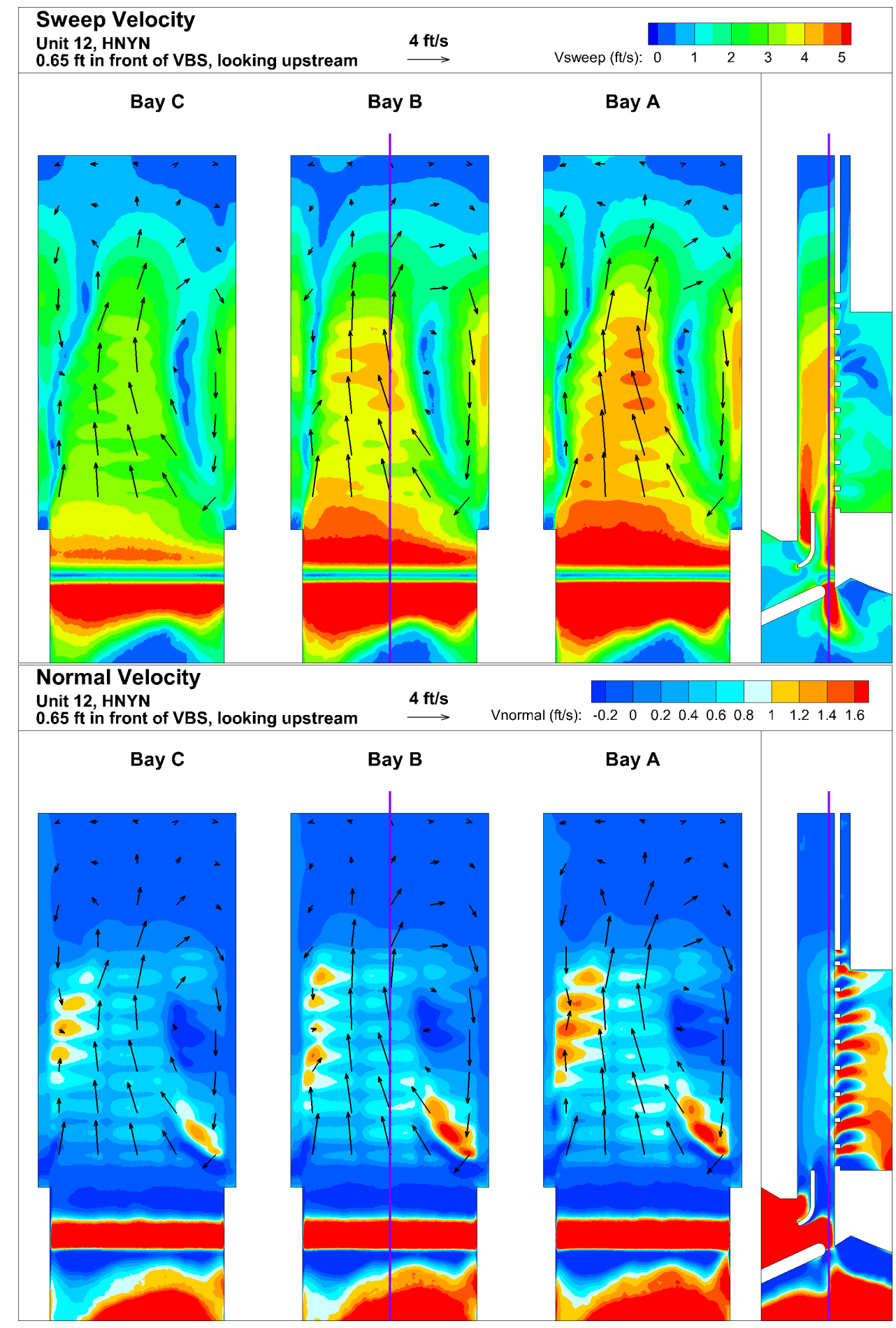

Figure 3.29. HNYN: Sweep (top) and normal (bottom) velocities $0.65 \mathrm{ft}$ in front of the VBS. 


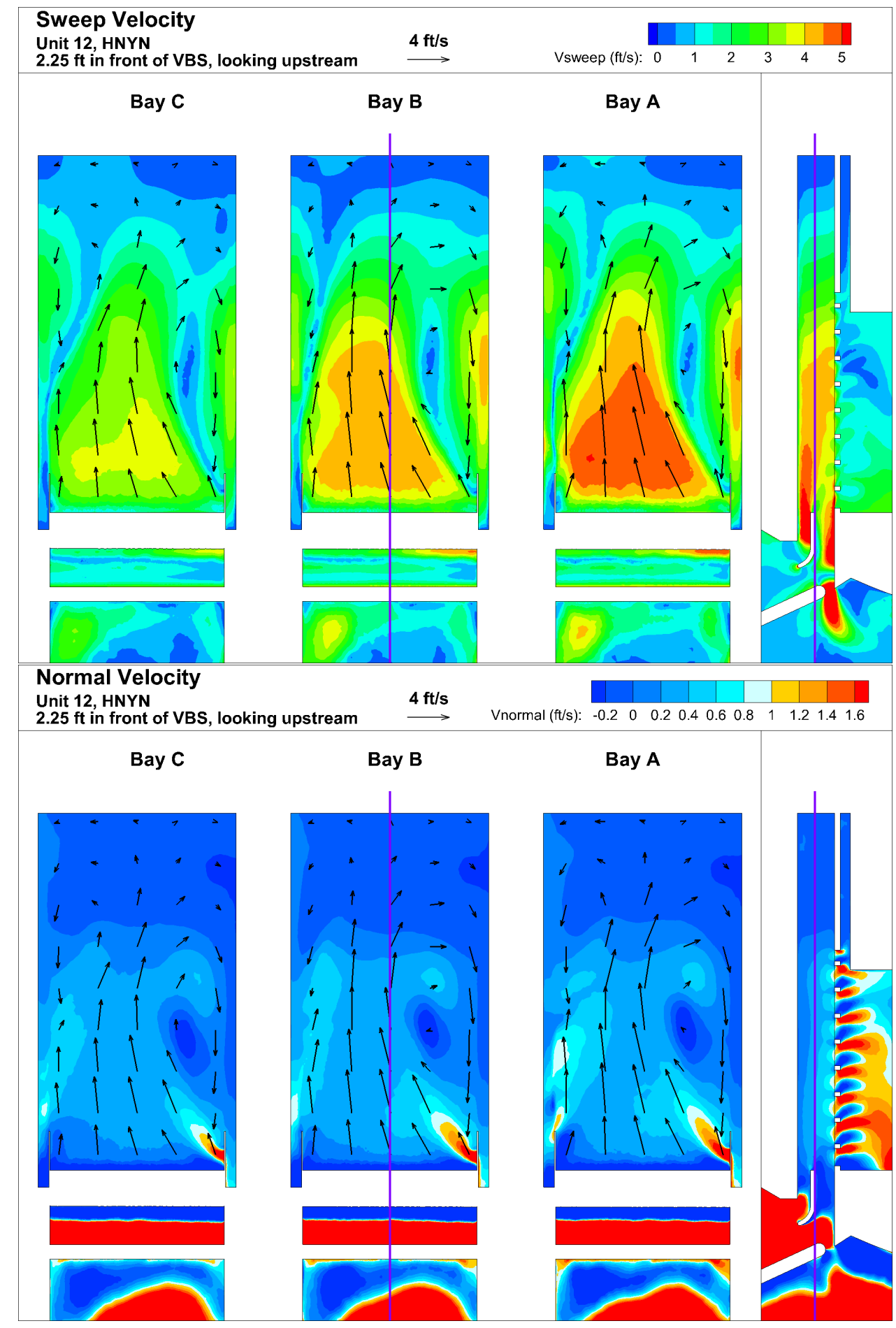

Figure 3.30. HNYN: Sweep (top) and normal (bottom) velocities $2.25 \mathrm{ft}$ in front of the VBS. 


\subsubsection{High Flow with B2CC On (HYNN)}

This scenario had the same flows as the baseline HNNN scenario with the addition of the B2CC operating at $5 \mathrm{kcfs}$. The numerical model results show very similar overall forebay velocities but a small increase in velocity magnitude in front Units 11 and 12 (Figures 3.31 and 3.32). Eddy locations were unchanged. Figure 3.33 shows the forebay streamlines. The velocity magnitude is reduced in front of Unit 12 relative to the baseline scenario (HNNN, Figure 3.34).

The flows within the Unit 12 gatewell were virtually the same as the HNNN scenario (Figures 3.35 and 3.36. 


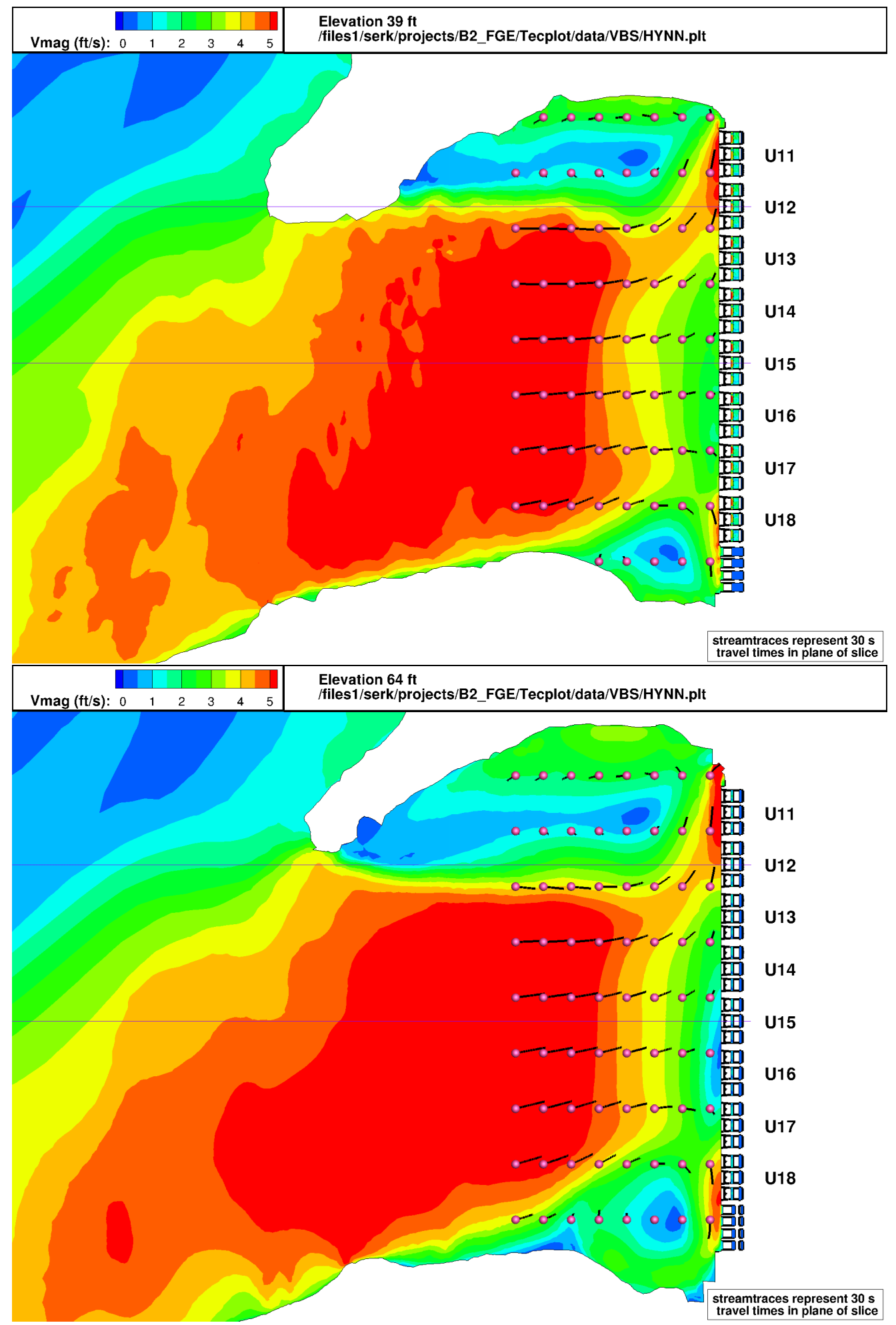

Figure 3.31. HYNN: Velocity magnitude and short streamlines at elevation $39 \mathrm{ft}$ (top) and $64 \mathrm{ft}$ (bottom). Flow is from left to right. 


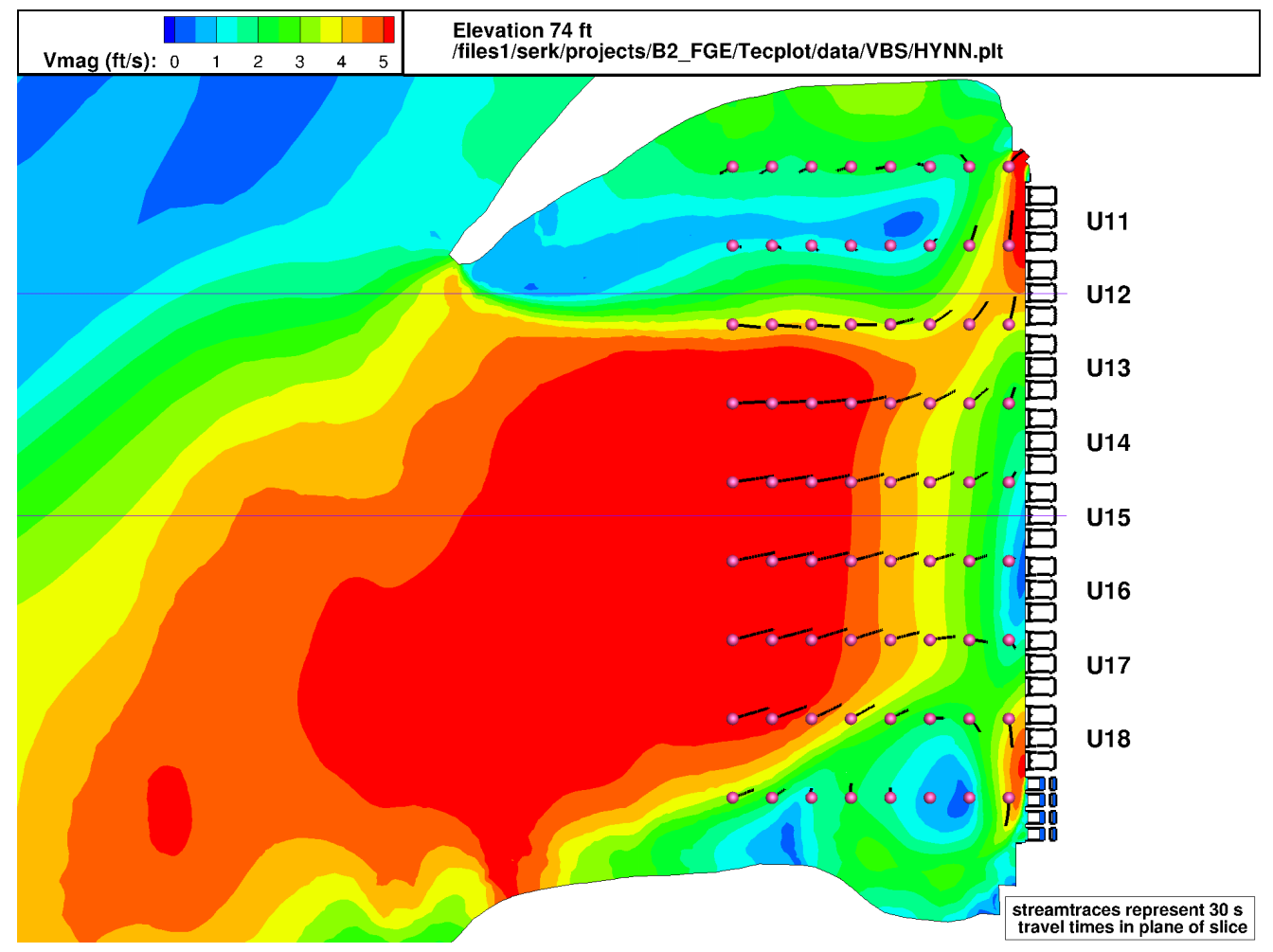

Figure 3.32. HYNN: Velocity magnitude and short streamlines at elevation $74 \mathrm{ft}$. Flow is from left to right.

\begin{tabular}{|lllllll|l|l|}
\hline & & & & & & & & $\begin{array}{l}\text { Streamtraces Starting } 300 \mathrm{ft} \text { in Front of Dam at Elevation 74, 54, and } 34 \mathrm{ft} \\
\text { /files1/serk/projects/B2_FGE/Tecplot/data/VBS/HYNN.plt }\end{array}$ \\
\hline
\end{tabular}

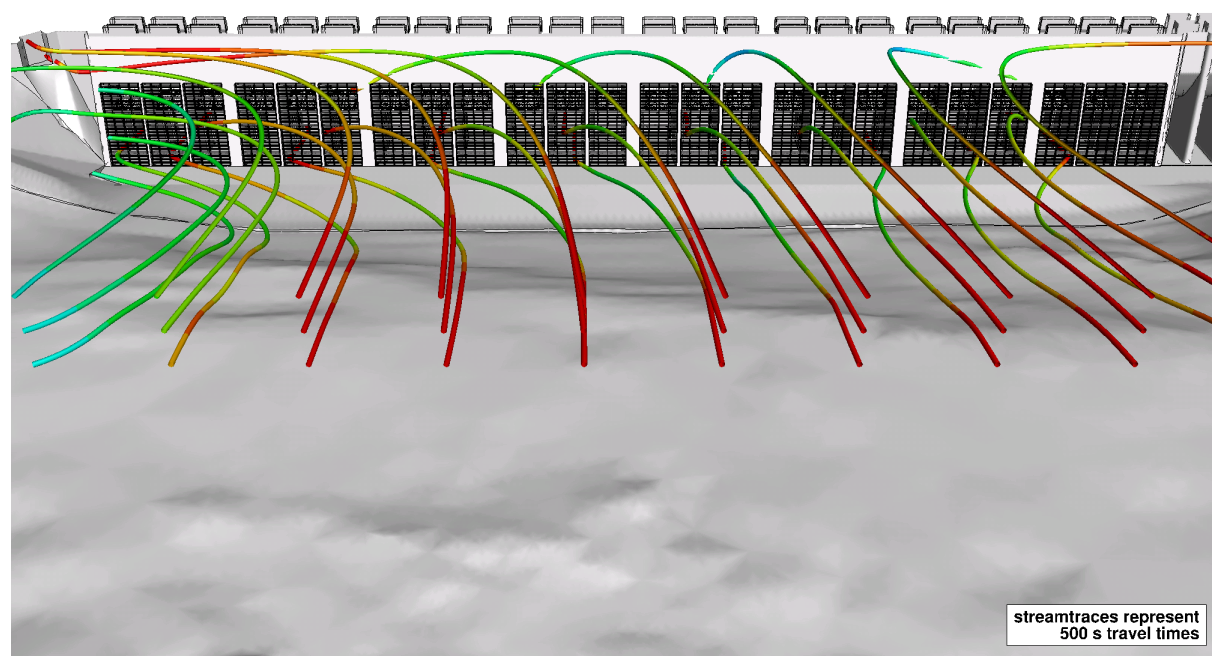

Figure 3.33. HYNN: Streamlines seeded 300-ft upstream of the powerhouse and colored by velocity magnitude. View is downstream looking into the turbine intakes. 


\begin{tabular}{|lllllll|l|l|}
\hline & & & & & & & Middle Unit 12 \\
Vmag (ft/s): & 0 & 1 & 2 & 3 & 4 & 5 & /files1/serk/projects/B2_FGE/Tecplot/data/VBS/HYNN.plt \\
\hline
\end{tabular}
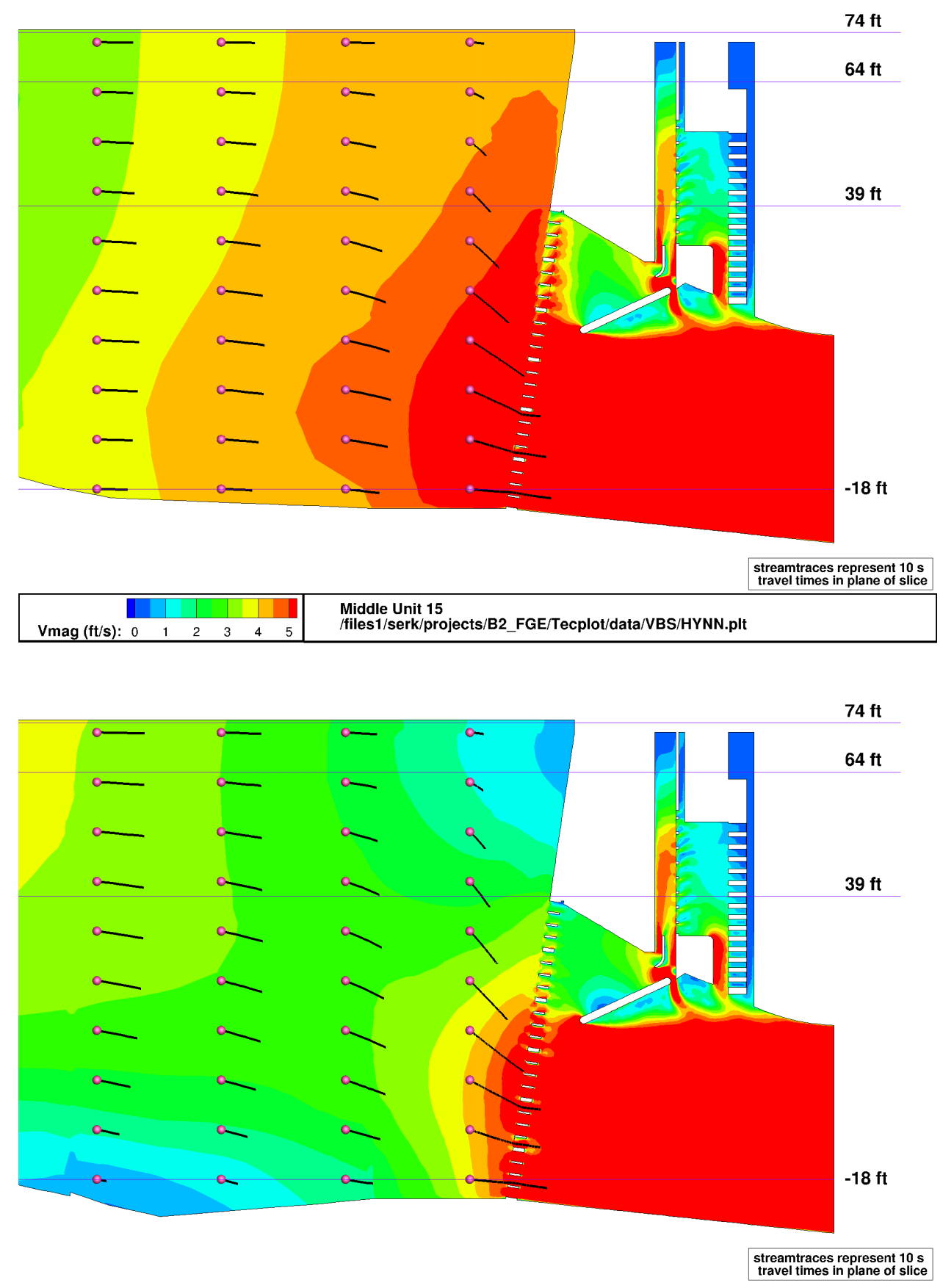

Figure 3.34. HYNN: Velocity magnitude and 10-s streamlines in the centerline Unit 12 (top) and Unit 15 (bottom). 


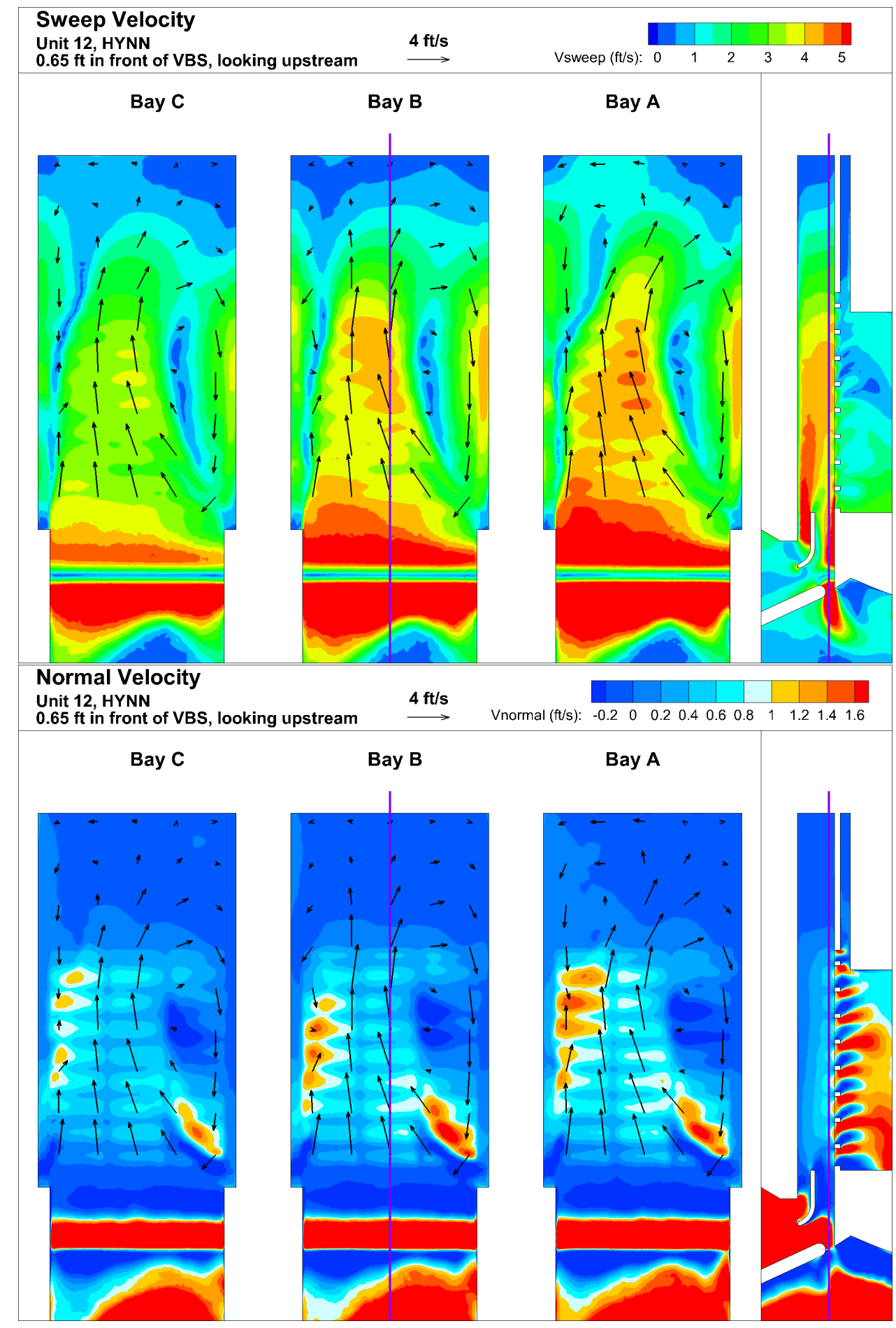

Figure 3.35. HYNN: Sweep (top) and normal (bottom) velocities $0.65 \mathrm{ft}$ in front of the VBS. 


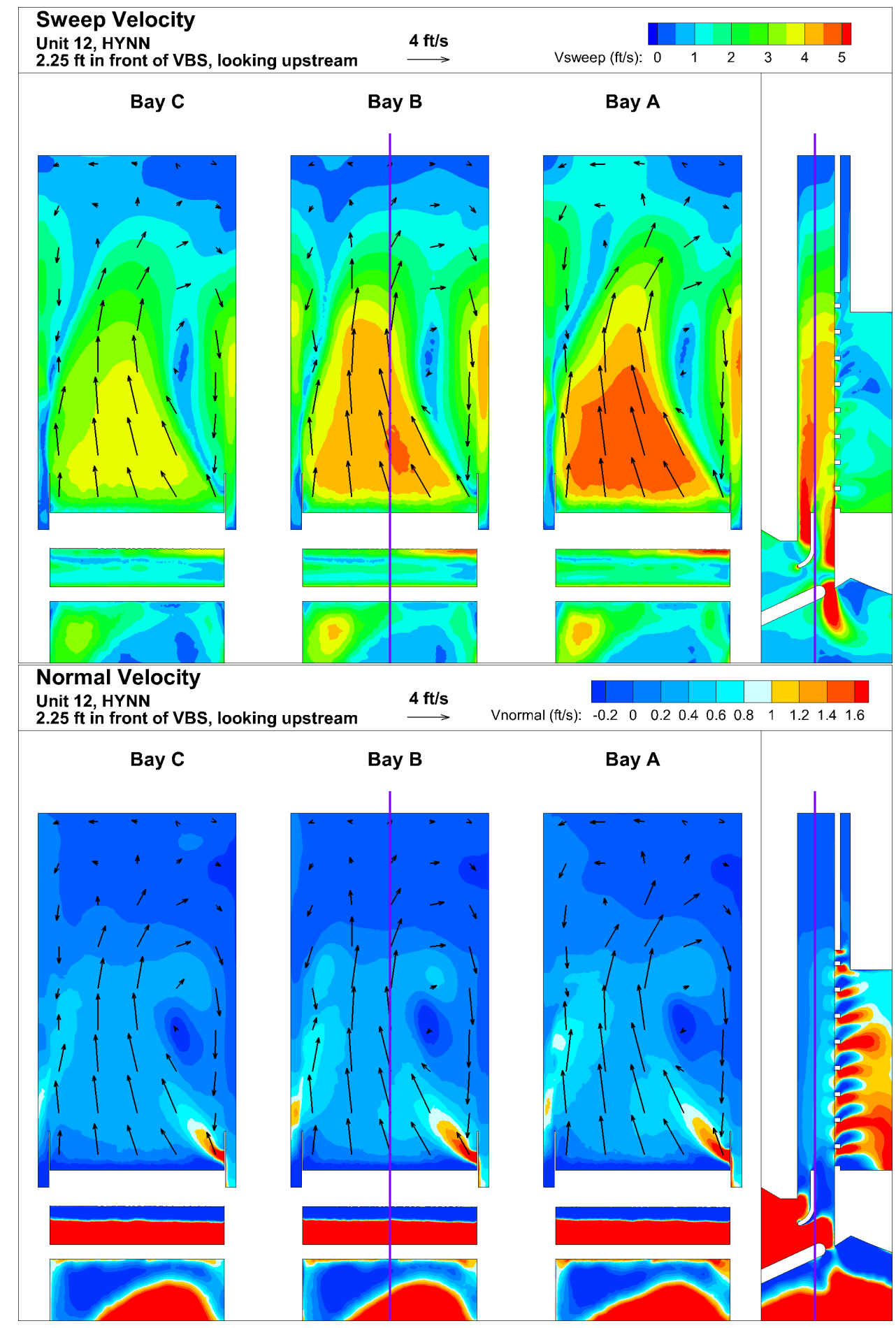

Figure 3.36. HYNN: Sweep (top) and normal (bottom) velocities $2.25 \mathrm{ft}$ in front of the VBS. 


\subsubsection{High Flow with BGS and Corner Collector On (HYYN)}

This scenario had the same flows as the baseline HNNN scenario with a BGS added to the forebay and the B2CC operating at $5 \mathrm{kcfs}$. The numerical model results show that these additions modified the forebay velocities by slightly reducing the lateral extent of the eddy near Units 11 and 12 (Figures 3.37 to 3.39) and lowering the velocities in front of Unit 12 (Figure 3.40).

The flows within the Unit 12 gatewell were virtually the same as the HNNN scenario (Figures 3.35 and 3.36 . 


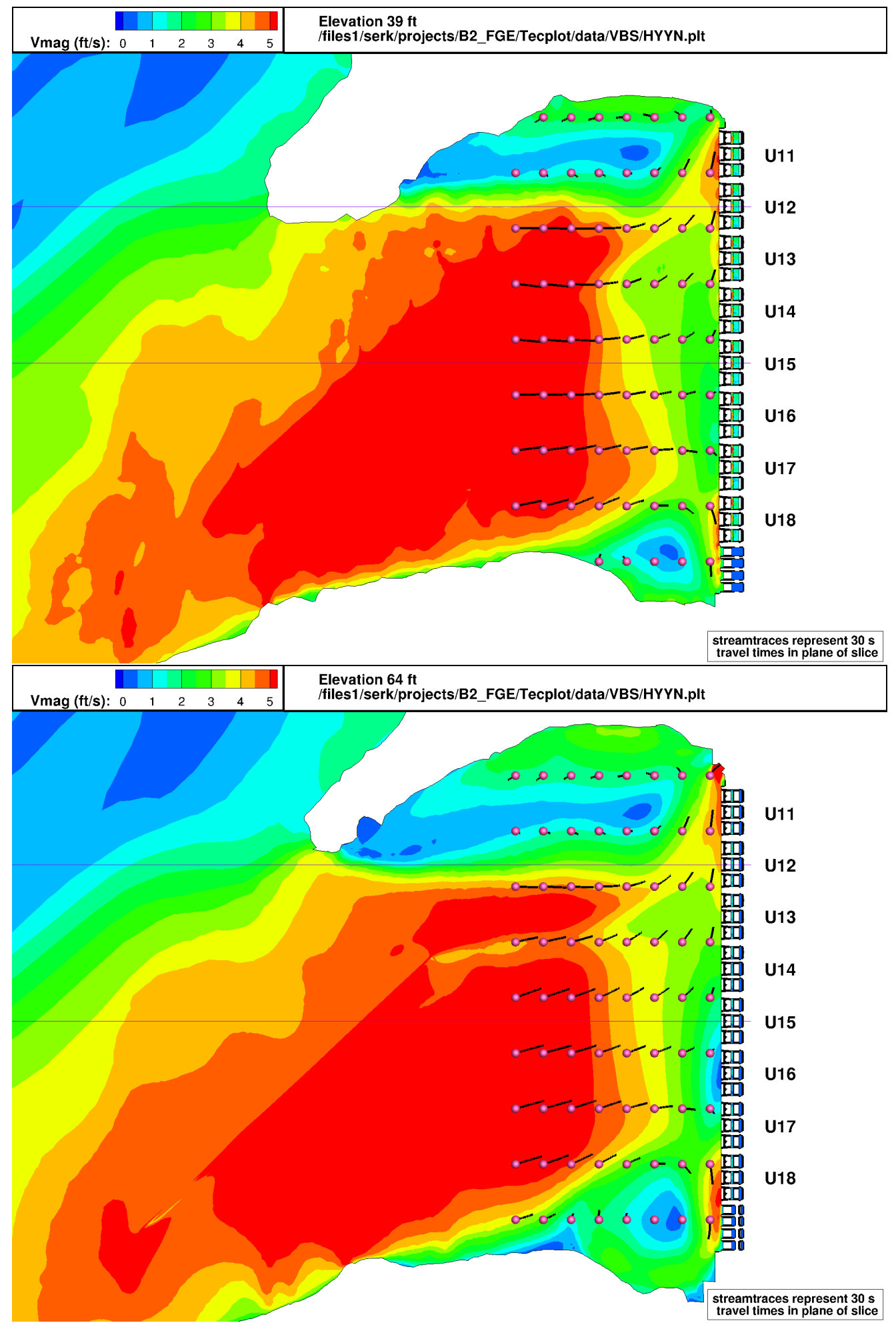

Figure 3.37. HYYN: Velocity magnitude and short streamlines at elevation $39 \mathrm{ft}$ (top) and $64 \mathrm{ft}$ (bottom). Flow is from left to right. 


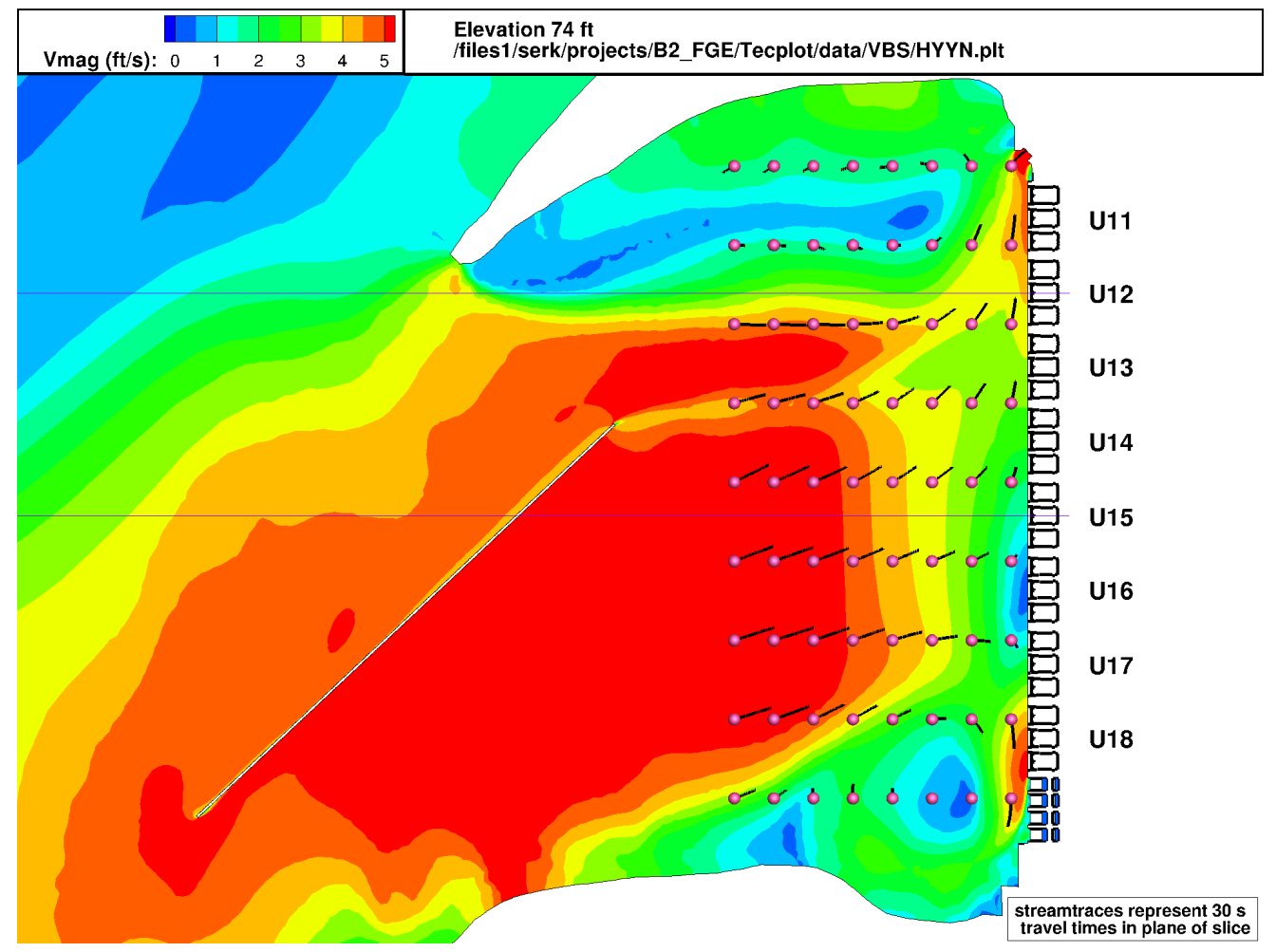

Figure 3.38. HYYN: Velocity magnitude and short streamlines at elevation $74 \mathrm{ft}$. Flow is from left to right.

\begin{tabular}{|lllllll|l|l|}
\hline & & & & & & & & $\begin{array}{l}\text { Streamtraces Starting } 300 \mathrm{ft} \text { in Front of Dam at Elevation 74, 54, and } 34 \mathrm{ft} \\
\text { /files1/serk/projects/B2_FGE/Tecplot/data/VBS/HYYN.plt }\end{array}$ \\
\hline
\end{tabular}

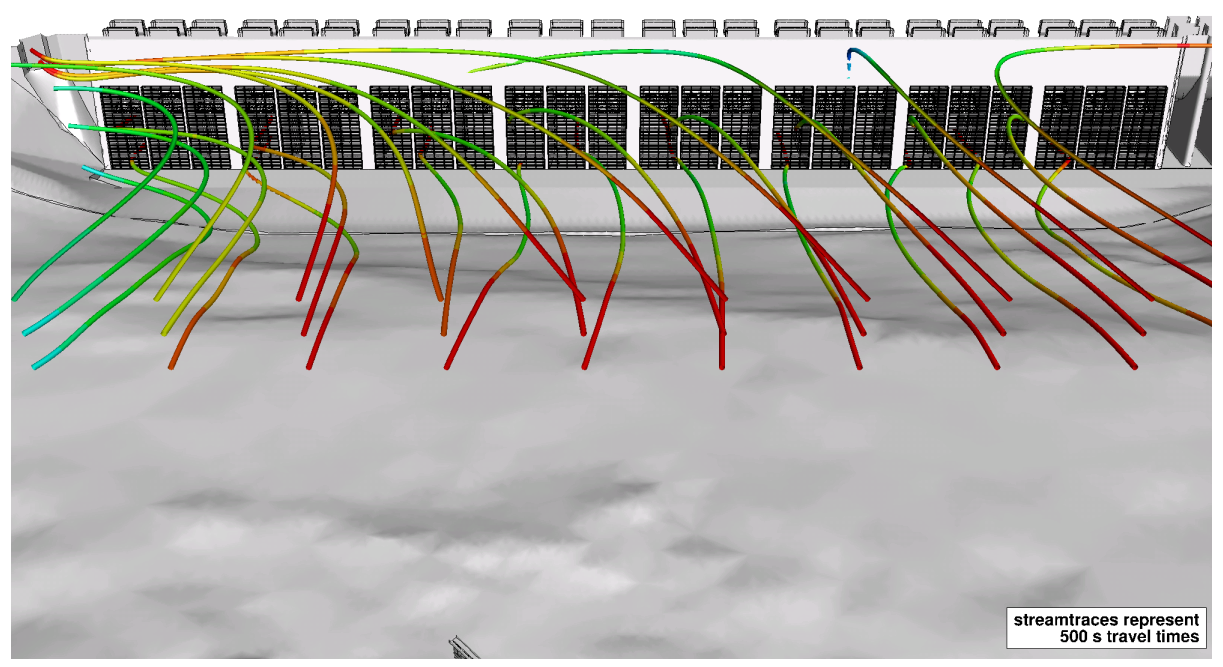

Figure 3.39. HYYN: Streamlines seeded 300-ft upstream of the powerhouse and colored by velocity magnitude. View is downstream looking into the turbine intakes. 


\begin{tabular}{|lllllll|l|l|}
\hline & & & & & & & Middle Unit 12 \\
Vmag (ft/s): & 0 & 1 & 2 & 3 & 4 & 5 & /files1/serk/projects/B2_FGE/Tecplot/data/VBS/HYYN.plt \\
\hline
\end{tabular}
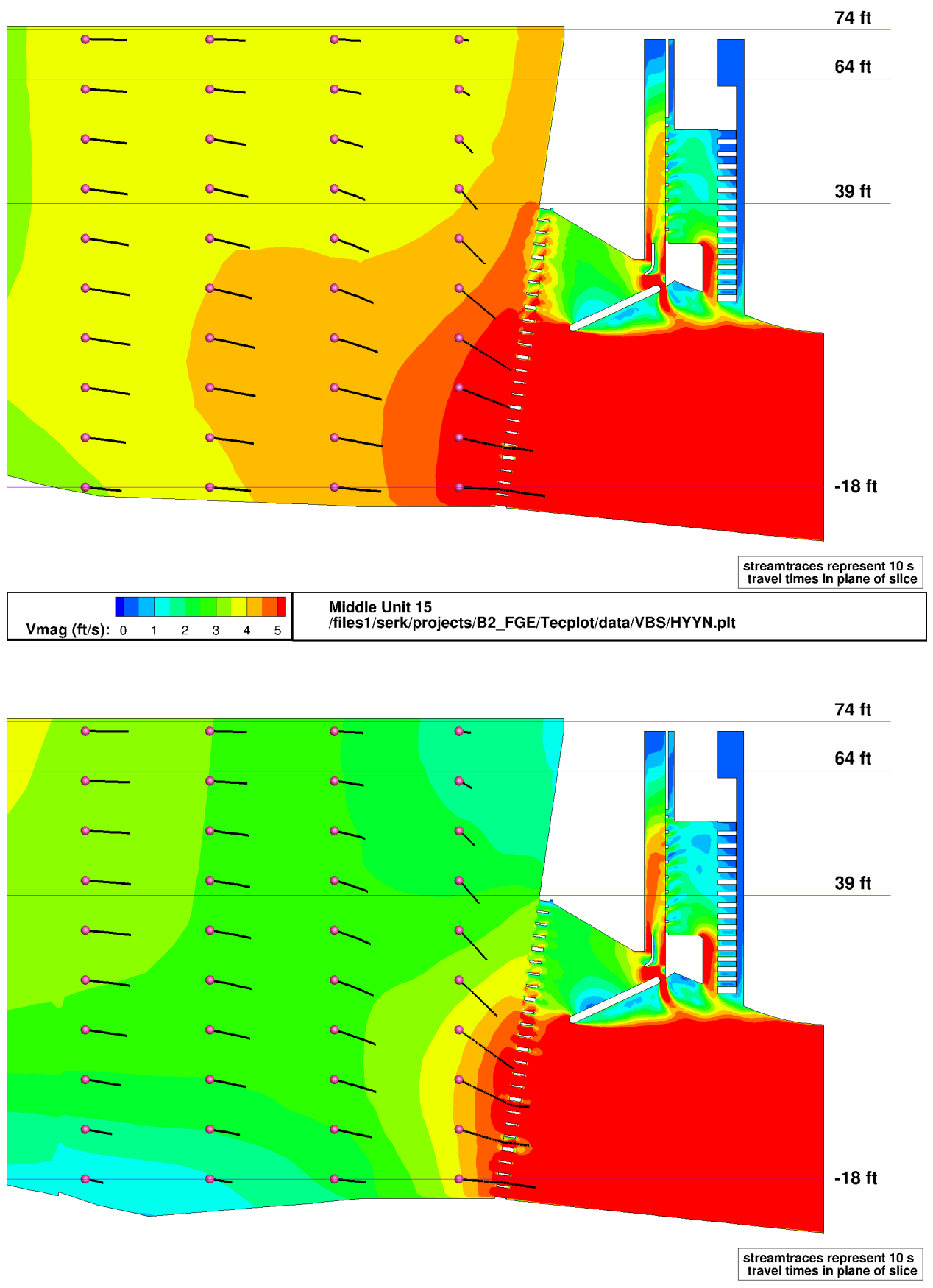

Figure 3.40. HYYN: Velocity magnitude and 10-s streamlines in the centerline Unit 12 (top) and Unit 15 (bottom). 


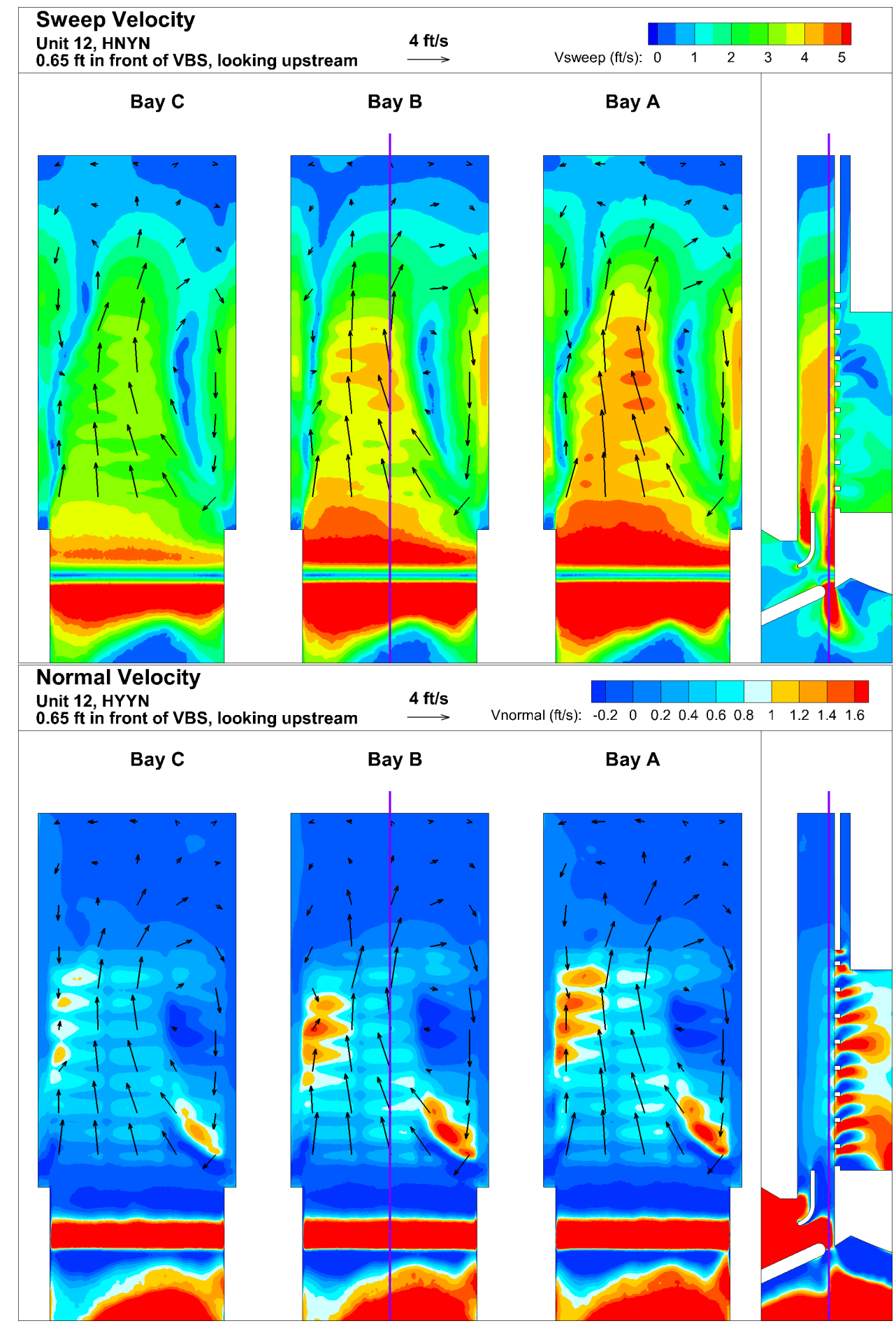

Figure 3.41. HYYN: Sweep (top) and normal (bottom) velocities $0.65 \mathrm{ft}$ in front of the VBS. 


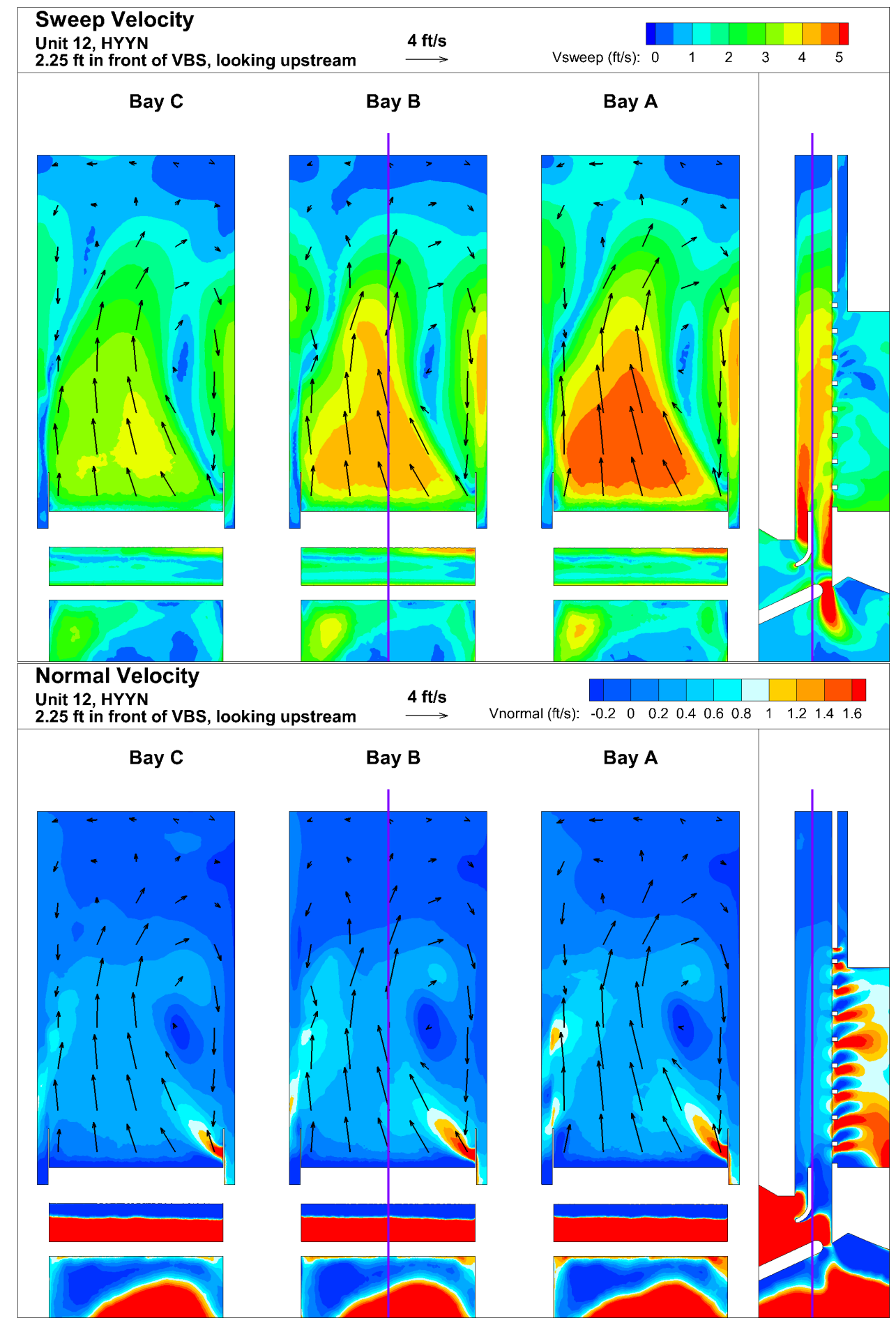

Figure 3.42. HYYN: Sweep (top) and normal (bottom) velocities $2.25 \mathrm{ft}$ in front of the VBS. 


\subsubsection{Comparison of Flows into the Gatewells for the Scenarios for Each Bay and Intake}

An objective of this study was to understand how flow into and within the gatewell changes as the fish move into a bypass system through an orifice near the top of the gatewell. Increasing flow into the gatewell slot and decreasing recirculation is believed to improve fish bypass and survival.

To assess differences between bays and turbine units across the powerhouse, flows for each bay of each unit were analyzed then compared across the scenarios. For each of the above scenarios, flow volumes were calculated to determine flows up the gatewell, through the gap behind the STS, and into the area above the STS for each bay of each unit. The flux plane locations are shown in Figure 3.43

The flow differences for Bays A, B, and C were from the turbine flow split that was specified in the numerical model boundary conditions. This explains the consistent within-turbine differences (Figure 3.44). For all four scenarios, there were very little overall differences in flow into the gatewell slots across the powerhouse (Figure 3.44), although there were minor differences in the units closest to the B2CC (i.e., Units 11, 12, and 13). The flow that did not go up the gatewell slot went through the gap.

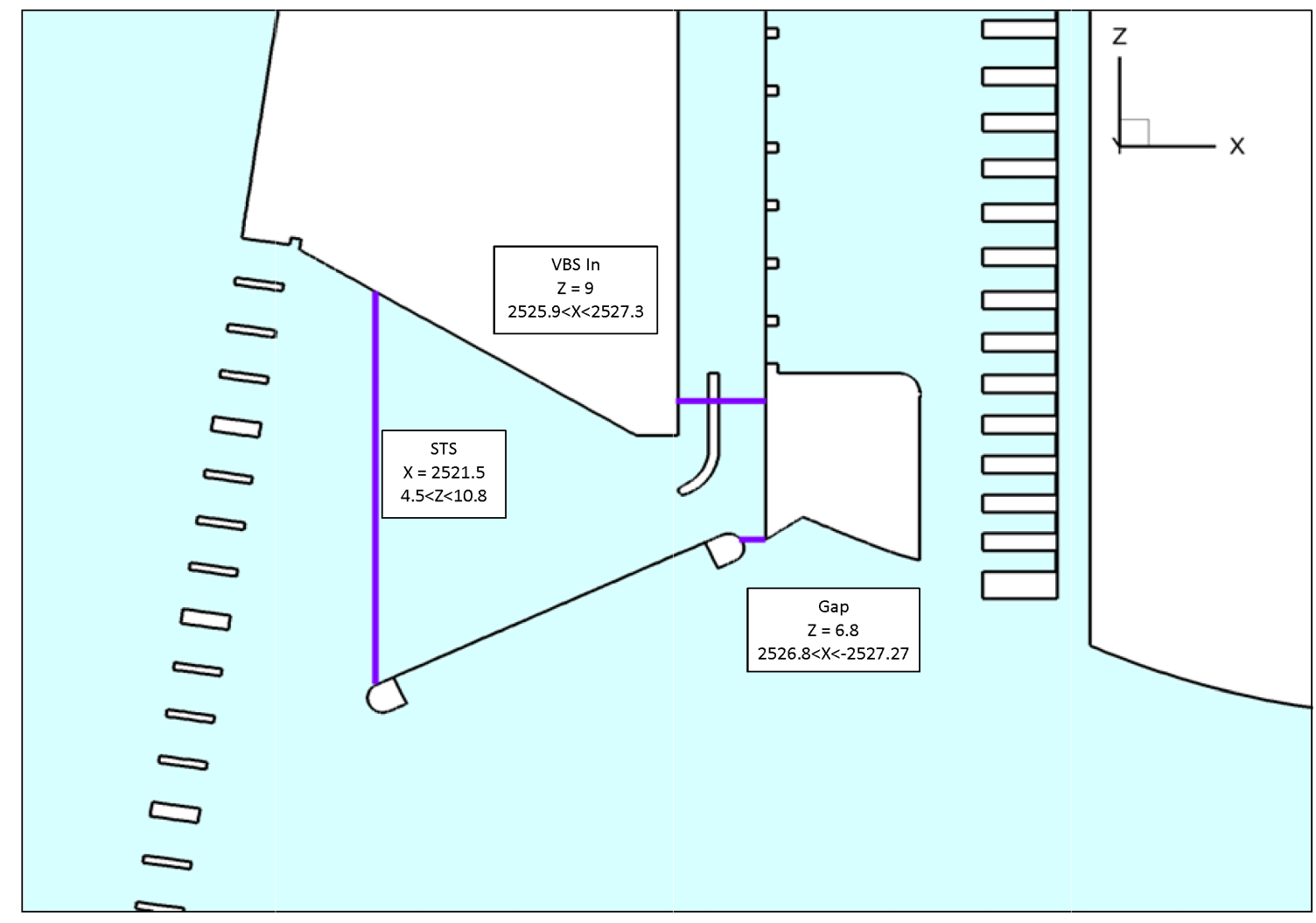

Figure 3.43. Locations of slices used for the flow calculations. 

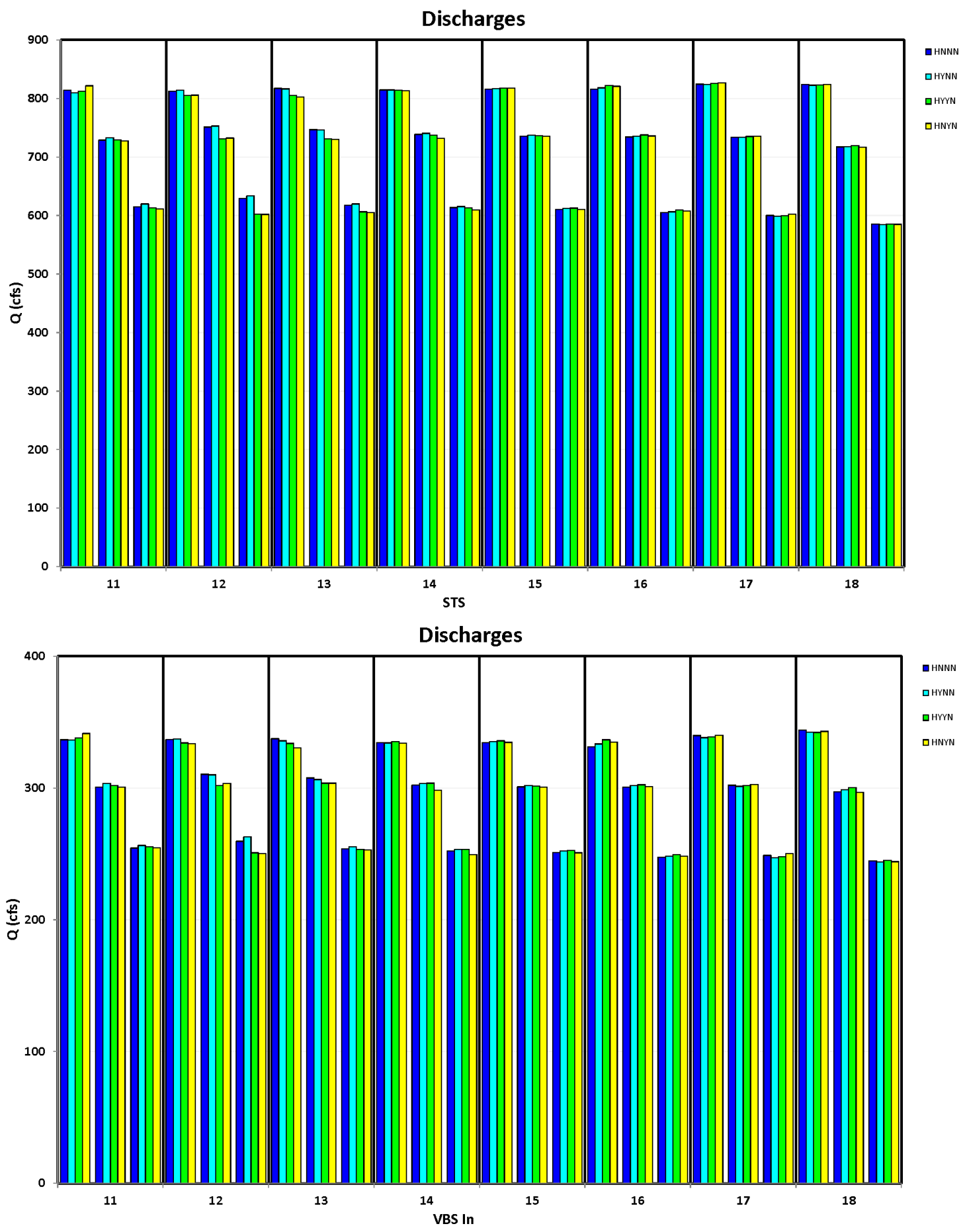

Figure 3.44. Flow into the STS (top) and up the gatewell (bottom) for each bay and by unit for the $\mathrm{B} 2$ for the four scenarios. 


\subsection{Slot Fillers}

As shown in the early portions of the CFD work, flow into the gatewell slot includes areas of recirculation that are believed to adversely affect juvenile salmon passing through the gatewell. The recirculation in the CFD model results and measured at the prototype was not present in the sectional single-bay reduced-scale physical model. The physical model does not include the gatewell slots. As the understanding of the gatewell flow conditions evolved, filling the gatewell slots to eliminate the flow expansion and reduce the recirculation was proposed by CENWP as one alternative to improve gatewell flow conditions for fish.

Three scenarios were modeled with slot fillers in place:

- HNNN with slot fillers in place.

- HYNN with solt fillers in place.

- HNNN with slot fillers in place but only half of the turbine units $(11,14,15$, and 18) operating.

The HNNN with slot fillers and the HNNN with slot fillers and half the turbines units operating were compared to the HNNN scenario. The HYNN with slot fillers in place was compared to the HYNN scenario.

\subsubsection{Comparison of Flows into the Gatewells with Slot Fillers}

It was expected that the largest impact of the slot fillers would be close to them, i.e., within the gatewell slot and on the STS. A possible surrogate for quantifying flow differences was to look at changes in flow volume over the STS and up the gatewell.

Figures 3.45 and 3.46 show that flux above the STS and into the VBS consistently increased for all units in the powerhouse. Table 3.1 lists the average increases in flow into the gatewell and above the STS, and the decrease in gap flow.

In the following sections, these flow differences are further explored because they affect the overall flow pattern within a gatewell. 

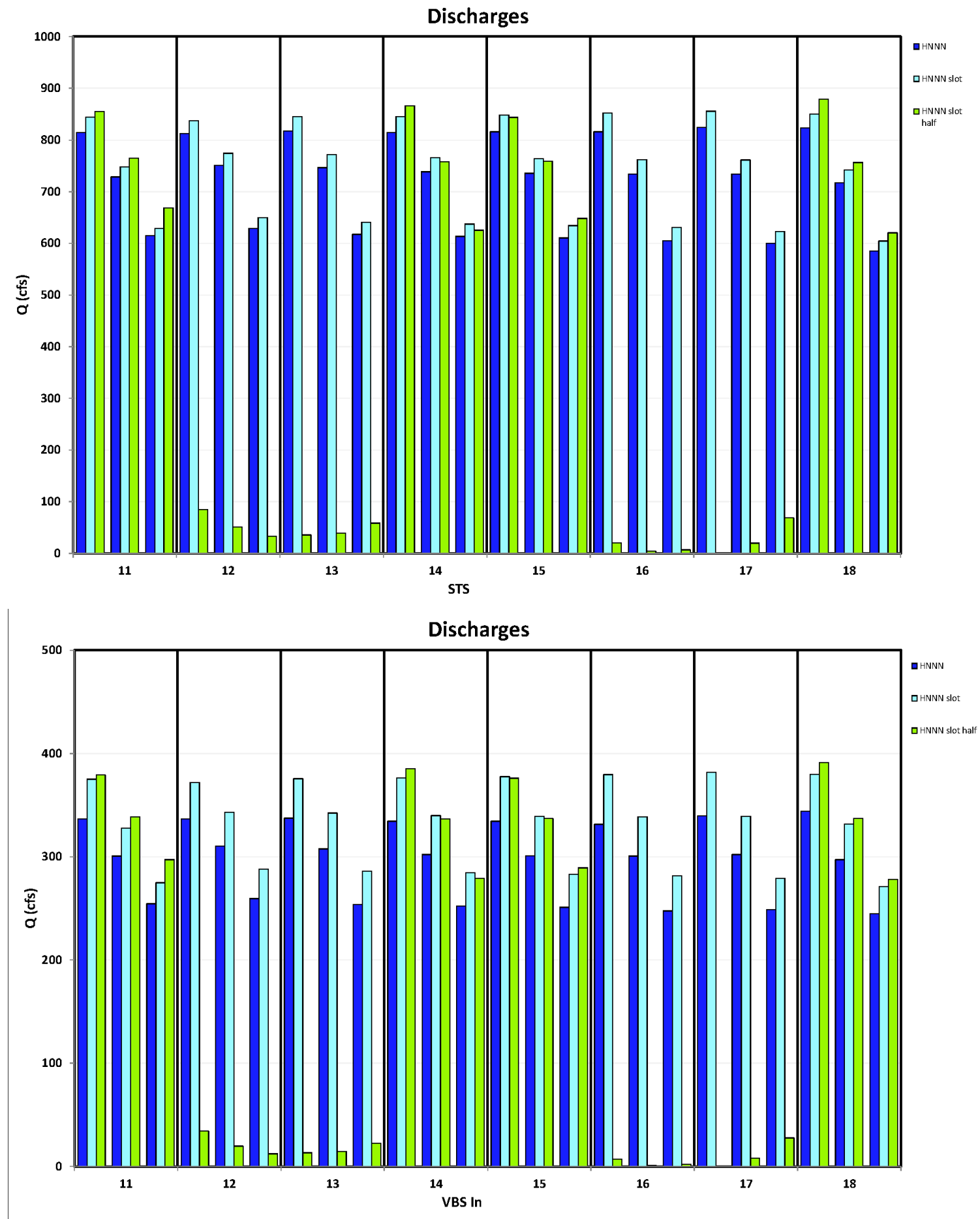

Figure 3.45. Slot Fillers, HNNN: Flow into the STS (top) and up the gatewell (bottom) for each bay and by unit for B2 with slot fillers (blue), without slot fillers (cyan), and with slot fillers and half of the turbines running (green). 

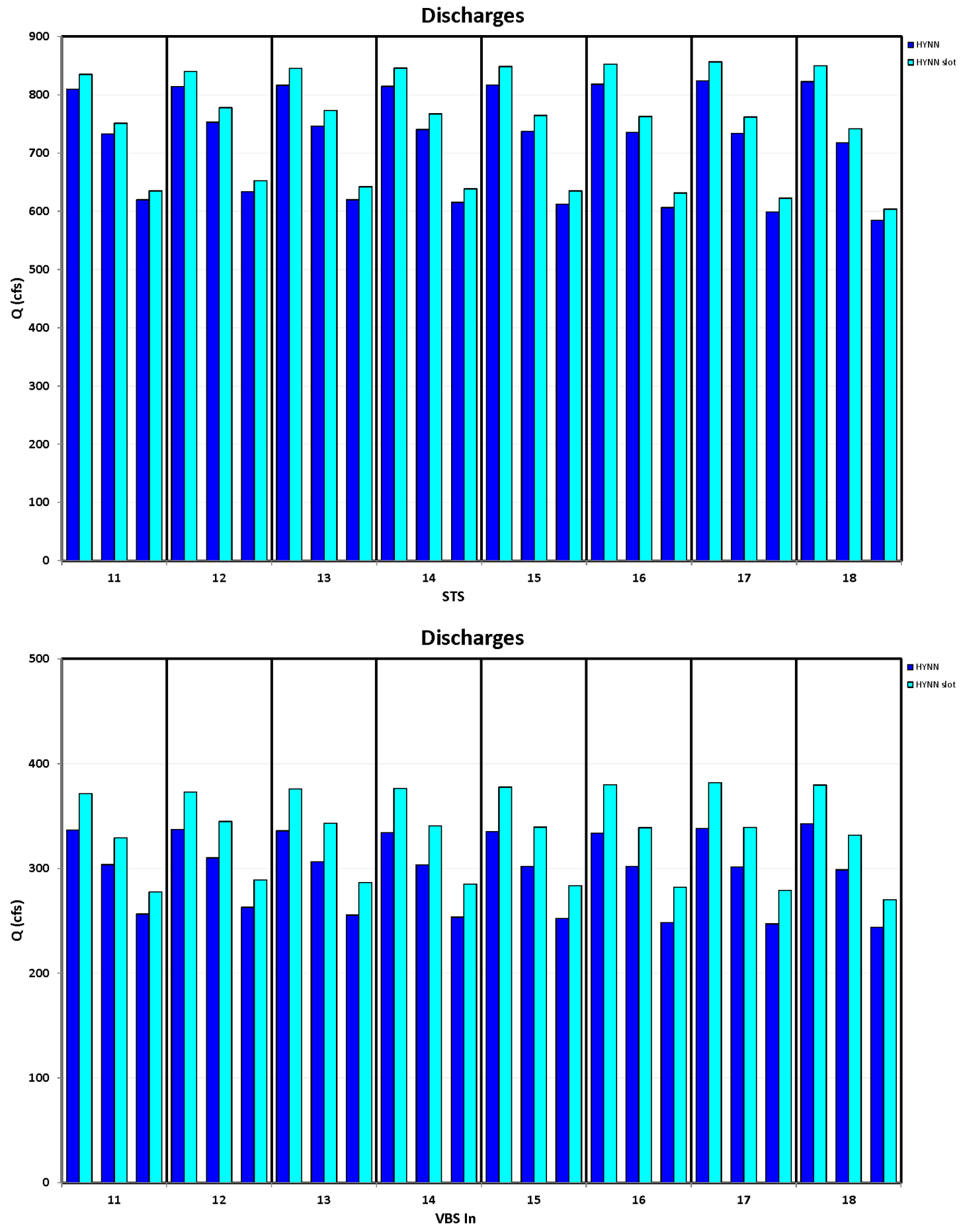

Figure 3.46. Slot Fillers, HYNN: Flow into the STS (top) and up the gatewell (bottom) for each bay and by unit for B2 without slot fillers (blue) and with slot fillers (cyan). 
Table 3.1. Summary of average flow differences at each bay with and without slot fillers in place. Positive numbers are flow increases for slot filler scenarios. All turbine units in slot-filler CFD model had slot fillers.

\begin{tabular}{lccc}
\hline & $\begin{array}{c}\text { HNNN } \\
\text { (cfs) }\end{array}$ & $\begin{array}{c}\text { HNNN half flow } \\
\text { (cfs) }\end{array}$ & $\begin{array}{c}\text { HYNN } \\
\text { (cfs) }\end{array}$ \\
\hline STS (per bay average) & 25.7 & 36.0 & 25.5 \\
VBS (per bay average) & 34.9 & 39.4 & 34.8 \\
VBS - Bay A average & 40.35 & 45.7 & 40.3 \\
VBS - Bay B average & 35.0 & 37.2 & 34.9 \\
VBS - Bay C average & 29.5 & 35.3 & 29.2 \\
Gap (per bay average) & -6.1 & -3.0 & -6.1 \\
\hline
\end{tabular}




\subsubsection{HNNN with Slot Fillers}

Although the use of slot fillers had very little observable impact on the forebay flows of the HNNN scenario (Figure 3.47), the flow in the gatewell had greatly reduced recirculation. Figures 3.48 through 3.51 show that flows within the gatewell slot had less recirculation with slot fillers in place (top figures) than without slot fillers in place (lower figures). The addition of the slot fillers resulted a larger flow into the gatewell and in a distribution of velocities across the screens that was more balanced, with lower maximum normal velocities and a smaller area of normal velocities that exceed the $1-\mathrm{ft} / \mathrm{s}$ criterion. 


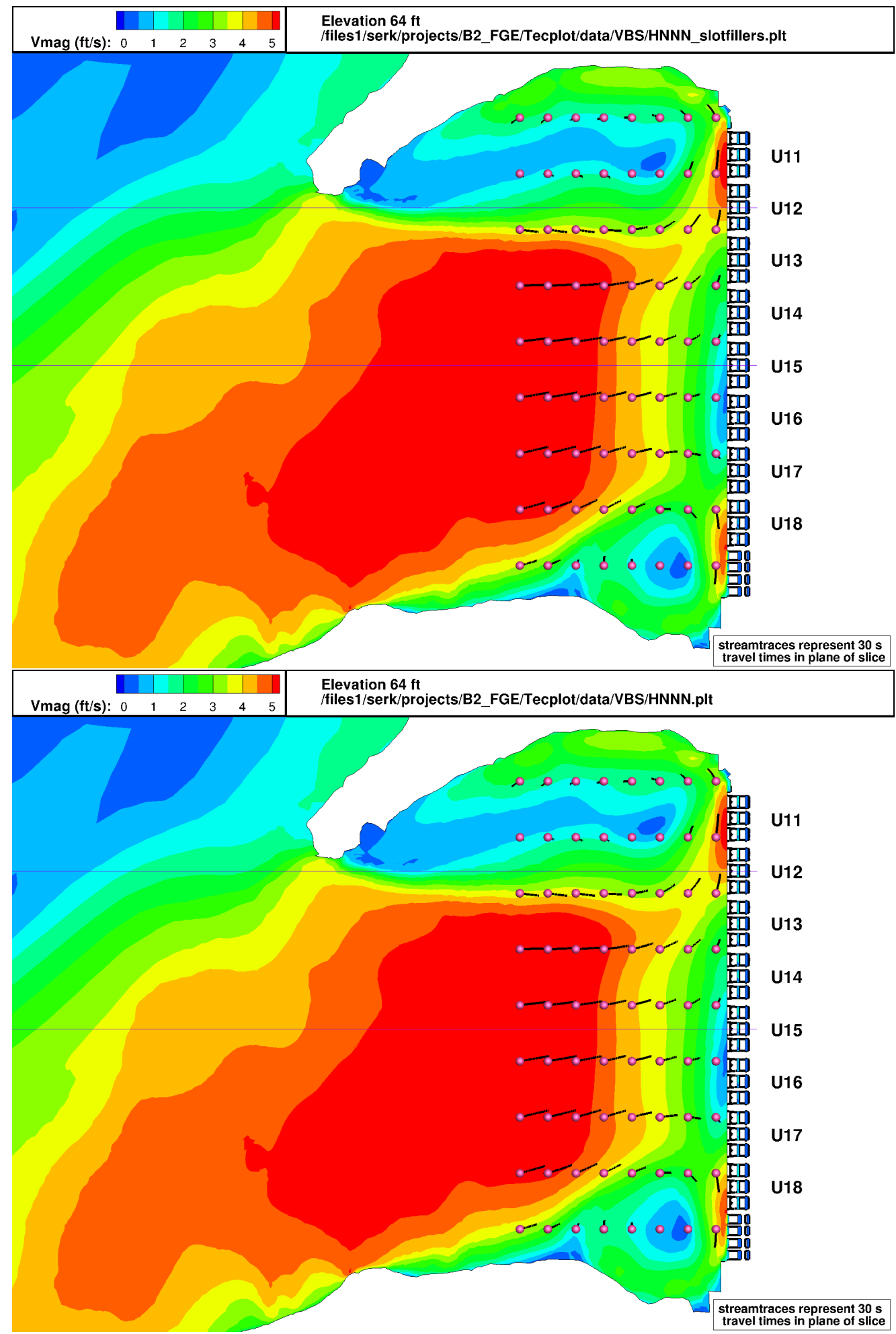

Figure 3.47. Velocity magnitude and short streamlines for the HNNN with (top) and without (bottom) slot fillers simulation at elevation $64 \mathrm{ft}$. Flow is from left to right. 


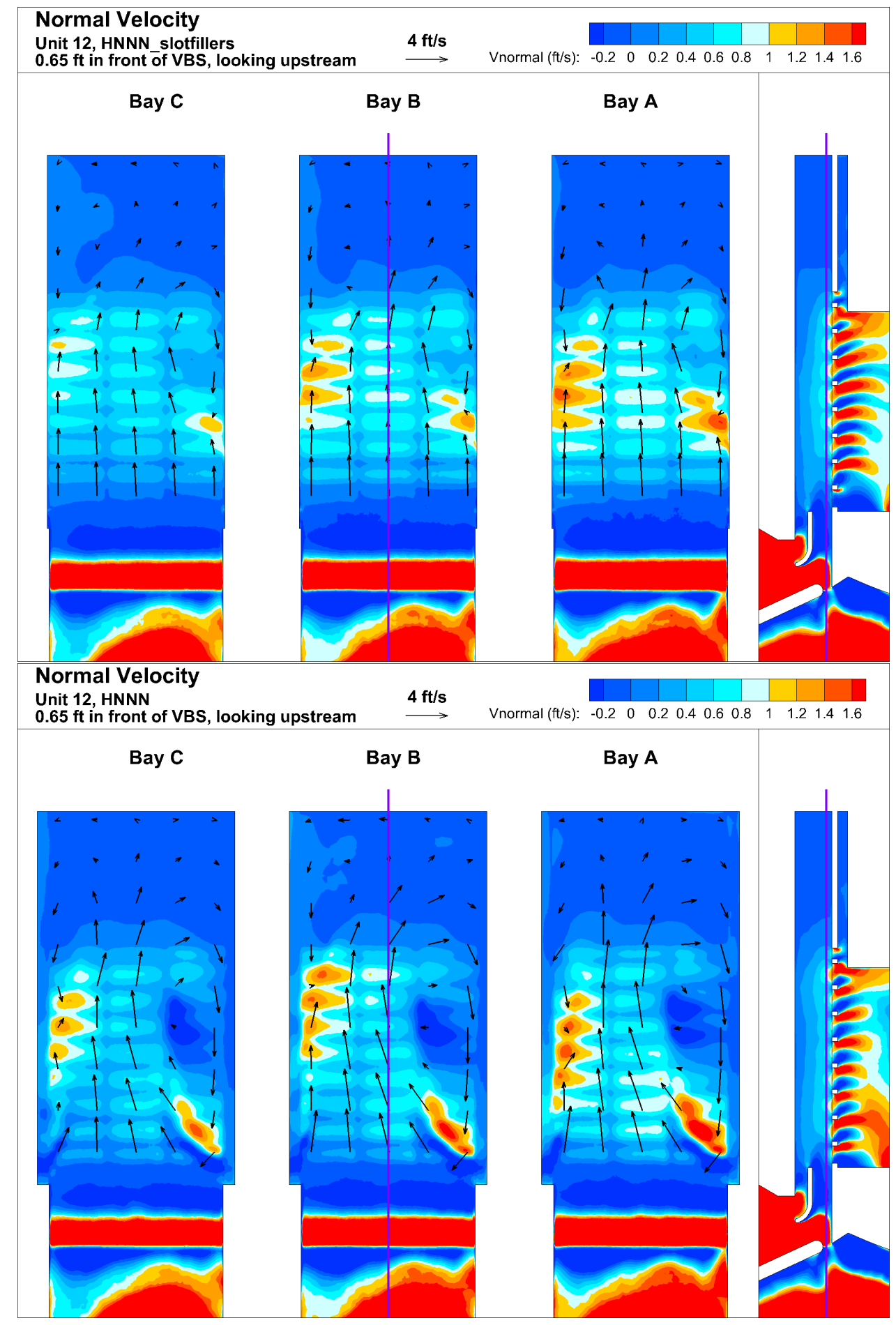

Figure 3.48. HNNN Unit 12 normal velocity with (top) and without (bottom) slot fillers $0.65 \mathrm{ft}$ from the VBS. 


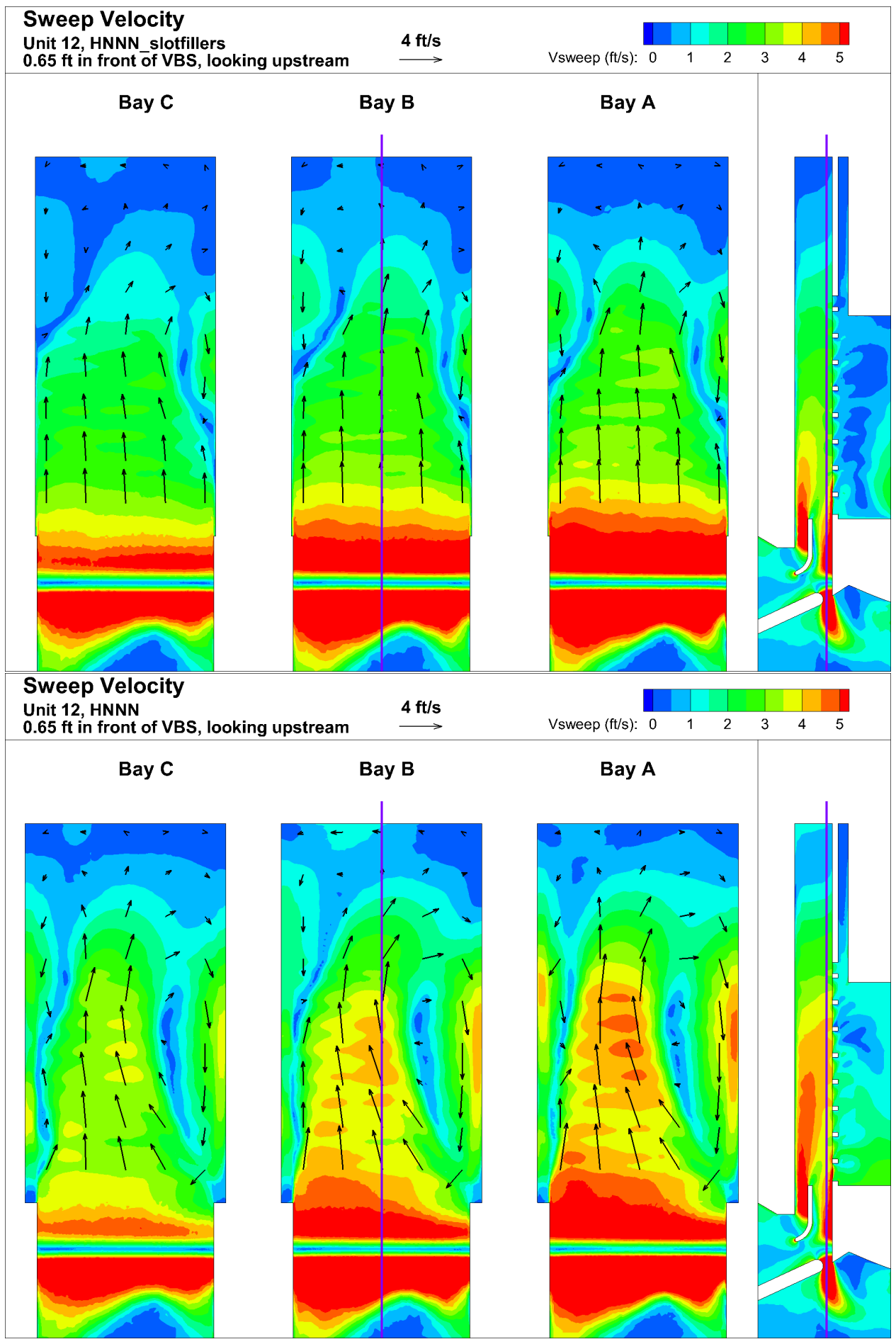

Figure 3.49. HNNN Unit 12 sweep velocity with (top) and without (bottom) slot fillers in place $0.65 \mathrm{ft}$ from the VBS. 


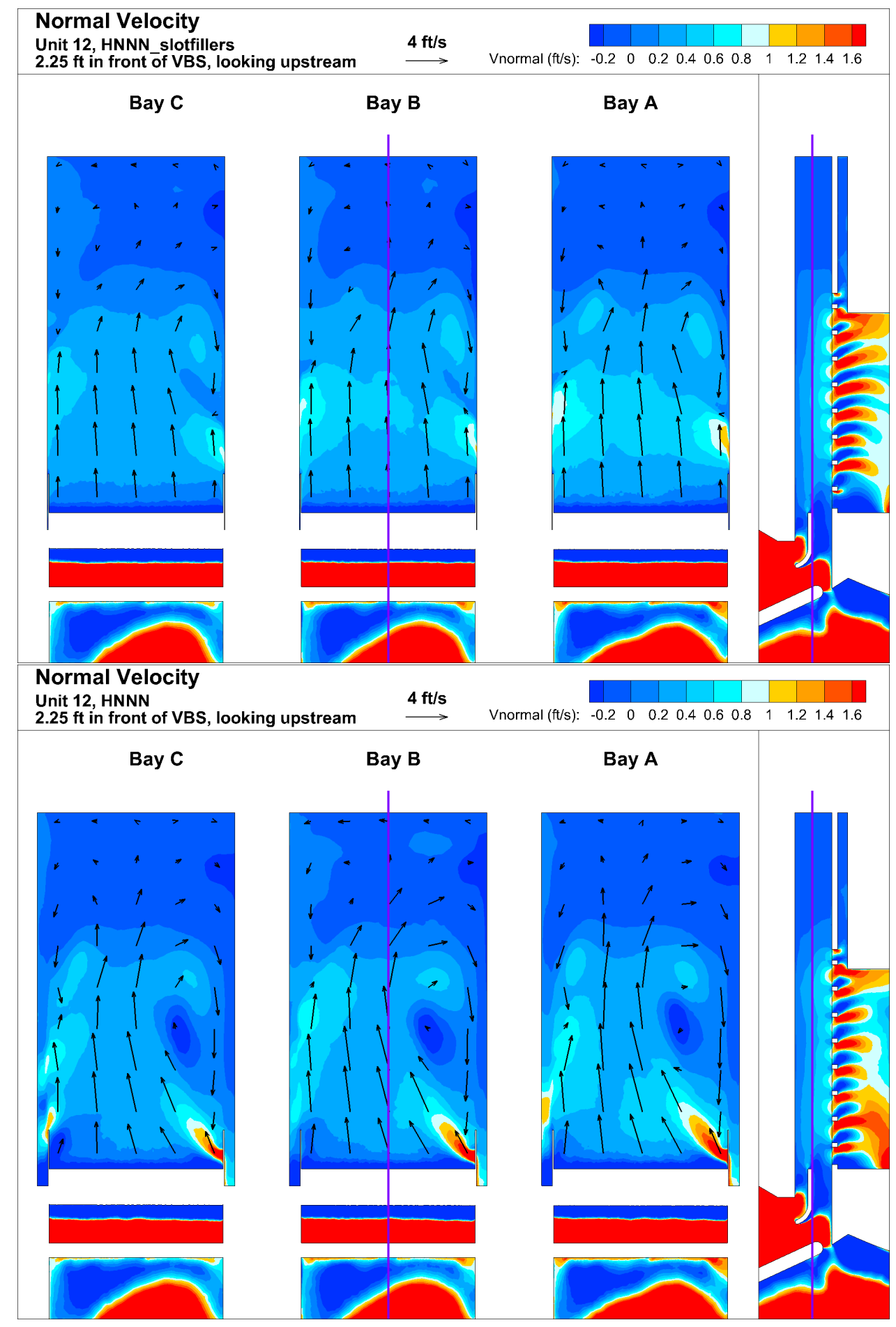

Figure 3.50. HNNN Unit 12 normal velocity with (top) and without (bottom) slot fillers in place $2.25 \mathrm{ft}$ from the VBS. 


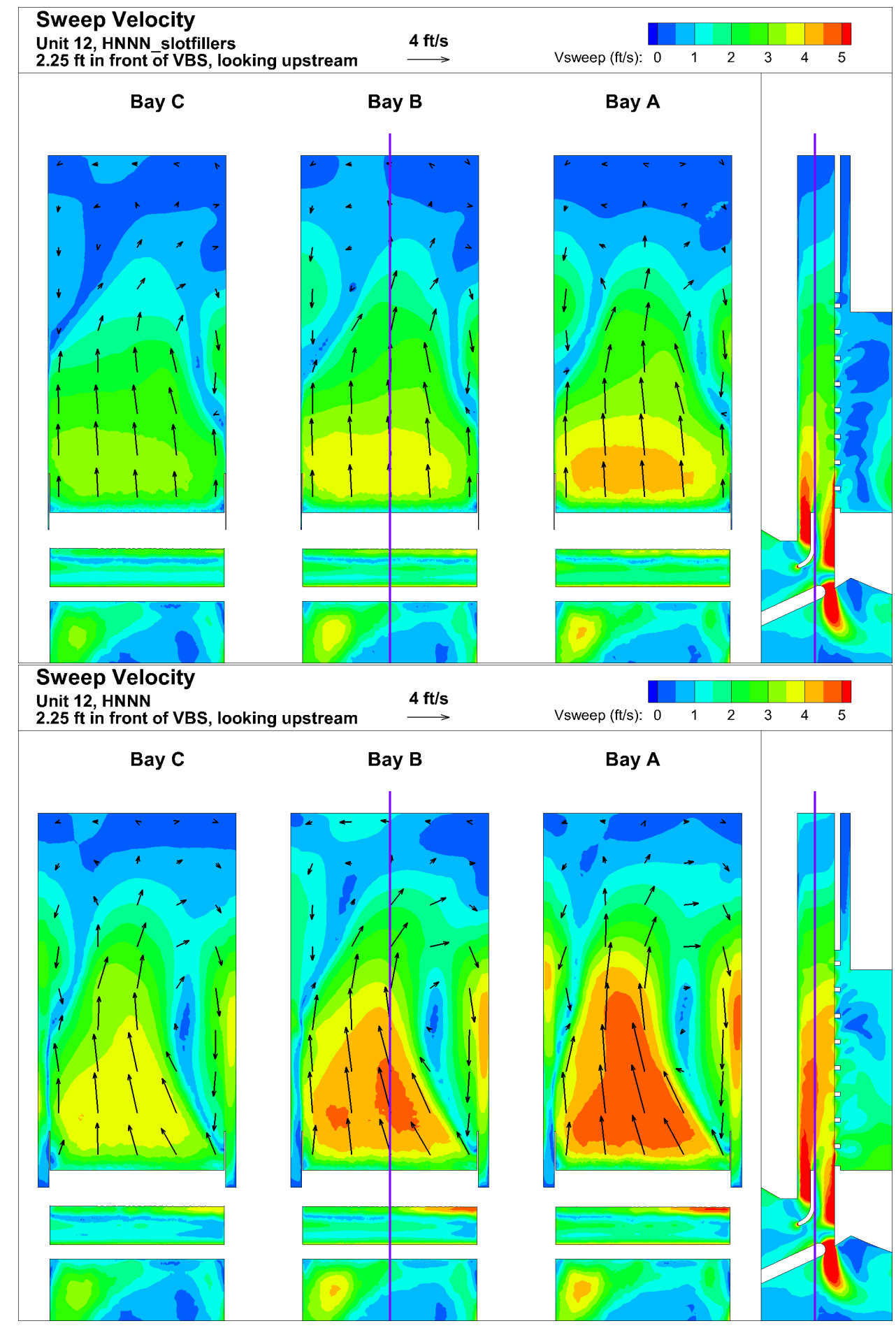

Figure 3.51. HNNN Unit 12 sweep velocity with (top) and without (bottom) slot fillers in place $2.25 \mathrm{ft}$ from the VBS. 


\subsubsection{HYNN with Slot Fillers}

Although the use of the slot fillers had little observable impact on the forebay flows of the HYNN scenario (Figure 3.52), the flow in the gatewell had greatly reduced recirculation. Figures 3.53 to 3.56 show that flows within the gatewell slot had less recirculation with slot fillers in place (top figures) than without slot fillers in place (lower figures). The addition of the slot fillers resulted in a larger flow into the gatewell and in a distribution of velocities across the screens that was more balanced; there were lower maximum normal velocities and a smaller area of normal velocities that exceed the $1-\mathrm{ft} / \mathrm{s}$ criterion. 


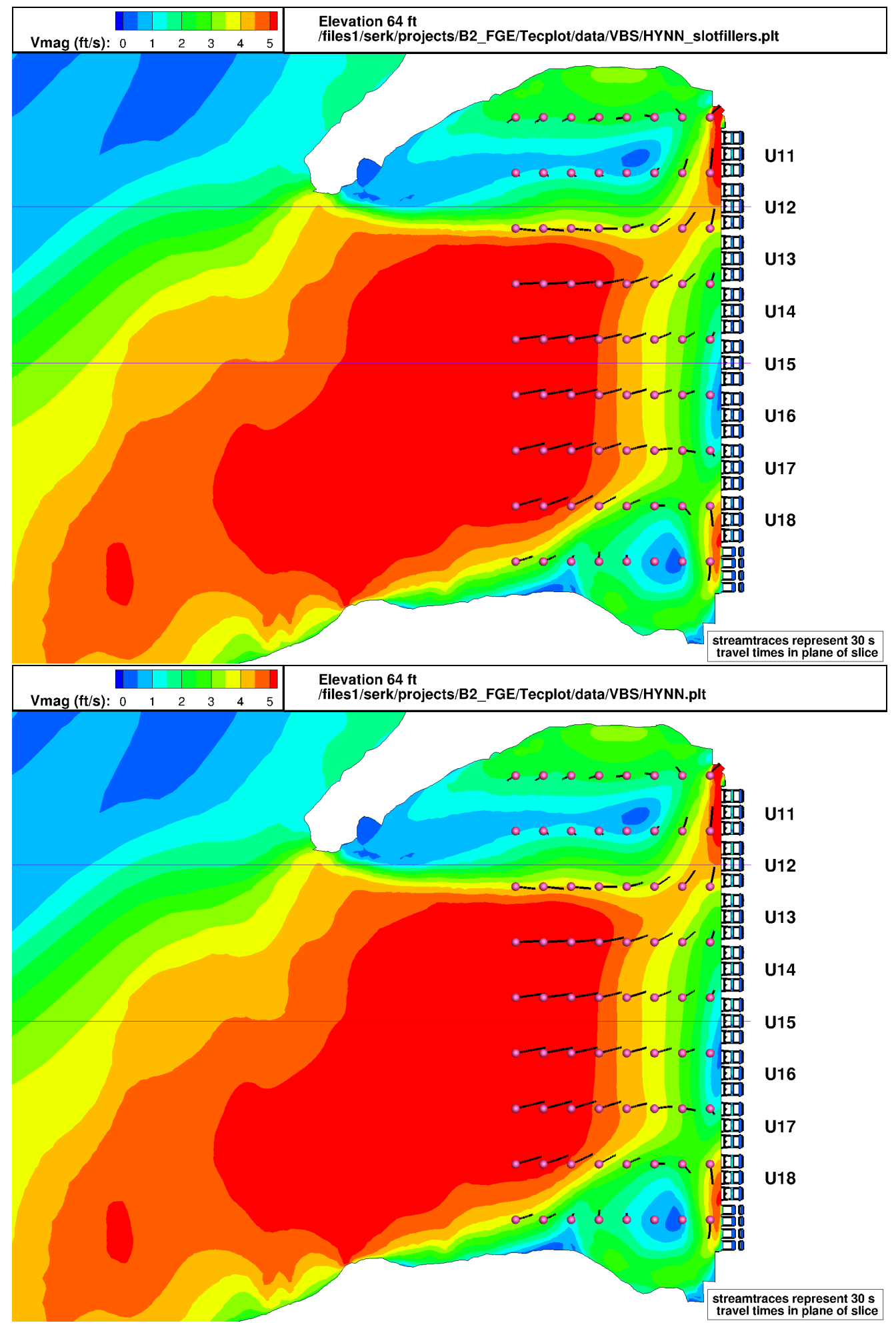

Figure 3.52. Velocity magnitude and short streamlines for the HYNN with (top) and without (bottom) slot fillers simulation at elevation $64 \mathrm{ft}$. Flow is from left to right. 


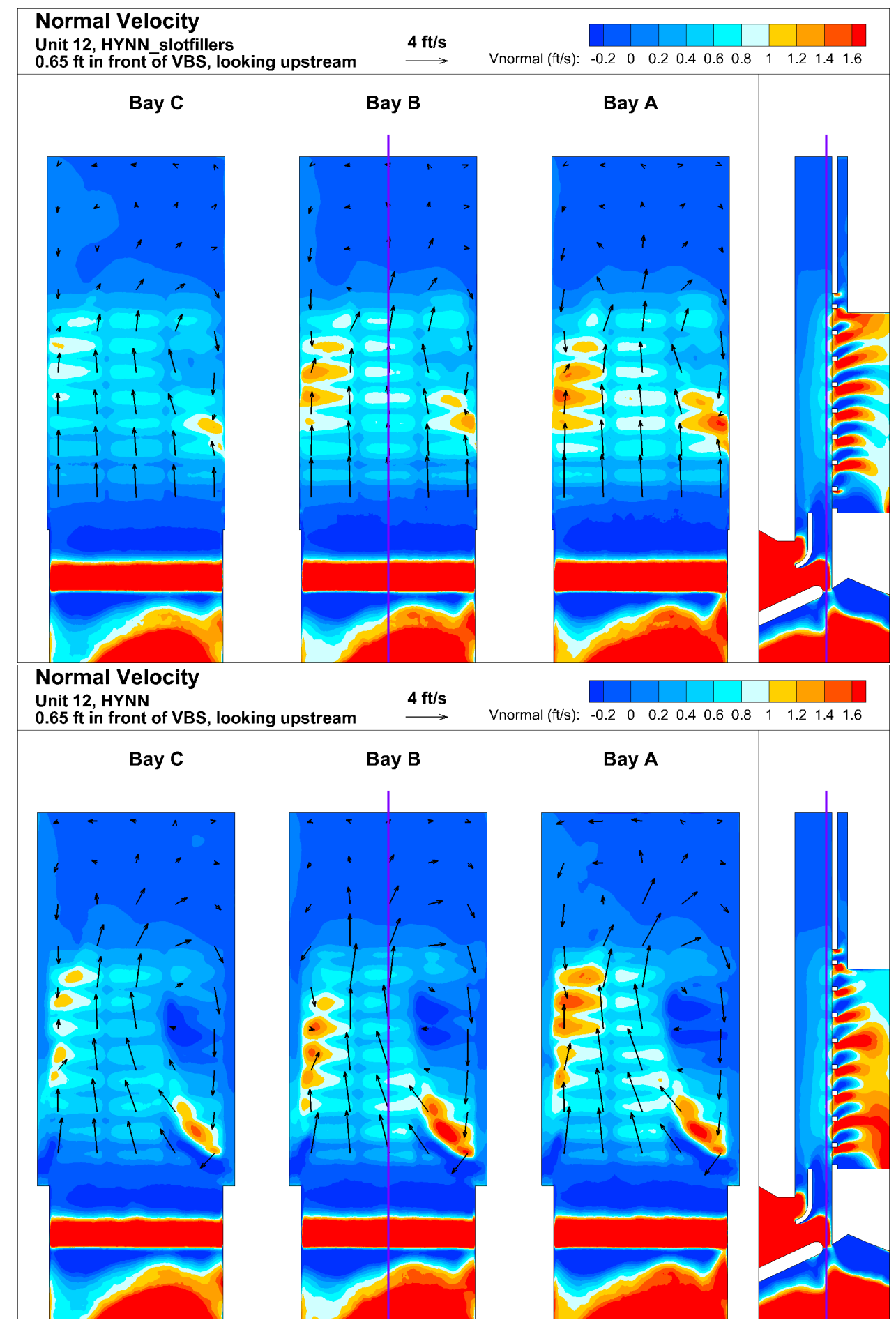

Figure 3.53. HYNN Unit 12 normal velocity with (top) and without (bottom) slot fillers $0.65 \mathrm{ft}$ from the VBS. 


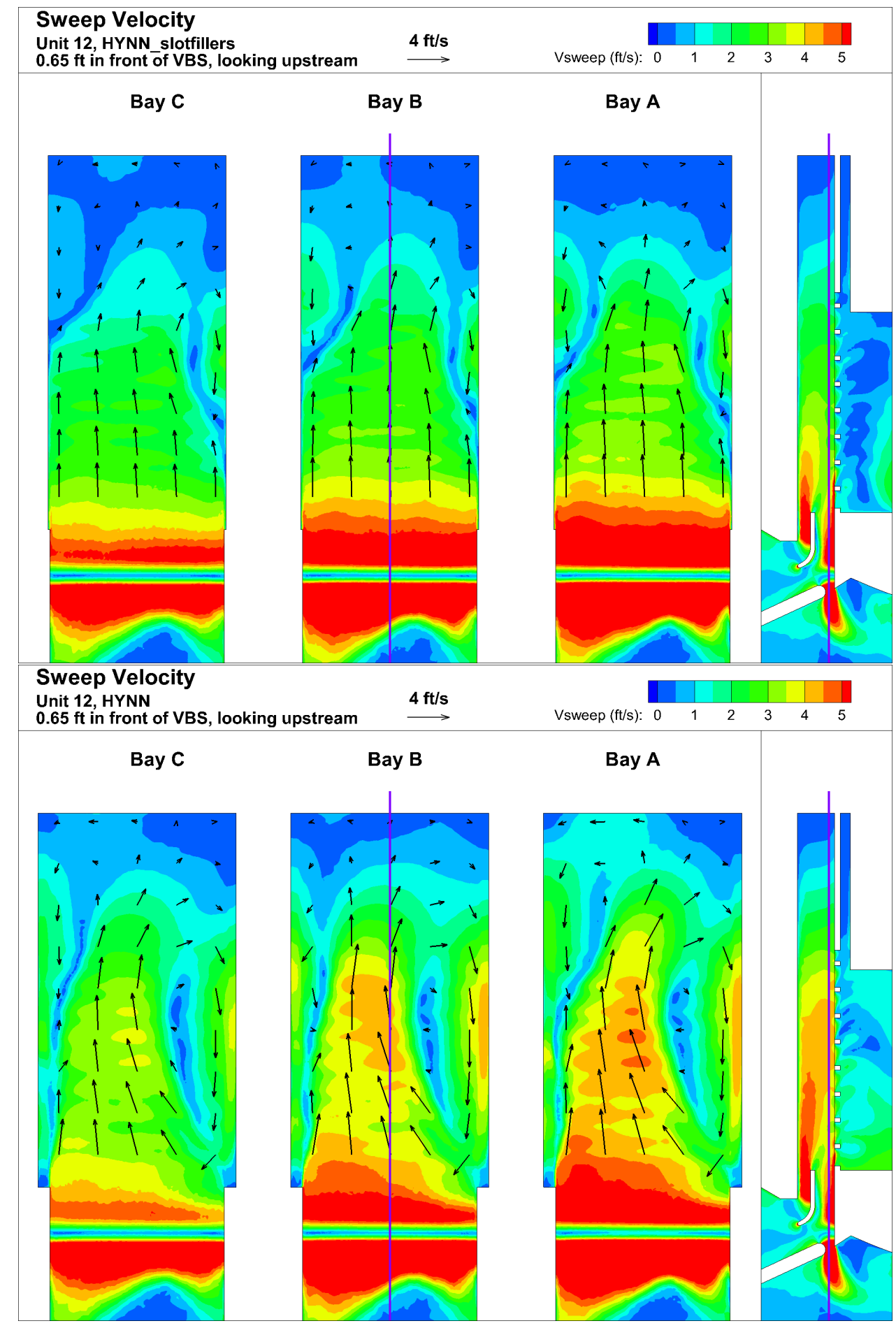

Figure 3.54. HYNN Unit 12 sweep velocity with (top) and without (bottom) slot fillers in place $0.65 \mathrm{ft}$ from the VBS. 


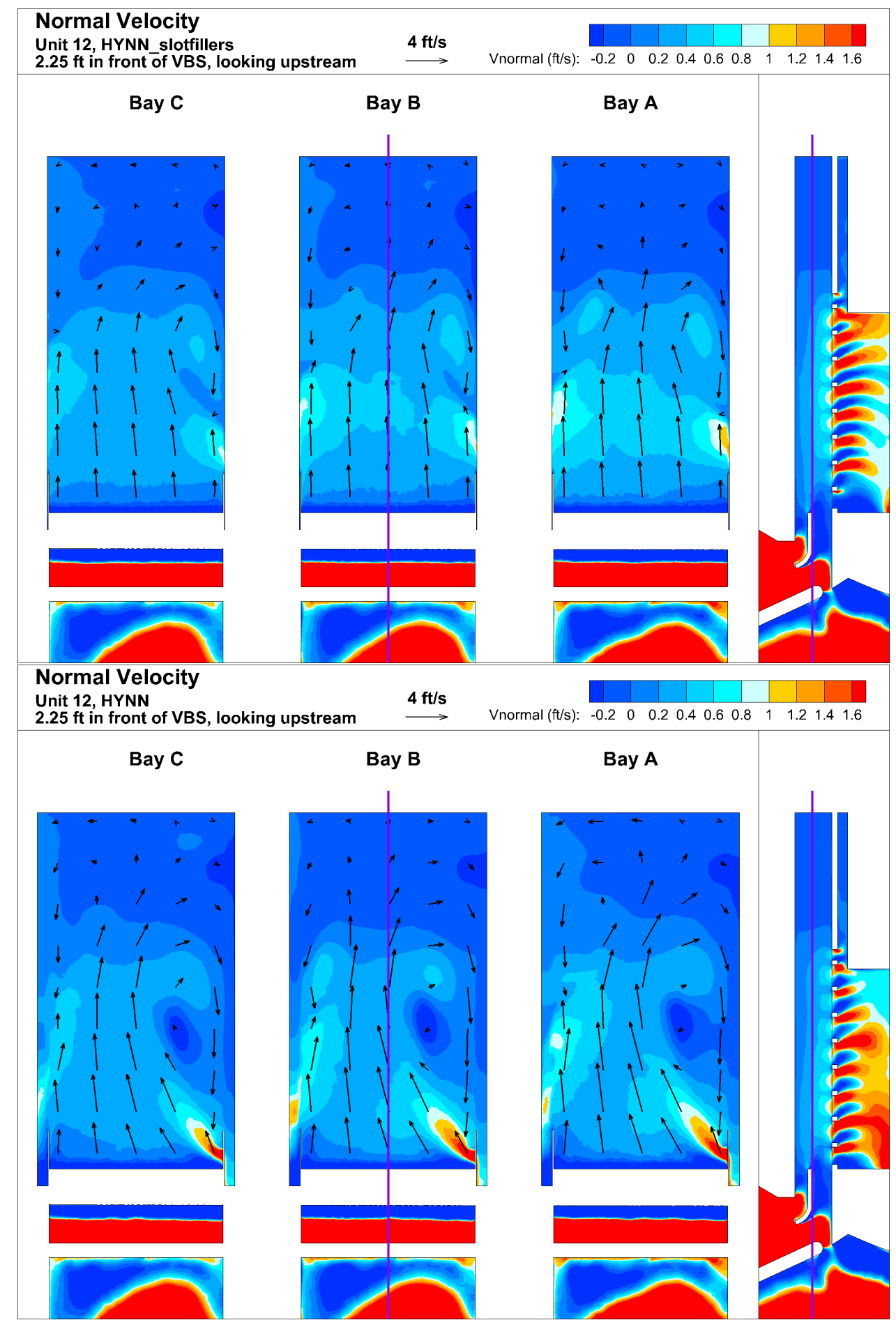

Figure 3.55. HYNN Unit 12 normal velocity with (top) and without (bottom) slot fillers in place $2.25 \mathrm{ft}$ from the VBS. 


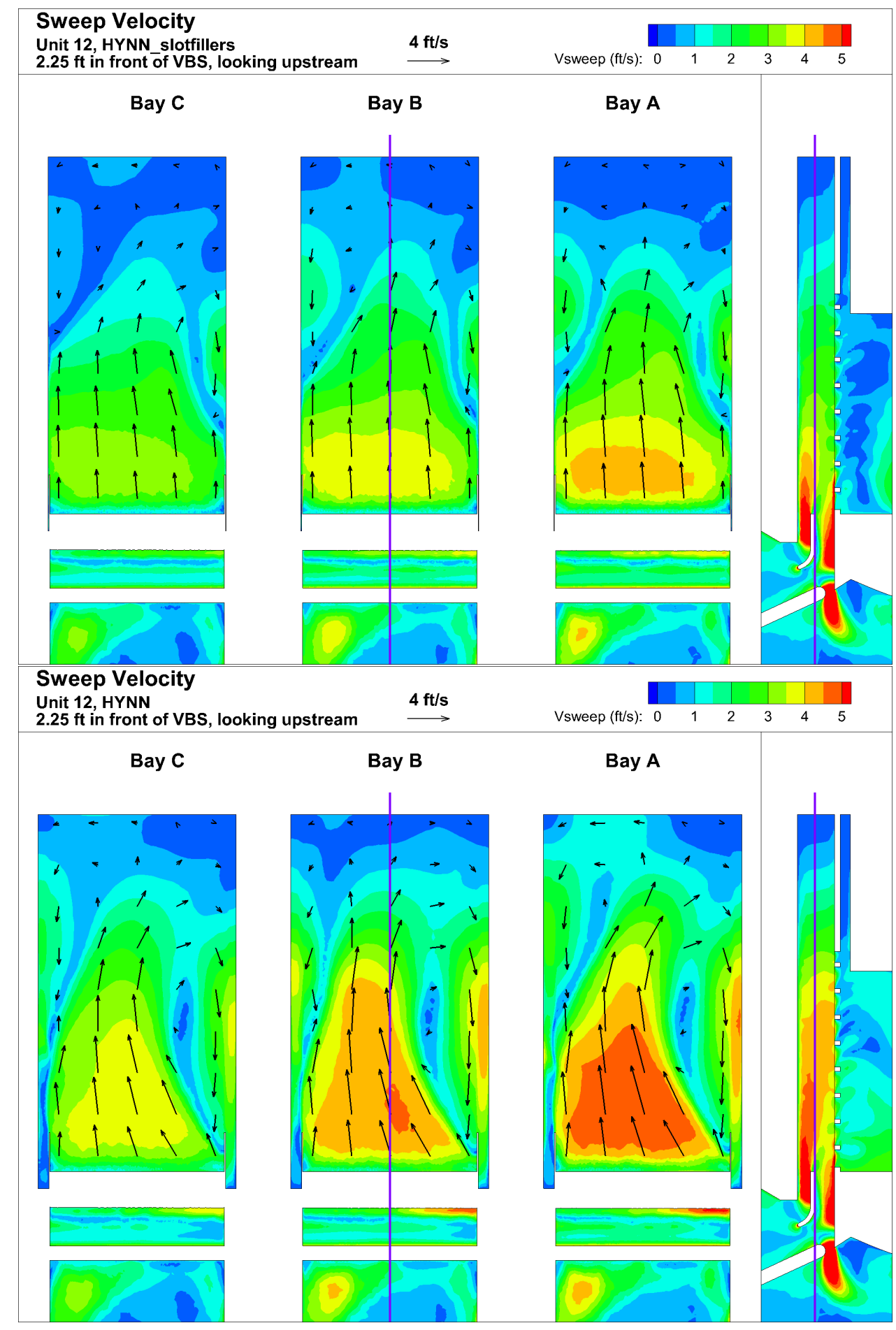

Figure 3.56. HYNN Unit 12 sweep velocity with (top) and without (bottom) slot fillers in place $2.25 \mathrm{ft}$ from the VBS. 


\subsubsection{HNNN with Slot Fillers, but with Half of the Units Operating}

B2 is often run at "half-load," meaning with half of the units operating. To improve forebay flow conditions, typically a unit on each end and two in the middle are operated (Units 11,14, 15, and $18)$.

The velocities, overall, are about half of those modeled in other scenarios (Figure 3.57). For the gatewell velocity comparisons, Unit 14 was used because Unit 12 was not operating. Figures 3.58 through 3.61 show the same pattern of improvement in the flow pattern occurred. Flows within the gatewell slot had less recirculation with slot fillers in place (top figures) than without slot fillers in place (lower figures). In addition, the distribution of velocities across the screens was more even with lower maximum sweep and normal velocities when the slot fillers were in place.

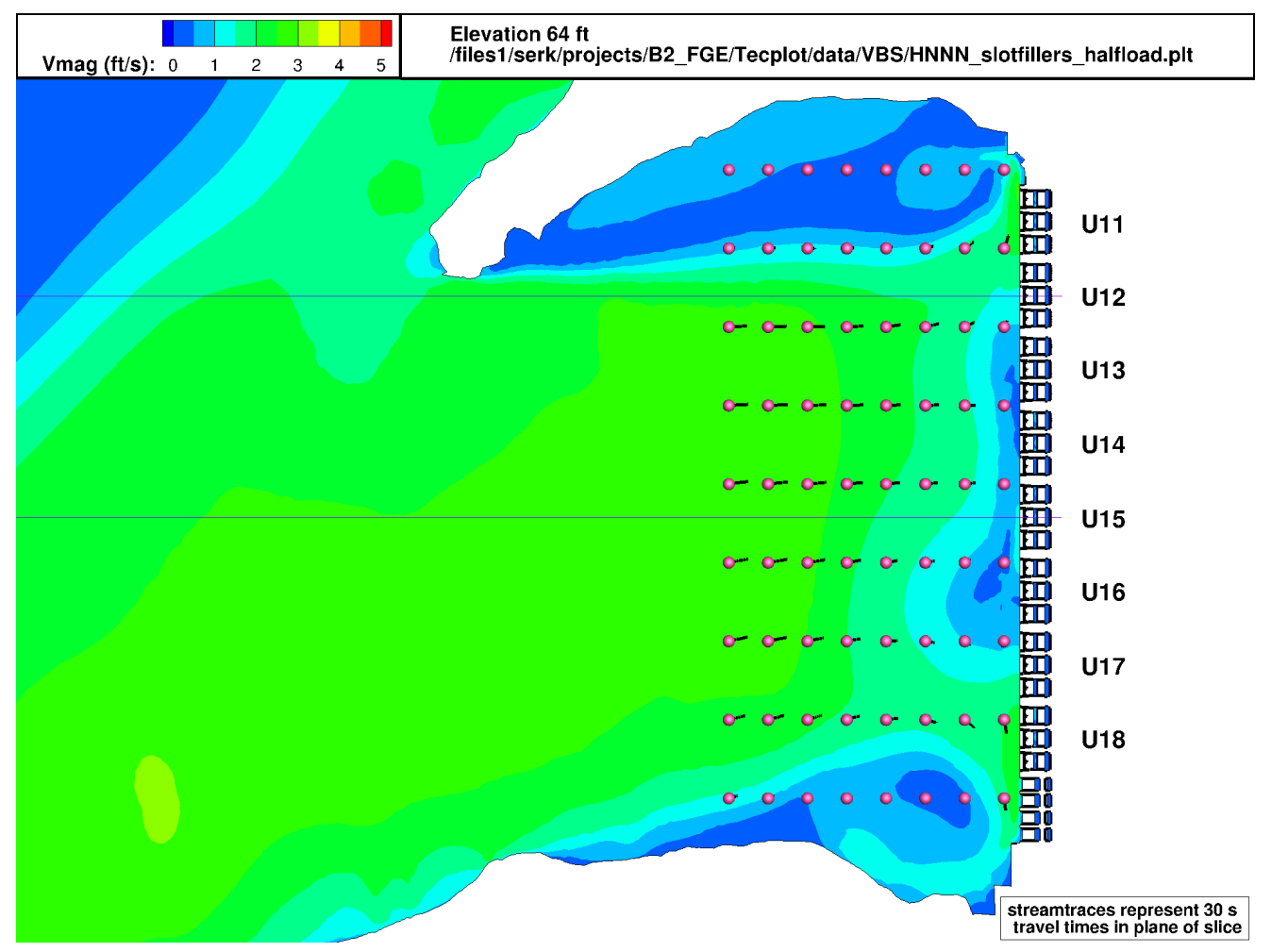

Figure 3.57. Velocity magnitude and short streamlines for the HNNN half load with slot fillers at elevation $64 \mathrm{ft}$. Flow is from left to right. 


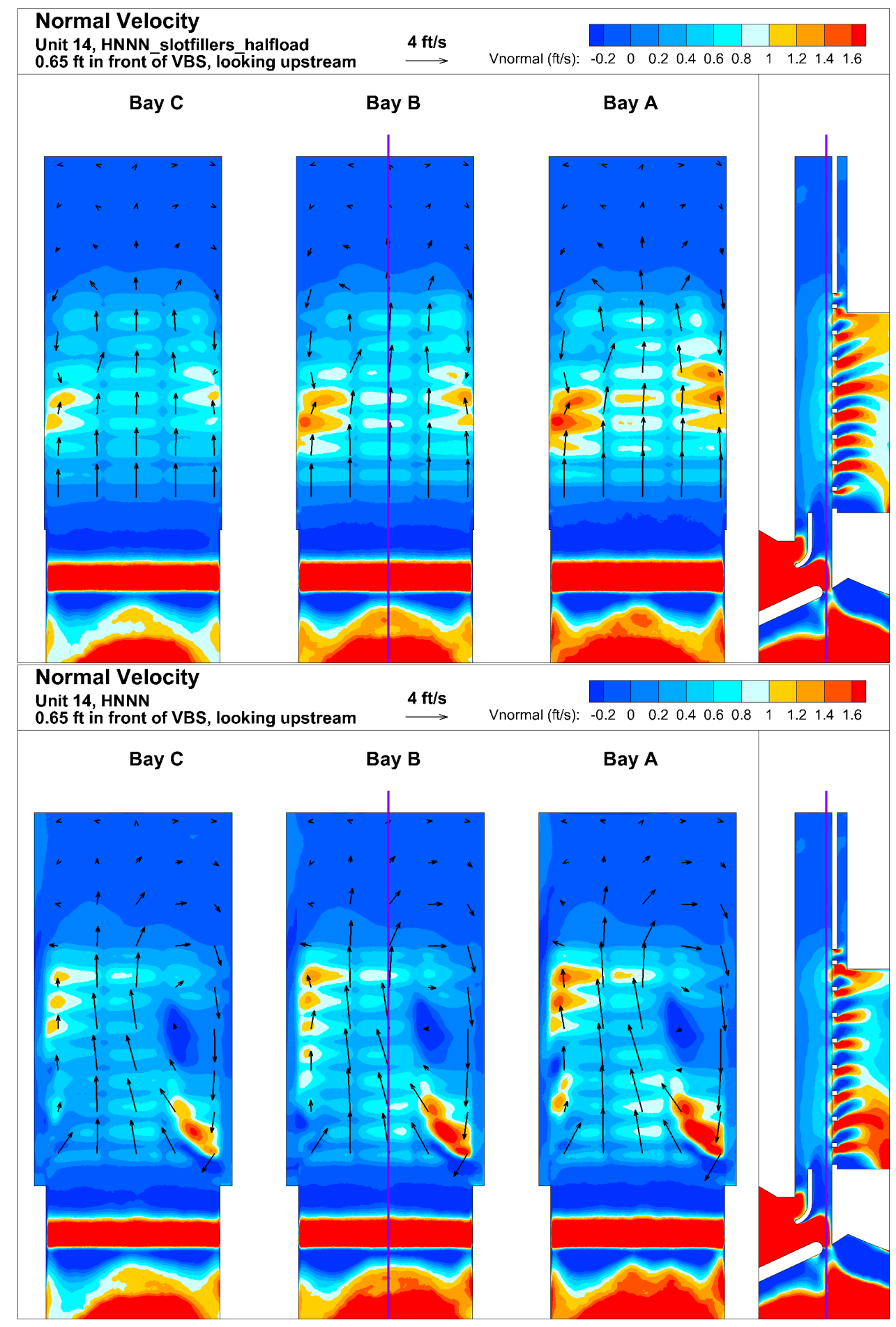

Figure 3.58. HNNN Unit 14 normal velocity with (top) and without (bottom) slot fillers $0.65 \mathrm{ft}$ from the VBS. 


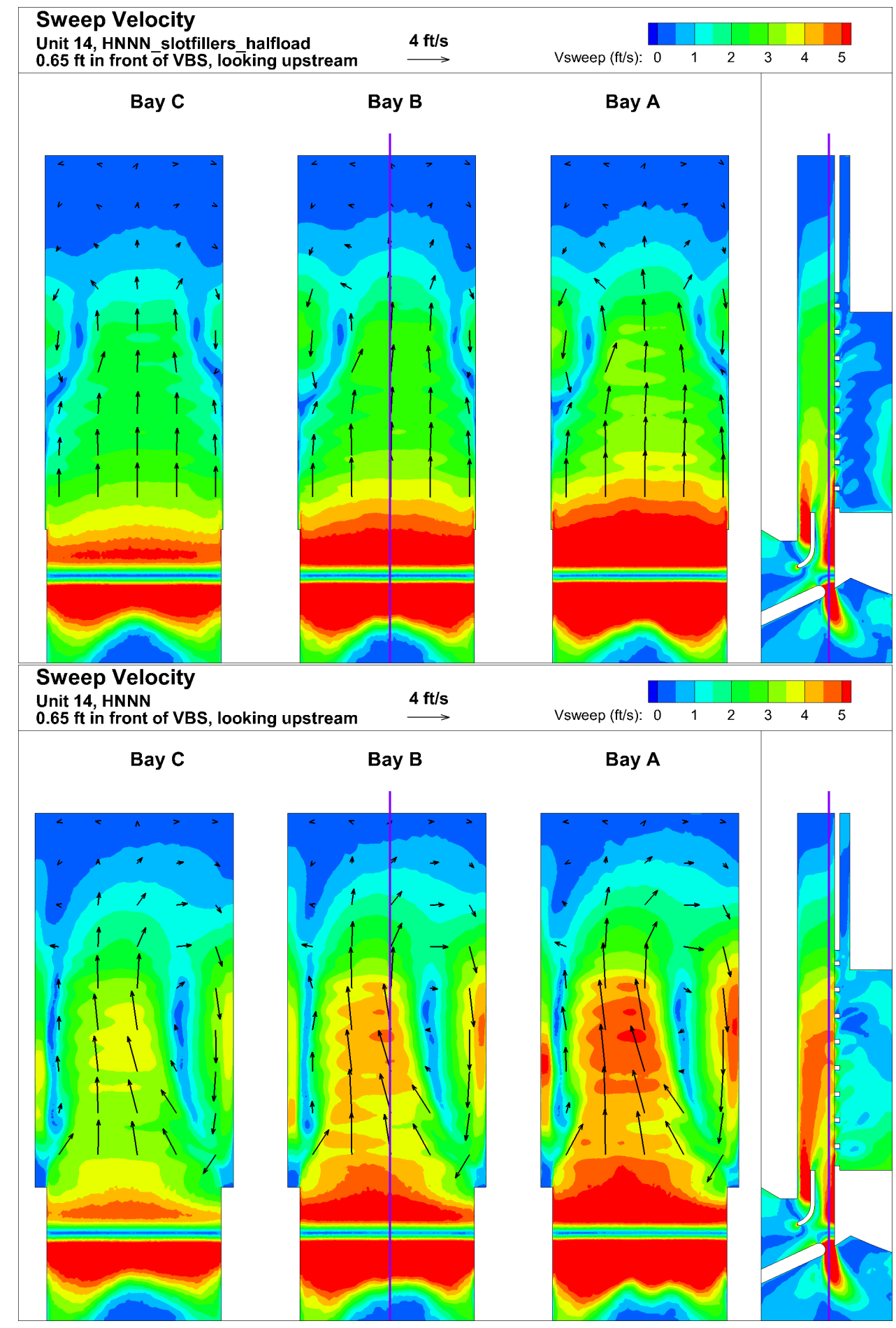

Figure 3.59. HNNN Unit 14 sweep velocity with (top) and without (bottom) slot fillers in place $0.65 \mathrm{ft}$ from the VBS. 


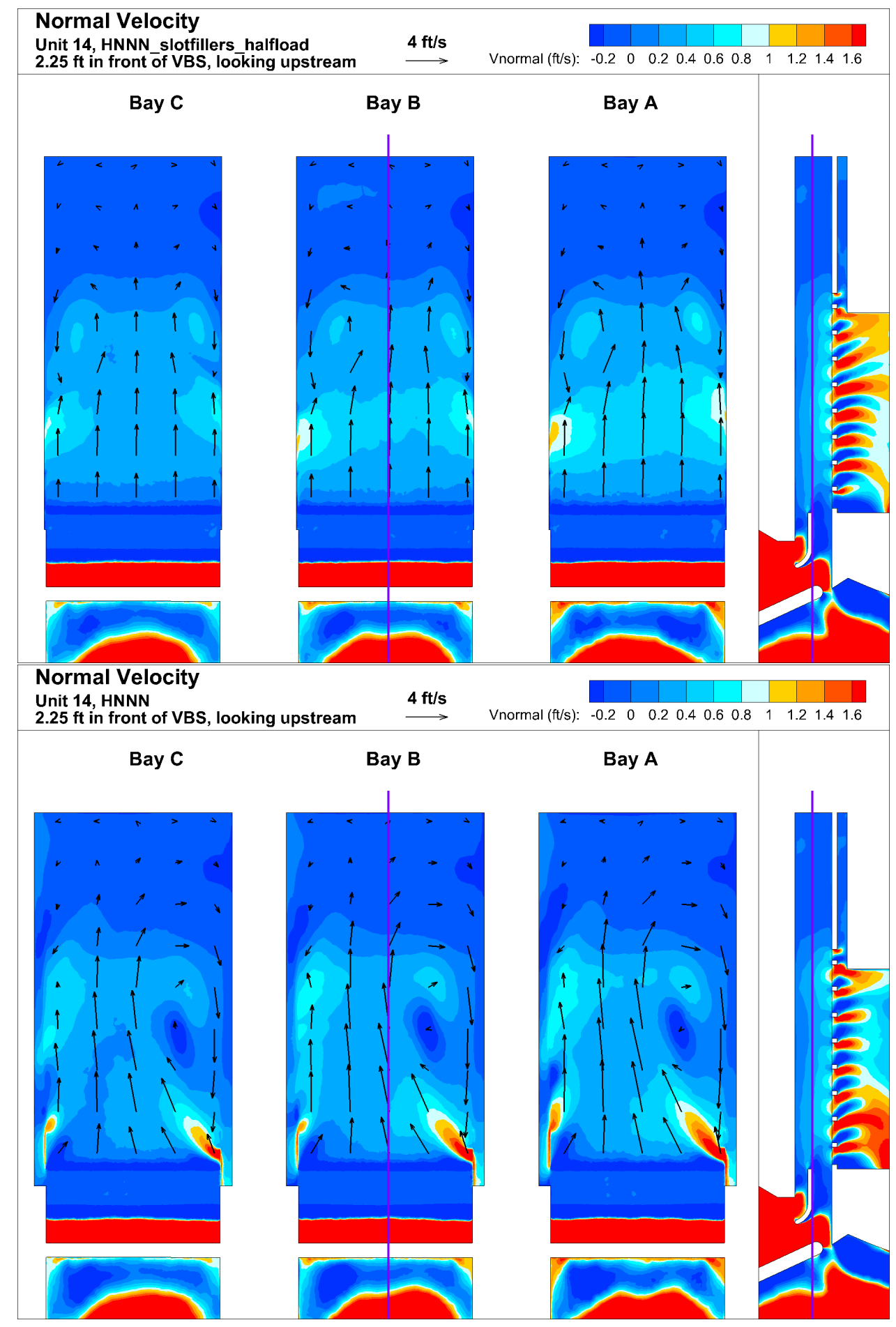

Figure 3.60. HNNN Unit 14 normal velocity with (top) and without (bottom) slot fillers in place $2.25 \mathrm{ft}$ from the VBS. 


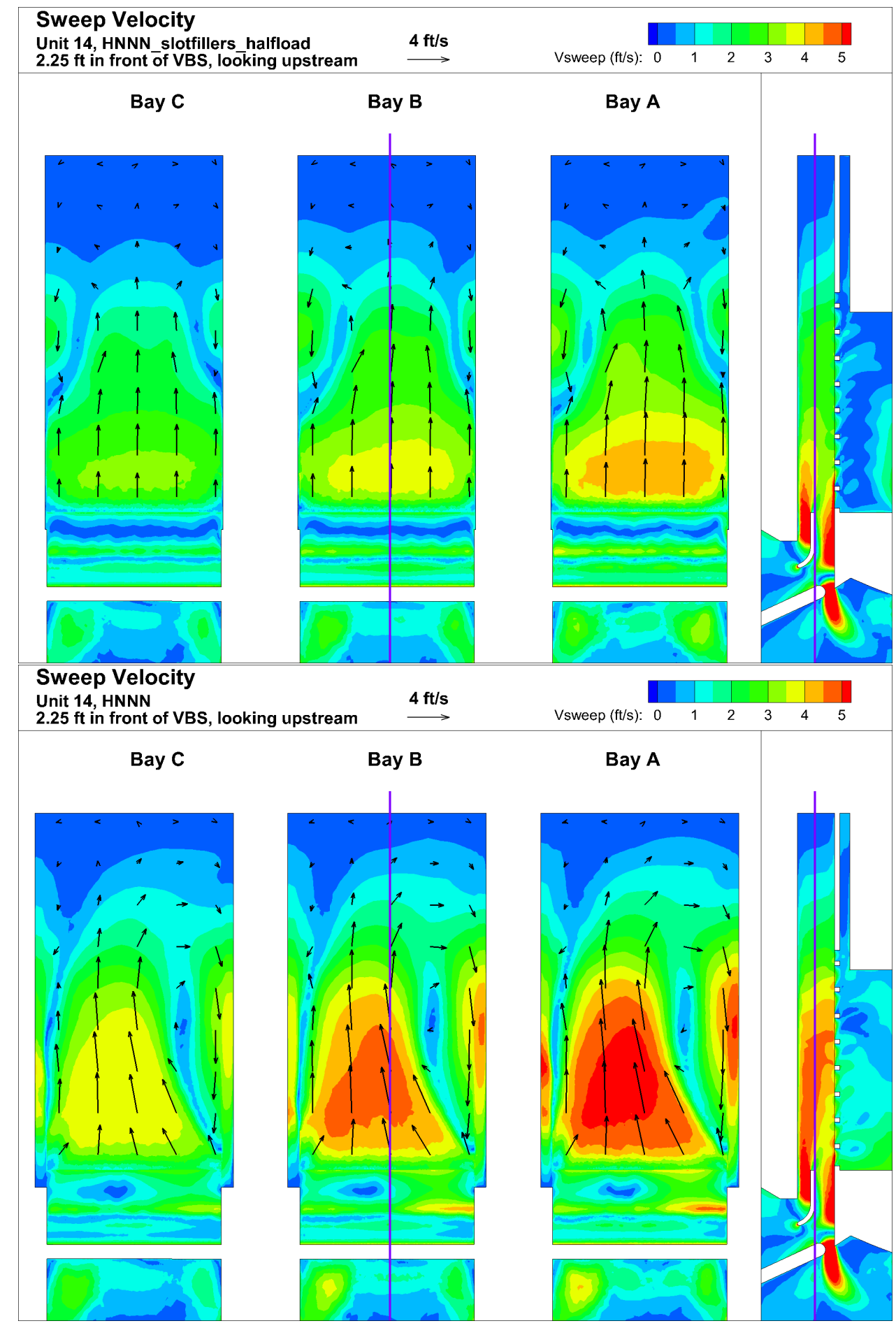

Figure 3.61. HNNN Unit 14 sweep velocity with (top) and without (bottom) slot fillers in place $2.25 \mathrm{ft}$ from the VBS. 
The preceding figures show that, for all three slot filler scenarios, the flow increased into the gatewells and the flow pattern within the gatewell was more balanced with less recirculation. These conditions are believed to be more conducive to smolt passage and survival.

These simulation results for slot fillers support the trend modeled the CENWP sectional model and show a consistent trend for all units of B2. 



\subsection{Conclusions}

In this study, the existing B2 forebay computational fluid dynamics (CFD) model was modified to include a more detailed representation of all B2 turbine intakes. The modified model was validated to existing field-measured forebay ADCP velocities.

The validated CFD model was used to simulate the impact on water velocities of adding a behavior guidance system (BGS), a B2 corner collector (B2CC), both the BGS and B2CC, and gatewell slot fillers.

These additions had small impacts on forebay flows. Most notable was that the addition of the BGS and B2CC reduced the lateral extent of the recirculation areas on the Washington shore and Cascade Island and reduced the flow velocity parallel to B2 in front of Units 11 and 12.

For these same scenarios, at the turbine intakes across the powerhouse, there was very little difference in the flow volume into the VBS gatewell for the forebay without B2CC flow or BGS, and the forebay with the BGS in place and/or the B2CC operating. The largest differences were at Units 11,12 , and 13.

The CFD model scenarios testing the impact of having gatewell slot fillers in place showed large differences in flow within the gatewells and through the VBS, but no impact on the forebay flows. The full forebay CFD model results showed very similar performance of the slot fillers to the CENWP single-unit model. With the slot fillers in place, the flow through the VBS increased at each turbine intake (average was 40, 35, and 29 cfs for Bays A, B, and C, respectively) and the gap flow decreased across the powerhouse for all scenarios. The increased flow up the gatewell was further enhanced when only half of the units were operating. The flow into the gatewell slot was increased about $35 \mathrm{cfs}$ for each bay of each intake across the powerhouse; this change was uniform across the powerhouse.

The flows in the gatewell of Unit 12, the most affected unit for the scenarios, were evaluated. In front of the VBS, the CFD model with slot fillers in place reduced the maximum velocities (in spite of the increased flow into the gatewell) and decreased the area of recirculation. The area near the VBS exceeding the normal velocity criterion of $1 \mathrm{ft} / \mathrm{s}$ was reduced and the flows were more balanced. 



\subsection{References}

ADAPCO, Computational Dynamics Limited. 2004. User Guide, STAR-CD Version 4.10. CD adapco Group, http://www.cd-adapco.com.

CENWP. 2011. Bonneville Second Powerhouse Fish Guidance Efficiency Program Post Construction Alternatives Report (60\% Report), Appendix C. U.S. Army Corps of Engineers, Portland, Oregon.

ENSR. 2000. Bonneville Second Powerhouse Forebay ADCP Field Data Collection. Final Report, Seattle, Washington. Prepared for the U.S. Army Corps of Engineers, Portland District. Document Number 3697-003-106B.

Hughes J, M Weiland, Z Deng, and J Martinez. 2011. Water Velocity Measurements on a Vertical Barrier Screen at the Bonneville Dam Second Powerhouse. PNNL-20746, Pacific Northwest National Laboratory, Richland, Washington. Prepared for the U.S. Army Corps of Engineers, Portland District.

Rakowski C, L Ebner, and M Richmond. 2005. "Juvenile Salmon Bypass and CFD Tools for Bonneville Dam on the Columbia River." Hydro Review XXIV(1):pp56-65.

Rakowski C, M Richmond, and J Serkowski. 2010. Bonneville Powerhouse 2 3D CFD for the Behavioral Guidance System. PNNL-19016, Pacific Northwest National Laboratory.

Rakowski C, J Serkowski, M Richmond, and K Recknagle. 2000. Development and Application of a 3D CFD Model for the Bonneville Project Powerhouse 1 and Powerhouse 2. Letter Report PNNL-13593, Pacific Northwest National Laboratory, Richland, Washington. Prepared for the U.S. Army Corps of Engineers. 


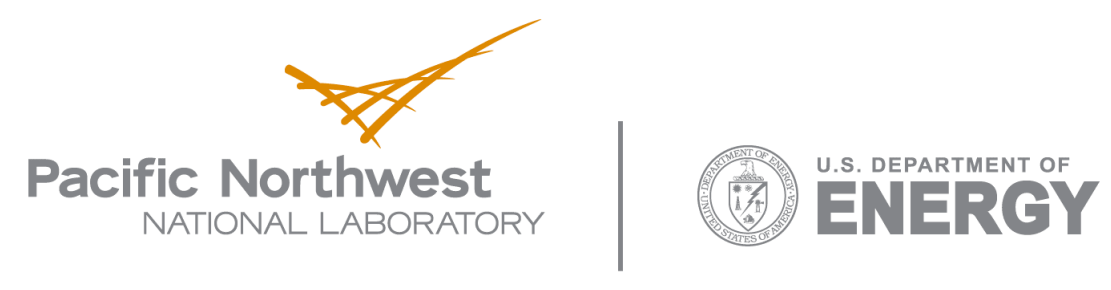

902 Battelle Boulevard

P.O. Box 999

Richland, WA 99352

1-888-375-PNNL (7665)

www.pnl.gov 